\title{
Root resorption associated with orthodontic tooth movement: A Systematic Review
}

\author{
A Thesis \\ Presented in Partial Fulfillment of the Requirement for \\ The Degree Master of Science in the \\ Graduate School of The Ohio State University \\ By \\ Belinda Jessica Weltman, H.B.Sc., D.M.D., M.Sc. \\ $* * * * *$
}

The Ohio State University

2009

Master's Examination Committee:

Dr. Katherine Vig, Advisor

Approved by:

Dr. Henry W. Fields, Jr.

Dr. Shiva Shanker

Dr. Eloise Kaizar

Advisor

Graduate Program in Dentistry 


\begin{abstract}
Background

It is generally accepted that one of the risks associated with orthodontic treatment is apical root resorption. Currently the orthodontic literature on root resorption does not provide a consensus on the factors associated with the onset, severity, and management of root resorption. Root resorption may affect the long-term prognosis and stability of the dentition, which is a compelling reason to identify causal factors so that the risks may be minimized, and the amount of root resorption reduced.
\end{abstract}

\title{
Objective
}

To evaluate root resorption as a primary outcome for a population of patients who received orthodontic tooth movement, in order to provide the best available evidence upon which clinical decisions can be made to minimize the risks and severity of root resorption.

\section{Search strategy}

Electronic databases were searched, non-electronic journals hand searched and experts in the field consulted. No language restrictions were placed. Additional missing information was obtained by contacting study authors. 


\section{Selection criteria}

The following criteria were met for study selection: a randomized clinical trial involving human subjects for orthodontic tooth movement, with fixed appliances, and recording root resorption during or after treatment.

\section{Data Collection and analysis}

Two authors independently reviewed and extracted data from selected studies on a standardized form. The primary outcome was the difference in the incidence or severity of root resorption between experimental and control patients for parallel design studies, and between experimental and control teeth, for split-mouth design studies.

\section{Main Results}

The searches retrieved 921 unique citations. After evaluating titles and abstracts 144 full articles were obtained; after the inclusion criteria were applied 13 publications, describing 11 trials, remained. Only one study (Mandall 2006) fulfilled all of the methodological quality assessment criteria. Differences in the methodologies and reporting made statistical research synthesis or combination impossible. However, there is evidence that comprehensive orthodontic treatment causes an increase in the incidence and severity of root resorption, and that heavy forces are particularly harmful.

There is some evidence that orthodontically induced inflammatory root resorption (OIIRR) is unaffected by archwire sequencing, bracket prescription, or self-ligation, and that previous trauma and unusual tooth morphology do not play a role. 


\section{Author's conclusions}

Any inferences from this systematic review about clinical practice should be treated with caution. Until more high quality trials are conducted, we would recommend that best practice is using light, intermittent forces, if possible, especially when engaging in intrusive movements. In patients where OIIRR has been identified during treatment, there is some evidence that a 2-3 month treatment pause (passive archwires), will lead to a decrease in total root resorption by the end of treatment.

More high quality clinical research examining root resorption with similar protocols is needed to provide a comprehensive evidence-based approach to managing root resorption associated with orthodontic tooth movement. 
Dedicated to my Parents 


\section{ACKNOWLEDGEMENTS}

I would like to thank my thesis advisor, Dr. Katherine Vig, and my thesis committee members, Dr. Henry W. Fields, Jr., Dr. Shiva Shanker, and Dr. Eloise Kaizar. I appreciate their guidance in the development of this study and the writing of the thesis. Each of them invested much effort in study design, interpretation of results, and thoughtful discussion. I am fortunate to have had the opportunity to work with them, and I will always value this research experience.

I would like to thank the Ohio State University College of Dentistry, Graduate Studies, and The Ohio State University Division of Orthodontics for the access and use of reference databases and journal articles. I would like to thank Jackie Hittner (AAO Librarian) and Jillian Brandt, (Document Delivery Specialist, Prior Health Sciences Library) for their aid in locating and obtaining obscure reference articles. I would like to thank Delta Dental for their support in funding my research. I would also like to thank Dr. Curtis Andrews, Dr. Allen Firestone, Dr. Zongyang Sun, and Richard Lukes for translation of foreign language articles.

I would like to thank my parents for their constant support and love through the many years of school. I am unable to put into words my appreciation and gratitude. I hope that I can continue to make them proud as an orthodontist, serving my patients with ethics, compassion and respect. 
Finally I would like to thank my husband Ryan, for all of his love and support, his proof reading skills, his computer advice and for being a wonderful test audience. He helped out above and beyond at home and with Aubrey while I was concentrating on this; I am so lucky and grateful to have him. 


\title{
VITA
}

\author{
August 4, 1978..............................Born, Ottawa, Ontario, Canada

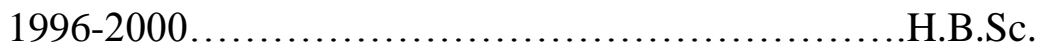 \\ The University of Toronto \\ Toronto, ON

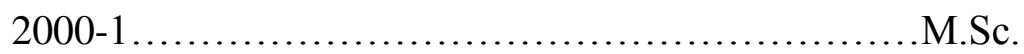 \\ The University of London \\ The London School of Hygiene \\ and Tropical Medicine \\ London, UK

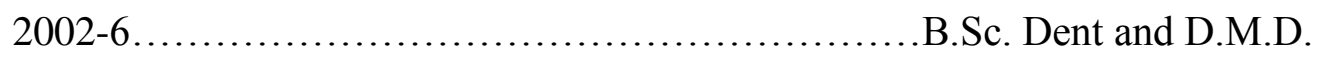 \\ The University of Manitoba \\ College of Dentistry \\ Winnipeg, Manitoba \\ 2006-present.................................Graduate Resident in Orthodontics \\ The Ohio State University \\ Columbus, Ohio
}

\section{FIELDS OF STUDY}

Major Field: Dentistry

Specialty: Orthodontics 


\section{TABLE OF CONTENTS}

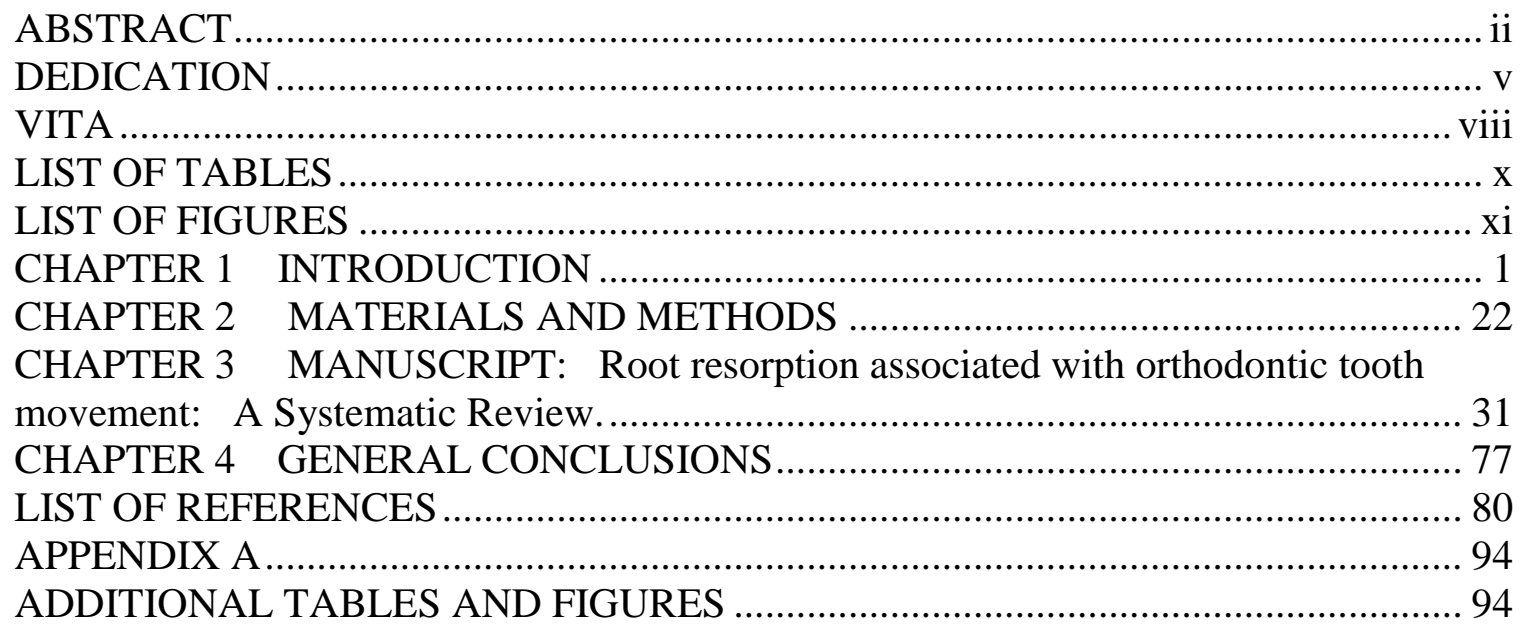




\section{LIST OF TABLES}

Table

Page

3.1: PICO Format and Null Hypothesis.....................................58

3.2: Databases included in the systematic review..........................59

3.3: Criteria for selecting studies to be included in the meta-analysis.............60

3.4: Criteria for assessing quality components in the trials included in the meta-analysis..........................................61

3.5: Characteristics of Included Studies................................62-64

3.6: Quality Assessment - Major Criteria.................................65

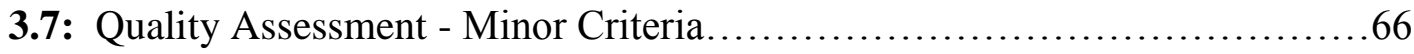

A.1: Characteristics of Excluded Studies.................................95-98 


\section{LIST OF FIGURES}

Figure $\quad$ Page

3.1: The QUOROM statement flow diagram of the citations retrieved by

Reviewing titles and abstracts, and trials that were evaluated in full text............67

A.1: Acar - Visual scoring of EARR ................................... 99

A.2: Levander - Amount of EARR by test group...........................99

A.3: Forest Plots....................................................... 100-105 


\section{CHAPTER 1}

\section{INTRODUCTION}

It is unknown how orthodontic treatment factors influence root resorption. The etiological factors are complex and multifactorial, but it appears that apical root resorption results from a combination of individual biological variability and the effect of mechanical factors. Root resorption is undesirable as it affects the long-term stability of the dentition. It has been reported that patients undergoing orthodontic treatment are more likely to experience severe apical root shortening than individuals who do not (Harris, 1993; Killiany, 1999). Patient factors such as genetics and trauma also have been associated with increased risk of root resorption (Al-Qawasmi, 2003; Harris, 1997; Newman, 1975).

Many general dentists and other dental specialists believe that root resorption is an avoidable phenomenon, and hold the orthodontist responsible if it occurs during the course of orthodontic treatment (Lee, 2003). It is important to determine which orthodontic treatment factors contribute to root resorption so that the detrimental effects can be minimized, and the incidence of resorption reduced.

There have been several reviews and a meta-analysis conducted to assess the relationship between orthodontics and root resorption. However, they were of a limited 
scope. The meta-analysis was restricted to English language publications, a Medline search and the effects on central incisors. Also, retrospective non-RCT studies were included (Segal, 2003). The goal of this project is to include a more comprehensive search using more restrictive quality criteria.

It is anticipated that variables relating orthodontic treatment to root resorption will be identified. By combining the results from clinical trials a more comprehensive evidence-based approach to root resorption associated with orthodontic tooth movement may provide important guidelines for contemporary clinical practice.

\section{REVIEW OF THE LITERATURE}

\section{AND \\ STATEMENT OF THE PROBLEM}

Apical root resorption can be related to orthodontic treatment and may present during or at the end of treatment. Root resorption begins approximately $2-5$ weeks into treatment, but it takes 3-4 months before it can be detected radiographically. It is a complex biological process of which many aspects remain unclear, but occurs when forces created at the root apex exceed the resistance and reparative ability of the periapical tissues (Parker 1998). The progress and severity of external apical root resorption (EARR) are affected by various risk factors.

There are 3 types of orthodontically induced inflammatory root resorption (OIIRR), and severity is determined by the extent to which root tissue is involved (Trope 1998; Brezniak 2002a). 
Surface resorption: only the outer cemental layers are resorbed, and are then fully regenerated or remodeled once the etiologic factor has been removed.

Deep resorption: the cementum and outer layers of dentin are resorbed and are usually repaired with cementum material. The final shape of the root after this resorption and formation process may or may not be identical to the original form.

Circumferential apical root resorption: tridimensional resorption of the hard tissue components of the root apex occurs, and root shortening is evident. When the root loses apical material beneath the cementum, no regeneration is possible and the resorption is irreversible, although, sharp edges may remodel.

Orthodontic forces result in tooth movement due to formation of pressure and tension zones within the periodontal ligament, resulting in an infiltration of osteoclasts into the area of compression, which then resorb bone. These forces also act on cementum, which are more resistant to resorption than bone (Brezniak 1993). However, some cementum and possibly dentin on the root surface will resorb if osteoclasts obtain access to the mineralized dental tissue because of a breach in the covering cell layer. The local area of overcompressed periodontal tissue - hyalinized zone, is sterile necrosis, which must be removed before tooth movement can progress. It accounts for the initial delay in orthodontic treatment and always precedes the root resorption process and, has been seen close to an area of root resorption coinciding with the pressure zones of the periodontal ligament (Kurol 1998). 
Following termination of orthodontic forces, root resorption typically ceases and a progressive remodeling and reparative process of the root surface is evident. According to Schwartz (1932), this occurs when pressure falls below the optimal forces of 20-26 $\mathrm{g} / \mathrm{cm} 2$. The resorption lacunae are filled in with new secondary cementum during periods of relative quiescence. Different spatial repair patterns have been reported, proceeding either from the periphery of the resorption cavity or from within the center (Owman-Moll 1998). Repair areas also exhibit many combinations of cellular (fast process trapping cells) and acellular (slow process) cementum. However, if an island of cementum or dentine becomes separated from the root surface, it will be resorbed, and repair of the damaged root will be impossible (Proffit 2006).

\section{Histopathology}

Root resorption (RR) is defined as microscopic areas of resorption lacunae visualized with histologic techniques (Hartsfield 2004). The etiology of root resorption requires two phases (Trope 1998).

1) Injury related to the external surface of the root yielding denuded mineralized tissue.

2) Extended stimulation of multinucleated cells

Denuded mineralized tissue is colonized by multinucleated cells, which initiate the resorption process. Without further stimulation by those cells involved in the resorption process, spontaneously repair will occur with cementum-like material within 2-3 weeks (surface resorption). 
If the stimuli remain, the inflammatory process in the presence of the denuded root will persist. This depends on activated osteoclastic cells and involves the deeper root (dentin), which is usually detected radiographically (Fuss 2003).

In OIIRR the injury results from the pressure applied to the root during tooth movement. This pressure produces ischemic necrosis of the periodontal ligament (PDL) localized in the pressure area (Trope 1998; Brezniak 2002a). Macrophage-like and multinucleated cells are activated by biochemical signals derived from the sterile necrotic tissue. The initial elimination of necrotic tissue takes place at the periphery of the hyaline zone. During removal of the hyaline zone, the nearby outer surface of the root can be damaged (Brezniak 2002a; Brudvik 1994; Brezniak 1993).

In severe cases the orthodontic pressure may directly damage the outer root surface including cementoblasts and precementum layers (Brezniak 2002a). Macrophage and multinucleated cell activity continues until no hyaline tissue is present and/or the force level decreases. Resorption lacunae expand the root surfaces involved and thereby indirectly decrease the pressure exerted through force application. Thus, the decompression allows the process to reverse and the cementum to be repaired (Trope 1998; Brezniak 2002a).

If the orthodontic forces are applied for several hours, multinucleated TRAPpositive cells develop odontoclastic-like morphology and functions and begin a complete cementum resorption, denuding mineralized dentin areas (Brezniak 2002a; Brudvik 1994). At this stage the resorption is still reversible provided that the pressure exerted by the orthodontic force stops and the extension of the root-damaged area is limited. 
In severe injuries, in which the damaged area is large or the time of the force application is long, multi-nucleated cells continue the resorptive process also including the exposed dentin. Odontoclasts, which were activated by the persistence of the inflammation, produce a tridimentional, non-reversible and radiographically evident root resorption (Brezniak 2002a; Brudvik 1994; Brezniak 1993).

\section{Idiopathic root resorption:}

Even in the absence of orthodontic treatment, root resorption can and does occur (Counts, 1993; Rivera 1994; Snelgrove, 1995). EARR has been reported 6 months after tooth bleaching, with no history of previous tooth trauma (Al-Nazhan, 1991).

\section{Incidence and prevalence orthodontically induced inflammatory root resorption:}

Histological studies report a greater than $90 \%$ occurrence of RR in orthodontically treated teeth (Stenvik 1970, McLaughlin 1964, Harry 1982). In most cases the loss of root structure is minimal and clinically insignificant. Lower percentages are reported when diagnostic radiographic techniques are used. Lupi et al. reported the incidence of EARR before treatment 15\% and after treatment 73\% (Lupi 1996).

Using Panoramic or peri-apical radiographs, the average OIIRR is usually less than 2.5mm (Linge 1983, Linge 1991; Mirabella 1995; Mavragani 2000; Sameshima 2001a), or varying from 6-13\% for different teeth (Blake 1995).

Using graded scales, OIIRR is usually classified as minor or moderate in most orthodontic patients (Levander 1988; Janson 1999; McNab 1999; Brin 2003). Severe resorption defined as exceeding $4 \mathrm{~mm}$ or $1 / 3$ of the original root length, is seen in $1-5 \%$ of 
teeth (Linge 1983, Levander 1988, Levander 1998; Lupi 1996; Taithongchai 1996; Janson 1999; McNab 1999; Kiliany 2002).

Regardless of genetic or treatment related factors, the maxillary incisors consistently average more apical root resorption than any other tooth, followed by mandibular incisors and mandibular first molars (Newman, 1975; Goldson, 1975; Malmgren O, 1982; Kennedy, 1983; Linge 1991; Kaley, 1991; Harris, 1997; Janson 1999; Sameshima, 2001; Brin 2003; Kook 2003).

This may be because the extent of orthodontic movement of these teeth is usually greater than in the rest of the dentition, and the characteristic root structure of the incisors, along with their relationship to bone and the periodontal membrane, tends to transfer most of the forces to the apex (English 2001).

\section{Orthodontic treatment related risk factors:}

1) Treatment duration

Some studies have concluded that prolonged orthodontic treatment times result in increased incidence of apical root resorption (Deshield 1969; McFadden 1989, Linge 1991, Baumrind 1996; Brin 2003; Segal 2004; Otis 2004; Fox 2005). The length of treatment has also been linked to the severity of root resorption (Casa 2001, JimenezPellegrin 20004, Sameshima GT 2004). However, others found no significant association between OIIRR and treatment time (Dermaut 1986; Levander 1988; Beck 1994;). 
Confounding variables such as more difficult treatment plans or lack of patient compliance may be associated with extended treatment durations, and these factors may also contribute to root resorption.

2) Magnitude of applied force

It is believed that higher stress causes more extensive root resorption because the rate of lacunae development is more rapid and the tissue repair process is compromised (Casa 2001; Faltin 2001; Chan 2004; Chan 2005; Chan 2006; Harris 2006; Barbagallo 2008). However, in some studies when the force magnitude was doubled and quadrupled from $50 \mathrm{cN}$, there was no effect on the frequency or severity of RR or on the rate of tooth movement, although individual variations in root resorption and rate of tooth movement were large (Owmann-Moll 1996a, Owmann-Moll 1996b).

\section{3) Direction of tooth movement}

Greatest damage is observed with intrusive tooth movements since they concentrate pressure at the tooth apex (Kaley 1991; Beck 1994; Parker, 1998; Faltin, 2001; Han 2005; Harris 2006). When examining Maxillary central incisors, movements torquing the apex lingually are strongly correlated with the onset of root resorption. A combination of intrusion and lingual root torque has the highest risk for OIIRR (Costopulos G 1996; Parker, 1998). One study reported that maxillary incisors are 4.5 times more likely to have severe root resorption if they undergo root torque (Kaley 1991). This is due to the substantial force that is required to torque the apex of maxillary 
incisors, and these torquing forces become concentrated at the apex, which is the most root resorption sensitive area in the tooth.

Bodily movements are associated with a lower risk of OIIRR because the stress is distributed more evenly along the root (Parker 1998; Reitan 1985).

4) Amount of Apical displacement

In a recent meta-analysis Segal and colleagues indicated that orthodontic inflammatory root resorption is correlated to the amount of apical displacement that occurs during treatment (Segal 2004; Fox 2005)

5) Method of force application

a. Continuous versus discontinuous

Some studies have found that discontinuous force application results in lesser root resorption than the application of a continuous force because the pause in an discontinuous force allows the resorbed cementum to heal and prevents further resorption (Faltin 2001; Acar 1999; Konoo 2001; Weiland 2003).

There was no difference between teeth that were moved with either a continuous or an interrupted-continuous force (Owman-Moll 1995c).

There is weak evidence that "jiggling" forces have a role in increasing root resorption and as a result the use of removable appliances and intermaxillary elastics should be reduced (Brezniak 2002b; Linge 1983; Linge 1980).

b. Type of appliance 
Rapid maxillary expansion, with cervical traction, has been implicated in severe maxillary first molar root resorption (Brezniak 1993).

Less root resorption was observed in patients with removable appliances than fixed appliances (Ketcham 1927).

c. Treatment technique

Some have suggested that the Begg technique may induce more harmful effects on the roots (Goldson 1975; TenHoeve 1976; McNab 2000). Others have found that there is no real significant difference between Begg, Tweed or various Straightwire edgewise techniques (Malmgren O 1982; Lew K 1990; Beck 1994; Alexander 1996; Parker 1998).

Bioefficient therapy, using 0.022 slot triangular brackets and wire sequencing beginning with $0.020 \times 0.020$ inch Bioforce Ionguard (GAC International) working up to $0.018 \times 0.025$ inch stainless steel arch wires (Unitek), was found to produce significantly less OIIRR than simplified standard edgewise or edgewise straight wire systems. It was believed that the use of heat activated and superelastic wires, and a smaller rectangular stainless steel wire during incisor retraction and finishing, also played a role in this finding (Janson 1999).

When comparing conventional edgewise systems to various active and passive self-ligating appliances no statistically significant differences in root resorption have been found (Blake 1995; Pandis 2008; Scott 2008). 


\section{Patient-related risk factors:}

Individual susceptibility is considered a major factor in determining root resorption potential with or without orthodontic treatment (Segal 2004; Hartsfield 2004; Pizzo 2007).

1) History of root resorption

There is a high correlation between the amount (number of teeth involved) and the severity of root resorption present at the start of treatment to the root resorption present when the orthodontic appliance is removed (Hartsfield 2004; Brezniak 1993, Hamilton 1999; Drysdale 1996).

2) Tooth root morphology / length/ Roots with developmental abnormalities

Through mostly observational studies, abnormal root shape and other dental anomalies have been reported as risk factors for OIIRR (Levander 1988; Sameshima 2001; Sameshima 2004; Kjaer I, 1995; Smale 2005, Thongudomporn 1998). However, other investigators have found no significant correlation between tooth anomalies and OIIRR (Lee, 1999; Brin 2003), nor significant correlations between peg-shaped roots or microdontia of lateral incisors and OIIRR (Kook 2003).

There is a common belief that short roots undergo more resorption (Newman 1975; McFadden 1989). A more recent study supports the opposite view that the tendency for resorption increases with increasing tooth length (Mirabella 1995). A possible explanation may be that long teeth need stronger forces to be moved, so the 
actual displacement of the root apex is greater during torquing movements (English 2001).

3) Genetic influences

Several studies support the idea that there is a genetic influence on OIIRR (Harris 1997; Hartsfield 2004; Ngan 2004). A study of 123 sibling pairs treated with the same technique by a single operator showed that there were significantly greater variances among-than within-sibling pairs (Harris, 1997).

More recently, OIIRR has been linked to the IL-1B gene substantiating an important genetic predisposition to this problem. It has been observed that the presence of IL-1B allele 1 is associated with a high risk of OIIRR (homozygous has 5.6 times increased risk than non-homozygous (Al-Qawasmi 2003a)).

Another candidate gene for EARR is TNFRSF11A (or another genetic locus found at the D18s64 polymorphic marker level) that encodes a TNF receptor that mediates signaling loading to osteoclastogenesis contributing to OIIRR during orthodontic treatment (Al-Qawasmi 2003b).

Sameshima and Sinclair reported that Asian patients have significantly less root resorption than Caucasian or Hispanic patients (Sameshima 2001a). However, the statistical analysis on these data does not clearly show whether this is due to genetic factors or to differences in orthodontic treatment approaches (Bollen 2002).

4) Systemic factors 
a) It has been demonstrated that root resorption can be reduced with the use of drugs and hormones.

The main drug employed for this purpose is bisphosphonates, which demonstrate a dose-dependent reduction of root resorption when administered in rats (Igarashi 1996; Adachi 1994). However, it has also been demonstrated that these drugs produce cemental surface alterations, by inhibiting acellular cementum formation, increasing the vulnerability of the dental root to the resorptive process (Attati 1996a; Attati 1996b).

Nabumetone, a drug belonging to the NSAID group, reduces the amount of root resorption along with the control of pain from intrusive orthodontic forces, without affecting the pace of tooth movement (Villa 2005).

b) Hormone deficiency / Hypothyroidism, hypopituitarism

It is thought that endocrine disturbances including hypothyroidism and hypopituitarism may play a role in the occurrence of root resorption.

In rats it has been demonstrated that administration of L-thyroxine increases the resistance of cementum and dentin to osteoclastic activity (Poumpros 1994). Shirazi et al. found that the administration of increased doses of L-thyroxine to rats resulted in the reduction of the extent of root resorption (Shirazi 1999).

A reduction of root resorption in humans was reported after the administration of the thyroid hormone thyroxine in three patients with no thryroid 
conditions (Loberg 1994; Christiansen 1994). These results must be interpreted with caution when considering thyroxine administration to orthodontic patients as no randomized clinical human trials looking at L-thyroxine have been reported.

c) Asthma

It was recently reported that patients with chronic asthma have an increased incidence of EARR that is confined to the maxillary molars. This finding may result from the close proximity of the roots to the inflamed maxillary sinus and the presence of inflammatory mediators in these patients (Brezniak 2002, McNab 1999). The inflammatory mediators produced in asthma may enter the periodontal ligament and act synergistically to increase susceptibility to resorption. Although the asthma group had elevated incidence of EARR, both asthmatics and healthy patients exhibited similar amounts of moderate and severe resorption (McNab 1999).

d) Root proximity to cortical bone

It is unclear if proximity to cortical bone is related to root resorption. Kaley and Phillips reported that the risk of root resorption was 20 times greater when the maxillary incisors were in close proximity to the cortical plate (Kaley 1991), but roots were assessed with Panoramic radiographs, and cortical plates were assessed with Lateral Cephalograms. A similar study that used only cephalometric radiographs reported a much weaker correlation between the proximity of the root and cortex with the degree of OIIRR (Horiuchi 1998). 
Another study using only cephalometric analysis failed to show any association (Otis 2004).

e) Alveolar bone density

It had been postulated that tooth movement in dense bone requires greater or longer force application and consequently results in more root resorption (Rygh 1972). In a rodent model, teeth were shown to move faster and still develop OIIRR in animals that had an induced decrease in bone density (Goldie 1984). A similar study in beagle dogs showed that tooth movement was slower in denser dentoalveolar complexes (Midgett 1981).

In a human study the amount of alveolar bone around the root, thickness of cortical bone, density of the trabecular network, and fractal dimension showed no significant correlation with the extent of the OIIRR (Otis 2004).

f) Chronic alcoholism

Chronic alcoholics receiving orthodontic treatment are at a high risk of developing severe root resorption during the course of orthodontic treatment (Davidovitch 1996).

5) Previous trauma

There is a belief that teeth with a previous history of trauma are more susceptible to RR than healthy control teeth (Andreasen 1985; Linge 1983; Linge 1991). 
Teeth with slight to moderate injuries may not have any greater tendency toward root resorption during orthodontic treatment than uninjured teeth (Malmgren 1982). Several studies found that no statistically significant difference in groups regarding OIIRR between patients with traumatized and non-traumatized teeth (Brin 2003, Mandall 2004).

However, if a previously traumatized tooth exhibits resorption before treatment, then there is a greater chance that orthodontic movement will enhance the resorptive process (Brezniak 1993; Hamilton 1999; Drysdale 1996; Hartsfield 2004)

6) Endodontic treatment

Some investigators have reported an increased frequency of resorption in endodontically treated teeth (Wickwire 1974).

It has been demonstrated that the endodontic treatment does not represent a risk factor for OIIRR. Teeth with previous root canal treatment exhibit a lesser propensity for apical root resorption during orthodontic tooth movement (Mirabella 1995; Drysdale 1996; Hamilton 1999; Brezniak 2002b). It has been suggested that endodontically treated teeth are more resistant because of an increased dentine hardness and density (Reitan 1985; Remington 1989).

7) Severity and type of malocclusion

The amount of orthodontic tooth movement is associated with the resulting extent of EARR (Segal 2005; Fox 2005; Parker 1998; Hartsfield 2004; Mirabella 1995). In turn 
the required amount of tooth movement is a function of the severity of the malocclusion, which makes the presence of a severe malocclusion a risk factor for EARR.

Class I patients with acceptable overjets were significantly less likely to show EARR than Class II or III patients (Kaley 1991).

Significant associations between EARR and the magnitude of overjet reduction during treatment have been found (Baumrind 1996; Sameshima 2001a; Brin 2003; Hartsfield 2004), but not by all investigators (Linge 1983). Class II div 1 patients experienced significantly more RR (mean $2 \mathrm{~mm}$ ) than Class I patients (mean $1 \mathrm{~mm}$ ) undergoing orthodontic treatment with first premolar extraction, although no significant differences were found between the amount of RR and tooth inclination or duration of active treatment (Taner 1999).

Patients undergoing extractions during orthodontics had greater root resorption, which may be related to longer treatment duration and an increased amount of tooth movement (Sameshima 2001b).

8) Patient age

There was a traditional belief that OIIRR increases with age (Linge 1983; Reitan 1974), but more recent evidence has shown no effect of age on RR (McFadden 1989, Harris 1990, Linge 1991, Harris 1993, Baumrind 1996, Sameshima 2004, Beck 1994, Bishara 1999).

Investigations have also found that that the risk of OIIRR is lower in patients treated before the age of 11 years. Roots that were incompletely developed before 
treatment reached a significantly greater length than those that were fully developed at the start of treatment (Linge 1983; Mavragnani 2002). Perhaps the layer of thick predentine on underdeveloped roots provides a preventive effect.

9) Gender

There does not appear to be an association between gender and root resorption incidence or severity experienced during orthodontic treatment. Reports of a higher incidence in both females (Newman 1975; Kjaer 1995; Horiuchi 1998) and males (Spurrier 1990; Baumrind 1996) exist. While other investigators have concluded there is no effect (Mcfadden 1989; Harris 1997; Parker 1998; Sameshima 2001).

\section{Long-term prognosis}

A reduction in root length causes an unfavorable crown: root ratio of the affected teeth, making them less suitable as abutments and anchorage for prosthetic restorations such as crowns, bridges or removable partial dentures.

It has been found that root resorption associated with orthodontic treatment ceases with the termination of active treatment (Remington 1989). When post treatment root resorption does occur, it is not necessarily associated with large amounts of root resorption during the active treatment period. It is more likely associated with other factors, such as traumatic occlusion and active force-delivering retainers (Copeland 1989).

Apical root loss of $3 \mathrm{~mm}$ is equivalent to $1 \mathrm{~mm}$ of crestal bone loss, so periodontitis will progress more rapidly to a critical alveolar bone level if it involved 
previously root resorbed teeth (Kalkwaf 1986). If you take an average sized normally shaped maxillary central incisor that experienced no alveolar bone loss during orthodontic treatment, a root shortened by $5 \mathrm{~mm}$ will still have $75 \%$ of its periodontal attachment remaining (95\% of patients), which may be why tooth loss due to apical shortening has not been reported in the literature (Kalkwaf 1986).

Even extensive root resorption does not usually affect the functional capacity or greatly compromise the longevity of the teeth. In patients who had experienced severe root resorption, 5-15 years after treatment, root lengths varied from 5.5-18.1 mm and decreasing length was significantly related to tooth mobility. No teeth had mobility scores greater than 1 on Miller's index (crown deviates within $1 \mathrm{~mm}$ of its normal position), and there was less risk of mobility if the total root remaining was greater than 9mm (Levander 2000). A retrospective study of 100 patients, not randomly selected, with severe root resorption observed at the conclusion of orthodontic treatment were recalled 14 years later and no tooth loss was observed, and hypermobility was found in only 2 cases (Remington 1989).

\section{Treatment and prevention}

During orthodontic treatment, progress radiographs should be obtained after 6-12 months to detect the early occurrence of OIIRR. If detected, active treatment should be halted for 2-3months with passive AW's. Levander (1994) found that a treatment pause of 2-3 months with passive archwires led to a decrease in the prevalence and severity of root resorption. 
If severe resorption is identified the treatment plan should be re-assessed with the patient. Alternative options might include prosthetic solutions to close spaces, releasing teeth from active archwires if possible, stripping instead of extractions, and early fixation of resorbed teeth (Brezniak 2002b).

After treatment, if severe EARR is present on the final radiographs, follow-up radiographic examinations are recommended until the resorption has stabilized. Termination of active EARR usually occurs after appliance removal. If it does not occur, sequential root canal therapy with calcium hydroxide may be considered (Pizzo, 2007). After orthodontic treatment some tooth mobility may occur, but only when $9 \mathrm{~mm}$ or more of the root has been resorbed (Levander 2000). Retaining the teeth with fixed appliances should be done with caution since occlusal trauma of the fixed teeth or segments might lead to extreme EARR (Brezniak 2002b).

\section{Adequacy of 2-D radiographs to analyze root resorption}

The detection of RR has been mainly through radiographs, light microscope, scanning electron microscope, and micro-CT. Radiographic detection is an important tool in identifying RR, but because of varying degrees of magnification the accurate quantitative value of radiographs is questionable. Surface resorption can only be detected if it occurs mesio-distally at direct right angles to the focal beam of the X-rays or if resorption has progressed to an advanced stage.

Panoramic radiographs have been found to overestimate the amount of root loss by $20 \%$ or more when compared with periapical radiographs (PA's) (Sameshima 2001a). Although the paralleling technique with PA's has been described as the technique of 
choice for detecting root shortening, it has also been shown to be geometrically inaccurate (Katona 2006).

Lateral cephalometrics have been shown to yield an accurate and reproducible view of upper incisor length, but is subjected to a 5-12\% enlargement factor as a result of the radiographic set up. Also, overlapping of the right and left side make the individual images unclear (Chan 2004b). While radiography is a valuable diagnostic tool in detecting RR, quantitative measurements are relatively poor and should be avoided (Chan 2004b).

It has been stated that periapical radiographs to assess root resorption are inaccurate (Katona 2006). It is believed that the compensatory algorithms are intrinsically ambiguous, and incapable of reliably identifying constant length roots (nonresorbing and nongrowing) even in explicitly defined "perfect" teeth, and further compromised by landmark identification.

3Dimentional volumetric quantitative evaluation of root resorption craters has been found to be a feasible alternative with a high level of accuracy and repeatability (Chan 2004a; Chan 2006; Darendeliler 2004). A mathematical computer based reconstruction of pre- and post treatment dental images have also been shown to be a reliable technique for measuring root resorption (Reukers 1998). 


\section{CHAPTER 2}

\section{MATERIALS AND METHODS}

The primary objective of this review was to evaluate the effect of orthodontic treatment on root resorption. The secondary objective was to examine the effects that systemic conditions and/or specific orthodontic mechanics have on the rate and severity of root resorption experienced. We formulated a focused research question using the PICO format:

Population: patients with no history of root resorption

Intervention: comprehensive orthodontics

Comparison: people who have not had orthodontics / teeth that were not moved orthodontically

Outcome: root resorption

\section{Null Hypothesis}

1) There is no difference in the incidence and severity of root resorption between patients, with no history of RR, undergoing comprehensive orthodontic treatment and an untreated group. 
2) There is no difference in the incidence and severity of root resorption between patients, with no history of RR, undergoing comprehensive orthodontic treatment who receive tooth movement with different techniques.

\section{Inclusion Criteria for Studies in this Review}

\section{Types of studies}

This review included randomized controlled trials (RCTs), published or unpublished, that evaluated root length before and after treatment in humans.

\section{Types of participants}

Patients of any age, gender or ethnicity who underwent comprehensive orthodontic treatment with full fixed appliances.

\section{Types of interventions}

Continuous versus non-continuous forces, Direction of tooth movement, Light versus heavy forces, Duration of treatment, Distance of Tooth Movement, Type of orthodontic appliance used.

The control group was either individuals or teeth within the same individual (including the split mouth technique) not subjected to the orthodontic force either through a placebo, bracket placement but no activation, or absence of the intervention.

\section{Types of outcome measures}

The primary outcome measure was the presence/absence of root resorption at the end of treatment. 
Secondary outcomes included the severity and extent of root resorption between experimental and control groups assessed either directly via histology or indirectly using radiographs. Patient based outcomes such as perception of root resorption; further complications (mobility, tooth loss) and quality of life data were also included.

\section{Search methods for identification of studies}

Detailed search strategies were developed for each database used in the identification of studies to be considered for inclusion in this review. The search strategy developed for MEDLINE via OVID is displayed below. This strategy was revised accordingly for each additional database used.

MeSH terms: in UPPER CASE. Free text terms: in lower case

\#1 ORTHODONTIC*: ME

\#2 "braces"

\#3 (\#1 or \#2)

\#4 ROOT RESORPTION*: ME

\#5 "external apical root resorption"

\#6 "root erosion"

\#7 "root blunting"

\#8 "root shortening"

\#9 "tooth-root resorption"

\#10 "orthodontically induced inflammatory root resorption"

$\# 11$ (\#4 or \#5 or \#6 or \#7 or \#8 or \#9 or \#10)

$\# 12$ (\#3 and \#11)

\#13 HUMAN*: ME

$\# 14$ (\#12 and \#13) 


\section{Electronic searches}

The following databases were searched, from their inception to October 2008.

- Cochrane Oral Health Group Register (October 2008)

- Cochrane Cental Register of Controlled Trials (CENTRAL) (The Cochrane library, October 2008)

- Cochrane Database of Systematic Reviews (The Cochrane library, October 2008)

- MEDLINE (1950- October 2008)

- PubMed (1966- October 2008)

- EMBASE (1974 - October 2008)

- Web of Science (1975- October 2008)

- EBM Reviews (1991- October 2008) (DARE)

- Computer Retrieval of Information on Scientific Project (www.crisp.cit.nih.gov) (1978 - October 2008)

- On-Line Computer Library Center (www.oclc.org/home) (1967- October 2008)

- GoogleIndex to Scientific and Technical Proceedings (www.isinet.com/isi/products/indexproducts/istp)( October 2008)

- LILACS - Latin American and Caribbean Center on Health Sciences Information (www.bireme.br/local/Site/bireme/I/homepage.htm) (October 2008)

- PAHO www.paho.org (Ocotber 2008)

- $\quad$ BBO (Brazilian Bibliography of Dentistry) (1966-October 2008)

- WHOLis searched via www.who.int/library/databases/en (October 2008)

- CEPS www.airiti.com/ceps/ec_en/to October $3^{\text {rd }} 2008$

- Conference Materials (www.bl.uk/services/bsds/dsc/conference.html)(August 2008)

- TrialsCentral www.trialscentral.org on October $3^{\text {rd }} 2008$

\section{Reference list searching}

To locate additional studies, the reference lists of review articles and all of the included studies were checked. 


\section{Unpublished studies}

SIGLE (System for Information on Grey Literature in Europe) (1976 to October 2008) and www.Clinicaltrials.gov (October 2008), National Research Register (UK) (www.controlled-trials.com) (1998 - October 2008), and ProQuest Dissertation Abstracts and Thesis database (www.lib.umi.com/dissertations) (1986 - October 2008) were searched to obtain information about studies published in the grey literature. For unpublished studies, requests were also sent to relevant professional organizations in an attempt to identify unpublished or ongoing studies.

\section{Hand searching}

Hand searches were undertaken to locate published material not indexed on available databases. The following journals were identified as being important for this review:

- American Journal of orthodontics and Dentofacial orthopedics

- Angle Orthodontist

- European Journal of Orthodontics

- [British] Journal of Orthodontics

- Clinical Orthodontics and Research

- Journal of Dental Research

- Journal of Clinical Orthodontics

\section{Language}

There were no language restrictions. Translation of Foreign language articles was produced by contacts within the Department of Dentistry at Ohio State University.

\section{Inclusion Criteria}

Randomized controlled trials (RCTs), published or unpublished, that evaluated root length before and after treatment in Human subjects. This review included patients 
of any age, gender or ethnicity who underwent comprehensive orthodontic treatment with full fixed appliances.

\section{Exclusion criteria}

This review excluded animal studies, studies including auto-transplanted teeth, and duplicate publications.

\section{Methods of the Review}

\section{Study Selection}

Two reviewers (BW and KV) independently examined and coded studies that were identified by the above methods according to type of study, participants, presence of an orthodontic intervention, presence of a root resorption outcome, and presence/type of the comparison group.

\section{Data extraction and management}

Two reviewers (BW and KV) extracted data independently, in duplicate, using specially designed data extraction forms. The data extraction forms were piloted on several papers and modified as required before use. Any disagreement was discussed and a third reviewer consulted where necessary. All authors were contacted for clarification on missing information. Data were excluded until further clarification becomes available or if agreement could not be reached. All studies meeting the inclusion criteria then underwent validity assessment and data extraction. Studies rejected at this or subsequent stages were recorded, with the reasons for exclusion in the table of excluded studies.

For each trial the following data were recorded: 
- Year of publication and country of origin

- Details of the participants including demographic characteristics and criteria for inclusion

- Details of the type of intervention (type of appliance, type/magnitude/duration/direction of force)

- Details of the outcomes reported (number of teeth affected, size and severity of $\mathrm{RR}$ )

\section{Quality Assessment}

Two reviewers (BW, KV) assessed the quality of the identified studies independently and in duplicate.

Four main quality criteria were examined:

1) Method of randomization, recorded as:

- Yes - adequate

- No - inadequate

- Unclear - unclear in the text and unable to clarify with the author

2) Allocation concealment, recorded as:

- Adequate

- Unclear - unclear in the text and unable to clarify with the author

- Inadequate

- Allocation assignment not used

3) Blinding of outcome assessors, recorded as:

- Yes - adequate

- No - inadequate

- Unclear - unclear in the text and unable to clarify with the author

4) Completeness to follow up, recorded as:

- Yes - numbers in the methods and results were the same, and/or not the same but with all dropouts explained

- No - numbers in the methods and the results were not the same and dropouts were not explained 
- Unclear - unclear in the text and unable to clarify with the author

Additional minor criteria examined included:

- Baseline similarity of the groups.

- Reporting of eligibility criteria.

- Measure of variability of primary outcome.

- Sample size calculation.

To assess reviewer agreement with respect to the methodological quality, a Kappa statistic was calculated.

\section{Assessment of heterogeneity}

Heterogeneity was to be assessed by means of the I-squared statistic (Higgins 2003).

\section{Data synthesis}

A weighted treatment effect was to be calculated and the results expressed as weighted mean differences (WMD and 95\% CI) for continuous outcomes and odds ratio (OR and 95\% CI) for dichotomous outcomes, using fixed and random effects models (Higgins 2008). Pooling of data and meta-analysis was only to be carried out if there was a sufficient similarity between studies in the types of participants, interventions and outcomes, including the time of the outcome measurement.

\section{Subgroup analysis and investigation of heterogeneity}

Subgroup analyses (fixed and removable appliances, children adolescents and adults, etc-) and publication type bias analyses were intended to determine bias and the significance of contributing factors (study quality, diagnostic criteria and severity of 
outcome, duration of orthodontic treatment, and duration of follow-up) to the overall results.

\section{Sensitivity analysis}

The use of sensitivity analyses was planned in order to examine the effect of the quality assessment items on the overall estimates of effect. 


\section{CHAPTER 3}

\section{MANUSCRIPT:}

Root resorption associated with orthodontic tooth movement:

A Systematic Review. 
TITLE: Root resorption associated with orthodontic tooth movement: A Systematic

\section{Review}

\section{AUTHORS:}

Belinda Weltman, M.Sc., D.M.D., M.S.

Katherine W.L. Vig, B.D.S., M.S., F.D.S., D. Orth.

Henry W. Fields, D.D.S., M.S., M.S.D.

Shiva Shanker, D.D.S., M.D.S., M.S.

Eloise E. Kaizar, B.S., B.A., PhD.

Dr. Weltman is in private practice in Vancouver, B.C.

Dr. Vig (Corresponding Author) is Professor Emeritus, Division of Orthodontics, The 4088 F Postle Hall, The Ohio State University College of Dentistry, 305 W $12^{\text {th }}$ ave, PO Box 182357, Columbus, OH 43218-2357. Telephone: 614-688-3146, Fax: 614-688-3077, E-mail: vig.2@osu.edu

Dr. Fields is Professor and Chair, Division of Orthodontics. The Ohio State University College of Dentistry.

Dr. Shanker is Clinical Associate Professor, Division of Orthodontics, The Ohio State University College of Dentistry.

Dr. Kaizar is an Assistant Professor, Department of Statistics, The Ohio State University. 


\begin{abstract}
Introduction: This systematic review evaluated root resorption as an outcome for patients who received orthodontic tooth movement. Results could provide the best available evidence for clinical decisions to minimize the risks and severity of root resorption. Methods: Electronic databases were searched, non-electronic journals hand searched and experts in the field consulted with no language restrictions. Study selection criteria included: randomized clinical trials involving human subjects for orthodontic tooth movement, with fixed appliances, and root resorption recorded during or after treatment. Two authors independently reviewed and extracted data from selected studies on a standardized form. Results: The searches retrieved 921 unique citations. Titles and abstracts identified 144 full articles from which 13 publications remained after inclusion criteria applied. Differences in the methodologies and reporting results made statistical comparisons impossible. Evidence suggests that comprehensive orthodontic treatment causes an increase in the incidence and severity of root resorption, and heavy forces are particularly harmful. Orthodontically induced inflammatory root resorption (OIIRR) is unaffected by archwire sequencing, bracket prescription, or self-ligation. Previous trauma and tooth morphology are unlikely causative factors. There is some evidence that a 2-3 month treatment pause will decrease total root resorption. Conclusions: Results from this systematic review are inconclusive in clinical management of OIIRR. We recommend that best practice include using light forces especially with incisor intrusion.
\end{abstract}

KEY WORDS: Root Resorption, Orthodontics, and Systematic Review 


\section{INTRODUCTION}

At present it is unknown how orthodontic treatment factors influence root resorption (RR). The etiological factors are complex and multifactorial, but it appears that apical root resorption results from a combination of individual biological variability and the effect of mechanical factors. Root resorption is undesirable because it can affect the long-term viability of the dentition. Reports in the literature indicate patients undergoing orthodontic treatment are more likely to experience severe apical root shortening than individuals who do not. ${ }^{1,2}$ Patient factors such as genetics and external factors including trauma are also thought to be associated with increased root resorption. ${ }^{3-5}$

Many general dentists and other dental specialists believe that root resorption is avoidable, and hold the orthodontist responsible should it occur during orthodontic treatment. ${ }^{6}$ It is important to clarify which orthodontic treatment factors contribute to root resorption so that the detrimental effects can be minimized, and the rates of resorption reduced.

\section{Incidence and prevalence of Orthodontically Induced Inflammatory Root} Resorption (OIIRR): Histological studies report a greater than $90 \%$ occurrence of RR in orthodontically treated teeth. ${ }^{7-9}$ Lower percentages are reported when diagnostic radiographic techniques are used. Lupi et al. reported the incidence of EARR before treatment as $15 \%$ and after treatment $73 \% .{ }^{10}$ In most cases the loss of root structure is minimal and clinically insignificant. 
Using Panoramic or peri-apical radiographs, the OIRR is usually less than $2.5 \mathrm{~mm},{ }^{11-5}$ or varying from $6-13 \%$ for different teeth. ${ }^{16}$ Using graded scales, OIIRR is usually classified as minor or moderate in most orthodontic patients. ${ }^{17-20}$ Severe resorption defined as exceeding $4 \mathrm{~mm}$ or $1 / 3$ of the original root length, is seen in $1-5 \%$ of teeth..$^{10,17-9,21-3}$

Regardless of genetic or treatment related factors, the maxillary incisors consistently averages more apical root resorption than any other tooth, followed by mandibular incisors and mandibular first molars. ${ }^{12,15,20,24-8}$

Orthodontic treatment related risk factors: These risk factors include treatment duration, ${ }^{17,29-39}$ magnitude of applied force, ${ }^{33,40-45}$ direction of tooth movement, ${ }^{27,38-9,41,46-9}$ amount of apical displacement, ${ }^{30,35}$ and method of force application (continuous versus intermittent, ${ }^{11,12,42,50-4}$ type of appliance, ${ }^{55-7}$ and treatment technique $\left.{ }^{16,18,24-5,38,46,57-62}\right)$.

Patient-related risk factors: Individual susceptibility is considered a major factor in determining root resorption potential with or without orthodontic treatment. ${ }^{30,63-4}$ These include: previous history of root resorption, ${ }^{55,64-6}$ tooth root morphology / length/ roots with developmental abnormalities, ${ }^{5,13,15,19,20,27,35-7,67-71}$ Genetic influences, ${ }^{3,4,15,64,72-4}$ Systemic factors ${ }^{75-78}$ (drugs - Nabumetone (NSAID) ${ }^{79}$, hormone deficiency / hypothyroidism, hypopituitarism ${ }^{80-83}$; asthma ${ }^{54,84}$ root proximity to cortical bone, ${ }^{27,29,85}$ alveolar bone density ${ }^{29,86-8}$, chronic alcoholism, ${ }^{89}$ ) previous trauma, ${ }^{12,20,24,54,64-6,90-92}$ endodontic treatment, ${ }^{13,49,54,65-6,93-4}$ severity and type of malocclusion, ${ }^{13,15,20,27,30-1,34,45,64,95-}$ ${ }^{6}$ patient age, ${ }^{1,11,12,14,17,31,35-6,97-9}$ and gender. ${ }^{4,5,15,31,35,45,66,85,100}$ 
Several reviews and a meta-analysis examined orthodontics and root resorption. However, they were of a limited scope and the meta-analysis was restricted to English language publications. A Medline search only included the effects on central incisors, and retrospective non-RCT studies were included. ${ }^{30}$ This project is designed to be more comprehensive in the search and more restrictive regarding quality measures. It is anticipated that variables relating orthodontic treatment to root resorption will be identified, and by combining the results from clinical trials a stronger evidence-based approach to root resorption associated with orthodontic tooth movement may provide important guidelines for contemporary clinical practice.

The purpose of this article is to report results of a systematic review of external apical root resorption in patients with fixed orthodontic appliances.

\section{MATERIALS AND METHODS}

The first phase of the meta-analysis involved the development of a specific protocol and research question. Table 1 outlines the PICO format used and the null hypothesis. The methods for this review were based on guidelines published by the Cochrane Database of systematic reviews. ${ }^{101}$ The primary objective of this review was to evaluate the effect of orthodontic treatment on root resorption. The secondary objective was to examine the effects that systemic conditions and/or specific orthodontic mechanics have on the rate and severity of root resorption. 
This review located citations to relevant trials in journals, dissertations, and conference proceedings by searching appropriate databases. Detailed search strategies were developed for each database used in the identification of studies (published and unpublished) to be considered for inclusion. Table 2 lists the databases searched in this review. To locate additional studies, reference lists of review articles and all included studies were checked. Requests were also sent to relevant professional organizations in an attempt to identify unpublished or ongoing studies. Hand searches were undertaken to locate published material not indexed in available databases.

No restrictions were placed on year, publication status, or language of the retrieved trials. Translations of foreign language articles were obtained by contacts within the College of Dentistry at Ohio State University.

Two reviewers (BW and KV) independently examined and coded studies that were identified by the above methods. Trials appropriate to be included in the review were randomized controlled trials (RCTs) fulfilling certain criteria concerning study design, participant characteristics, intervention characteristics, presence of a root resorption outcome, and presence/type of the comparison group. Details about the selection criteria are given in Table 3.

The same reviewers extracted data independently, using specially designed data extraction forms. The data extraction forms were piloted on several papers and modified as required before use. Any disagreement was discussed and a third reviewer consulted when necessary. All authors were contacted for clarification on missing information. Data were excluded until further clarification became available or if agreement could not 
be reached. All studies meeting the inclusion criteria then underwent validity assessment and data extraction. Studies rejected at this or subsequent stages were recorded, with the reasons for exclusion listed in the table of excluded studies (Appendix A Table 1).

The two reviewers evaluated the quality of the trials included in the review independently by assessing four main criteria: method of randomization, allocation concealment, blinding of outcome assessors, and completeness to follow up. Additional minor criteria were examined including: baseline similarity of the groups, reporting of eligibility criteria, measure of variability of primary outcome, and sample size calculation. Details about the assessment criteria are given in Table 4.

\section{Statistical methods}

To assess reviewer agreement with respect to the methodological quality, a Kappa statistic was calculated. One reviewer entered that data into Review Manager (version 5.0; Cochrane Collaboration, Boston, Mass).

Quantitative synthesis of data from multiple studies was to be carried out according to procedures recommended by the Cochrane Collaboration. ${ }^{101}$

\section{RESULTS}

The electronic and hand searches retrieved 921 unique citations, which were entered into a QUORUM flow chart (Fig 1) to illustrate the path by which the final trials were selected. After evaluating titles and abstracts 144 full articles were obtained (2 articles could not be located). After evaluating the full text, as well as querying primary authors, we determined that 13 publications, describing 11 trials, fulfilled the criteria for 
inclusion. Summary details of the studies examined and reasons for inclusion or exclusion are recorded in Table 5 'Characteristics of included studies table' and Appendix Table 1 'Characteristics of excluded studies table'. Because these studies used different methodologies and reporting strategies, it was not possible to undertake a quantitative synthesis. A qualitative analysis is therefore presented.

\section{Methodological Quality}

The assessments for the four main methodological quality items are shown in Table 6. A study was assessed to have a high risk of bias if it did not record a 'YES' in three or more of the four main categories, moderate if two of the four did not record a 'YES' and low if randomization, assessor blinding and completeness of follow up were considered adequate.

Following examination of the publications and further contact with the authors, if necessary and as noted in Table 6 , the method of randomization was considered adequate for 10 of the 11 trials, ${ }^{20,40-1,43,45,47,62,91,102-3}$ but the method of allocation concealment was only adequate in 4 of these..$^{20,47,91,103}$ The method of randomization and allocation concealment was inadequate or unclear for the remaining 7 publications. ${ }^{40-1,43,45,50,62,102}$ Blinding for outcome evaluation was reported in 5 trials. $^{20,46,62,91,103}$ The reporting and analysis of withdrawals and dropouts was considered adequate in all 11 trials. $^{20,40-}$ 1,43,45,47,50,62,91,102-3 In total, 5 studies were assessed to have low risk of bias, five were assessed to have moderate risk of bias, and one was assessed to have the potential for high risk of bias. ${ }^{50}$ 
The minor methodological quality criteria examined are shown in Table 7. Six studies fulfilled all the minor methodological quality criteria. ${ }^{40-1,43,45,62,91}$ Sample size was justified in 6 of the 11 trials..$^{40-1,43,45.62,91}$ Five studies carried out a comparison to assess comparability of the experimental and control group at baseline. ${ }^{20,62,91,102-3}$ Four studies were considered to be comparable at baseline as they were of a spilt mouth design using intraindividual controls. ${ }^{40-1,43,45}$ Comparability at baseline for $\operatorname{Han}^{47}$ was considered to be adequate as there was an intraindividual control for experimental groups, and control teeth were randomly selected (same age/orthodontic treatment plan as experimental individuals). The study by $\mathrm{Acar}^{50}$ was found to not be comparable at baseline as there was an intraindividual control for both experimental groups, but control teeth were not randomly selected (same age/orthodontic treatment plan as experimental individuals). Ten studies had clear inclusion/exclusion criteria. ${ }^{20,40-1,43,45,47,62,91,102-3}$ All studies carried out an estimate of measurement error. ${ }^{20,40-1,43,45,47,50,62,91,102-3}$

The Kappa scores and percentage agreements between the two raters assessing the major methodological quality of the studies were: randomization 1.0, 100\%; concealment 0.72, 82\%; blinding 0.91, 95\%; and withdrawals $1.0,100 \%$.

The included studies were grouped into 11 comparisons according to clinical questions of interest.

\section{Discontinuous versus Continuous Force}

Acar $^{50}$ compared a $100 \mathrm{~g}$ force applied using elastics in either an interrupted (12hrs/day) or continuous (24hrs/day) application. Teeth experiencing orthodontic 
movement had significantly more root resorption that control teeth. Continuous force produced significantly more root resorption than discontinuous force application.

The authors have some reservations about the reliability of this study's results. We were unable to contact the original author to clarify the methodology, and based on the information available the risk of bias was judged to be high. It only met one of the major and one of the minor methodological criteria.

\section{Removable Thermoplastic Appliance versus Fixed Light and Heavy force}

Barbagallo $^{41}$ compared removable thermoplastic appliance (TA) force application with fixed orthodontic force application. Results show that teeth experiencing orthodontic movement had significantly more root resorption than control teeth. Heavy force $(225 \mathrm{~g})$ produced significantly more root resorption (9x greater than control) than light force (25g) (5x greater than control) or TA force (6x greater than control) application. Light force and TA force resulted in similar root resorption cemental loss.

This study was judged to have a moderate risk of bias since patients were randomly allocated to experimental and control groups, but that allocation was not concealed and assessors not blinded to treatment groups. All minor methodological criteria were met.

\section{Light (25g) versus Heavy (225g) Continuous Force}

Four split-mouth studies from the same research group compared fixed orthodontic light $(25 \mathrm{~g})$ continuous force with fixed heavy $(225 \mathrm{~g})$ continuous force in 
patients in need of premolar extraction to relieve crowding/overjet. Three studies applied a buccal tipping force, ${ }^{41,43,45}$ and one applied an intrusive force. ${ }^{40}$

With the exception of light-force group in a study by Chan ${ }^{45}$, all teeth experiencing orthodontic movement had significantly more root resorption that control teeth. ${ }^{40-1,43}$ Chan $^{45}$ found the mean volume of the resorption crater in the light-force group was 3.49 times greater than in the control group (not significant). All studies found that heavy force application produced significantly more root resorption than light force application or control. ${ }^{40-1,43,45} \mathrm{Chan}^{45}$ found the mean volume of the resorption crater was 11.59 times greater in the heavy force group than in the control group (significant). Heavy forces in both compression and tension areas produced significantly more root resorption than in regions under light compression and light tension forces.

Barbagallo $^{41}$ also found that heavy force produced significantly more root resorption (9x greater than control) than light force (5x greater than control).

In contrast to the other studies in this section Harris ${ }^{40}$ administered intrusive forces. Results showed that the volume of root resorption craters after intrusion was directly proportional to the magnitude of the intrusive force. A statistically significant trend of linear increase in the volume of the root resorption craters was observed from control to light ( $2 \mathrm{x}$ increased) to heavy ( $4 \mathrm{x}$ increased) groups.

All four studies were judged to have a moderate risk of bias as only two of the major methodological criteria were met. All minor methodological criteria were met. 


\section{Intrusive versus Extrusive Force}

$\mathrm{Han}^{47}$ found that RR from extrusive force was not significantly different from the control group. Intrusive force significantly increased the percentage of resorbed root area (4-fold). The correlation between intrusion/extrusion and RR in the same patient was $r=$ $0.774(\mathrm{p}=0.024)$.

This study was judged to have a low risk of bias as all of the major methodological criteria were met. Minor methodological criteria aside from sample size calculation were met.

As mentioned previously, Harris ${ }^{40}$ found that the volume of root resorption craters after intrusion was directly proportional to the magnitude of the intrusive force. This study was judged to have a moderate risk of bias.

\section{Archwire sequence}

Mandall ${ }^{91}$ compared three orthodontic archwire sequences in terms of patient discomfort, root resorption, and time to working archwire. All patients were treated with upper and lower pre-adjusted edgewise appliances ( 0.22 inch slot) and all archwires were manufactured by Ormco (Amersfoort, The Netherlands). Results showed no statistically significant difference between archwire sequences, for upper left central incisor root resorption ( $\mathrm{F}$ ratio, $\mathrm{P}=0.58)$. There was also no statistically significant difference between the proportion of patients with/without root resorption between archwire sequence groups (Chi-square 5, $\mathrm{P}=0.8,2 \mathrm{df}$ ). This study was well designed, and considered unlikely to have significant bias. It was the only study to fulfill all of the methodological quality assessment criteria. 


\section{Effect of a treatment pause in patients experiencing OIRR}

Levander ${ }^{102}$ investigated the effect of a pause, in active treatment, on teeth that had experienced apical root resorption during the initial 6-month period with fixed appliances. All patients were treated with Edgewise 0.018-inch straight wire appliances. Results showed that the amount of root resorption was significantly less in patients treated with a pause $(0.4 \pm 0.7 \mathrm{~mm})$ than those treated with continuous forces without a pause $(1.5 \pm 0.8 \mathrm{~mm})$. No statistically significant correlations were found between root resorption and Angle classification, trauma history, extraction treatment, time with rectangular archwires, time with Class II elastics, or total treatment time. The study was rated as having a moderate risk of bias, because it only fulfilled two major criteria and there was no a priori sample size calculation. We were unable to contact the author to clarify the allocation concealment and assessor blinding of this study.

\section{Straightwire versus Standard edgewise}

Reukers ${ }^{103}$ compared the prevalence and severity of root resorption after treatment with a fully programmed edgewise appliance (FPA) and a partly programmed edgewise appliance (PPA). All FPA patients were treated with 0.022 slot Roth prescription (Acompany San Diego, California), and misplaced brackets were rebonded. All PPA patients were treated with 0.018 slot Microloc brackets (GAC Central Islip, New York), and archwires were adjusted for misplaced brackets. Results showed no statistically significant differences in the amount of tooth root loss (FPA 8.2\%, PPA 7.5\%) or prevalence of root resorption (FPA 75\%, PPA 55\%) between groups. This study was well designed, and considered unlikely to have significant bias, but did involve variations of 
two variables - slot size and appliance programming, so undetected interactions could have been present.

\section{Trauma versus No Trauma}

Three studies evaluated the effect of previous trauma (but no sign of EARR) on the occurrence of OIIRR during orthodontic treatment. ${ }^{20,91,102}$

Brin $^{20}$ showed that incisors with clinical signs or patient reports of trauma had essentially the same prevalence of moderate to severe OIIRR as those without trauma. Mandall $^{91}$ reported that history of incisor trauma was not associated with increased root resorption (t-test: $\mathrm{P}=0.59)$. Levander ${ }^{102}$ also showed no statistically significant correlations between root resorption and trauma history.

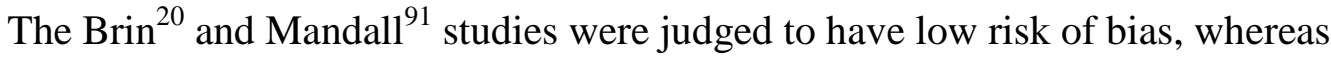
the Levander ${ }^{102}$ study was judged to have moderate risk of bias.

\section{Teeth with unusual morphology}

Brin $^{20}$ examined the severity of root resorption in teeth with unusual morphology. Results showed that teeth with roots having unusual morphology before treatment were not significantly more likely to have moderate to severe OIIRR than those with more normal root form. This study was judged to be a low risk of bias as it fulfilled all of the major methodological criteria. However, there was no a priori sample size calculation, as this was a secondary endpoint for the RCT. 


\section{Two-phase versus one-phase class II treatment}

Brin $^{20}$ examined the effect of two-phase versus one-phase class II treatment on the incidence and severity of root resorption. Results showed that children treated in two phases with a bionator followed by fixed appliances had the fewest incisors with moderate to severe OIIRR, whereas children treated in a single phase with fixed appliances had the most resorption. However, there was no statistical significance between these groups. As treatment time increased, the odds of OIIRR also increased (P $=0.04)$. The odds of a tooth experiencing severe root resorption were greater if a large reduction of overjet occurred during phase two. This study was judged to be a low risk of bias as it fulfilled all of the major methodological criteria. There was no a priori sample size calculation, as this was a secondary endpoint for the RCT.

\section{Self ligating versus Conventional orthodontic bracket systems}

$\mathrm{Scott}^{62}$ investigated the effect of either Damon3 self-ligating brackets or a conventional orthodontic bracket system on lower incisor root resorption. Patients were treated with Damon3 self-ligating (Ormco, Glendora, California) or Synthesis (Ormco Glendora, Claifornia) conventionally ligated brackets with identical archwires / sequencing in all patients. Results showed that mandibular incisor root resorption was not statistically different (Damon3 2.26mm SD 2.63; Synthesis 1.21mm SD 3.39) between systems. This trial was judged to be a low risk of bias. It fulfilled three of the major methodological criteria and all of the minor methodological criteria. The author was contacted for further information. 


\section{Investigation of heterogeneity, Sensitivity Analyses \& Publication Bias}

No meta-analysis, combining more than one study, was undertaken so this did not apply.

\section{Secondary Outcomes}

Other outcomes such as patient's perception of root resorption, tooth mobility, tooth loss or quality of life data were not recorded for any of the studies.

\section{DISCUSSION}

Orthodontically induced inflammatory root resorption (OIIRR) is considered to be a particularly important sequelae associated with orthodontic treatment. However, only 11 trials were considered appropriate for inclusion in this review and their protocols were too variable to proceed with a meta-analysis. This reflects the state of the relevant research on this topic.

It is widely accepted that properly executed well-designed randomized controlled trials provide the best evidence on the efficacy of health care interventions. In spite of the considerable amount of OIIRR research reported in the scientific literature on clinical trials they were not randomized, prospective, or representative of 24-month comprehensive orthodontic care. Moreover, in many studies the measurement techniques for OIIRR were not uniform, or on similar teeth. Other systematic reviews have also

commented on the lack of uniformity for reporting data within the dental literature. ${ }^{104-6}$ 
The detection of OIIRR has been mainly through radiographs, light microscope, scanning electron microscope, and micro-CT. Clinically, radiographics are an important diagnostic tool in detecting OIIRR, but the varying degrees of magnification, and the limitations involved with 2-D measurement of a 3-D phenomenon make the quantitative value of radiographs questionable and geometrically inaccurate. ${ }^{107-9}$ Quantitative 3-D volumetric evaluation of root resorption craters has been found to be a feasible alternative with a high level of accuracy and repeatability. ${ }^{43,45,110}$ It is important that future studies utilize both accurate, reliable and valid measurement tools so meaningful comparisons can be made.

This systematic review included 6 RCT split mouth studies. The results of the quality assessments, the small sample sizes and the short experimental periods of these studies led to the conclusion that their validity is limited. Each spit-mouth study analyzed premolars, which are teeth not routinely/severely affected by OIIRR. Also, none of the split-mouth studies lasted longer than 9 weeks. We have evidence to suggest that orthodontic force applied to teeth over a short period can produce resorption lacunae in the absence of EARR. ${ }^{111}$ Longer trials would be more appropriate to evaluate the full effects of orthodontic tooth movement on root resorption. As a result the scientific evidence supporting clinical recommendation to reduce OIIRR in patients undergoing fixed orthodontic appliance therapy is insufficient to allow many useful conclusions to be drawn.

Our results show that teeth experiencing orthodontic movement had significantly more root resorption that control teeth. ${ }^{40-1,43}$ Heavy force application produced 
significantly more root resorption than light force application or in controls. ${ }^{40-1,43,45}$ It is believed that higher forces cause more extensive root resorption because the rate of lacunae development is more rapid and the tissue repair process is compromised. ${ }^{30,40-5}$ Earlier non-randomized studies contradict these finding. According to Owman-Moll, when the force magnitude was doubled and quadrupled from $50 \mathrm{cN}$, there was no effect on the frequency or severity of root resorption or on the rate of tooth movement in his experiments. Although individual variations in root resorption and rate of tooth movement were large, normal individual variations may overshadow the effect of a doubled force magnitude. ${ }^{112-3}$ These results should be interpreted with caution as selection criteria for the premolars were not strict, and external factors that might predispose teeth to RR were not excluded. Also, the accuracy of the serial sectioning protocol in identifying and measuring all craters was questionable and craters could easily have been partially or even completely missed. ${ }^{44}$

We have limited evidence that continuous force produced significantly more root resorption than interrupted force application. ${ }^{50}$ This is in agreement with the results of studies with less rigorous designs that found that discontinuous force application results in lesser root resorption than the application of a continuous force. ${ }^{42,51-2}$ This is believed possible because the pause in a discontinuous force allows the resorbed cementum to heal and prevents further resorption. This finding contradicts results from an earlier nonrandomized similar split-mouth study by Owmann-Moll where there was no difference in RR between teeth that were moved with either a continuous or an interrupted-continuous 
force. ${ }^{53}$ However, these results should be interpreted with caution, as force decay was evident in the springs used in the continuous force groups.

Our limited evidence suggests that both light forces and forces from thermoplastic appliances result in similar root resorption cemental loss, which was significantly more than seen in controls. ${ }^{41}$ A recent longitudinal study of 100 consecutive Invisalign patients showed no measurable root resorption. ${ }^{115-6}$ There are no other strong studies that investigated this topic, but a case report has shown a significant EARR outcome with aligner treatment. $^{114}$

In our investigation both studies examining intrusive force application found significantly increased RR rates compared to controls. ${ }^{40,47}$ Root resorption from extrusive force was not significantly different than controls. ${ }^{47}$ This is in agreement with previous literature indicating that greatest damage is observed with intrusive tooth movements since they concentrate pressure at the tooth apex. ${ }^{27,38,40,42,46-7}$ When examining maxillary central incisors, movements torquing the apex lingually are strongly correlated with the onset of root resorption. In combination, intrusion and lingual root torque are the strongest causes of OIIRR. ${ }^{46-8}$

This systematic review included 5 RCTs examining patients undergoing comprehensive orthodontic treatment. Four of these studies were judged to be of high quality and have a low risk of bias, ${ }^{20,62,91,103}$ and one was judged to have a moderate risk of bias. ${ }^{102}$ 
When comparing straightwire and standard edgewise techniques no statistically significant differences in the amount of tooth root loss or prevalence of root resorption were observed between groups. ${ }^{103}$ Some have suggested that the Begg technique may induce more harmful effects on the roots..$^{25,58-9}$ Other studies have suggested that there is no real significant difference between Begg, Tweed or various Straightwire edgewise techniques. ${ }^{24,38,46,60-1}$ Bioefficient therapy using contemporary orthodontic materials was found to produce significantly less RR than simplified standard edgewise or edgewise straight wire systems. It was believed that the use of heat activated and superelastic wires, and a smaller rectangular stainless steel wire during incisor retraction and finishing played a role in this finding. ${ }^{18}$

Historically there has been a belief, based mostly upon observational data and animal studies, that all teeth with a previous history of trauma are more susceptible to OIIRR than healthy control teeth. ${ }^{11-2,117}$ Others investigators have reported that teeth with slight to moderate injuries may not have any greater tendency for root resorption during orthodontic treatment than uninjured teeth. ${ }^{25}$ In this systematic review, when examining data from 3 RCT's meeting our inclusion criteria, we found that incisors with clinical signs or patient reports of trauma (but no signs of EARR) had essentially the same prevalence of moderate to severe OIIRR as those without trauma. ${ }^{20,91,102}$ There is a lack of RCT data examining patients with previously traumatized teeth that have exhibited root resorption before orthodontic treatment. Observational data indicate a greater chance that orthodontic movement will enhance the resorptive process in this case. ${ }^{25,55,65-6}$ 
We found that teeth with roots having unusual morphology before treatment were only slightly more likely to have moderate to severe OIIRR than those with more normal root form, but the difference was not statistically significant. ${ }^{20}$ Through mostly observational studies abnormal root shape and other dental anomalies have been reported as risk factors for OIIRR. ${ }^{15,37,67-9,102}$ Other investigators have found no significant correlation between tooth anomalies and OIIRR, ${ }^{20,70}$ nor significant correlations between peg-shaped roots or microdontia of lateral incisors and OIIRR. ${ }^{28}$

When comparing conventional edgewise systems to various active and passive self-ligating appliances a case-control study by Blake $^{16}$ and a prospective clinical trial by Pandis ${ }^{57}$ found no statistically significant differences in root resorption between systems. Our findings were in agreement, mandibular incisor root resorption did not differ between self-ligating (Damon3, 2.26mm SD 2.63) and conventional (Synthesis, $1.21 \mathrm{~mm}$ SD 3.39) systems. ${ }^{62}$

There is a lack of evidence in the literature in favor or against the results we found with respect to archwire sequencing, ${ }^{91}$ and one-phase and two-phase class II treatments with respect to OIIRR prevalence or severity. ${ }^{20}$

There is evidence that comprehensive orthodontic treatment causes an increase in external apical root resorption. With the exception of the light force group in one trial, ${ }^{45}$ all teeth experiencing orthodontic tooth movement had statistically significant more root resorption that control teeth in each of the 11 trials included in this review, although individual variation was large. 
It is important to advise orthodontic patients of their risk before initiating treatment. A significant reduction in root length can cause an unfavorable crown: root ratio of the affected teeth, making them less suitable as abutments and anchorage for prosthetic restorations. Also, apical root loss of $3 \mathrm{~mm}$ is equivalent to $1 \mathrm{~mm}$ of crestal bone loss, so periodontitis will progress more rapidly to a critical alveolar bone level if it involves teeth with root resorption. ${ }^{118}$

It has been found that root resorption associated with orthodontic treatment ceases with the termination of active treatment. ${ }^{119}$ Even extensive root resorption does not usually affect the functional capacity or greatly compromise the longevity of the teeth. An average sized normally shaped maxillary central incisor that experienced no alveolar bone loss during orthodontic treatment, with a root shortened by $5 \mathrm{~mm}$ will still have $75 \%$ of its periodontal attachment remaining (95\% of patients), which explains why tooth loss due to apical shortening has not been reported in the literature. ${ }^{118}$ A retrospective study, in which 100 patients were recalled 14 years after orthodontic treatments, found no incidences of tooth loss and hypermobility in only 2 cases. ${ }^{119}$ A more recent retrospective analysis of patients who had experienced severe root resorption (root lengths 5.5$18.1 \mathrm{~mm})$, recalled 5-15 years after treatment, found that no teeth had mobility scores greater than 1 on Miller's index (crown deviates within $1 \mathrm{~mm}$ of its normal position), and no teeth had been lost. ${ }^{120}$

\section{Implications for Clinical practice}

There is evidence that comprehensive orthodontic treatment causes an increase in the incidence and severity of root resorption, and that heavy forces are particularly 
harmful. Until more high quality clinical trials are conducted, we would recommend that best practice is using light forces, especially when engaging in intrusive movements.

However, there is no evidence that OIIRR is affected by archwire sequencing, bracket prescription, or self-ligation. There is also little evidence that previous trauma (with no history of EARR) and unusual tooth morphology play a role in increased OIIRR.

During orthodontic treatment, progress radiographs obtained after 6-12 months may detect the early OIIRR. In patients where OIIRR has been identified, there is some evidence that a 2-3 month treatment pause (with a passive archwire), will decrease further root resorption.

If severe resorption is identified the treatment plan should be re-assessed with the patient. Alternative options might include prosthetic solutions to close spaces, releasing teeth from active archwires if possible, stripping instead of extracting, and early fixation of resorbed teeth. ${ }^{54}$

After treatment, if severe OIIRR is present on the final radiographs, follow-up radiographic examinations may be recommended until the resorption has stabilized. Termination of active OIIRR usually occurs after appliance removal. If it continues, sequential root canal therapy with calcium hydroxide may be considered. ${ }^{63}$ Caution should be exercised when retaining the teeth with fixed appliances since occlusal trauma of the fixed teeth or segments might lead to extreme EARR. ${ }^{54}$ 


\section{Implications for research}

More evidence is required to determine risk factors identifying those susceptible to external apical root resorption and effective ways to decrease the severity and prevalence of EARR in the orthodontic population. There is a need for parallel group studies, with appropriate randomization, allocation concealment and masking of outcome assessment. They should be based on an estimated sample size calculation to ensure adequate power, and be conducted over the full length of orthodontic treatment.

The use of standardized techniques to measure root length/volume before and after treatment should be encouraged to provide a permanent record, allowing before and after comparisons of incidence and severity of root resorption with assessment blinding, error analysis and consensus measures. Studies should also assess patient centered outcomes, including the effect of severe root resorption on quality of life post treatment, and occurrence of further complications such as mobility, and tooth loss. Other factors, such as genetic predisposition, and systemic factors should be assessed, so that we may better understand how individual susceptibility affects the incidence and severity of OIIRR.

\section{CONCLUSIONS}

1. Increased incidence and severity of OIIRR is found in patients undergoing comprehensive orthodontic therapy. 
2. Heavy force application produced significantly more OIIRR than light force application or control.

3. Other trends from split mouth studies could not be substantiated because of small subject numbers and short treatment times.

4. Standard reporting methods of future clinical trials are recommended so data can be pooled and stronger clinical recommendations made. 


\section{LEGEND}

Table 3.1: PICO Format and Null Hypothesis

Table 3.2: Databases included in the systematic review

Table 3.3: Criteria for selecting studies to be included in the meta-analysis

Table 3.4: Criteria for assessing quality components in the trials included in the metaanalysis

Table 3.5: Characteristics of Included Studies

Table 3.6: Quality Assessment - Major Criteria

Table 3.7: Quality Assessment - Minor Criteria

Figure 3.1: The QUOROM statement flow diagram of the citations retrieved by reviewing titles and abstracts, and trials that were evaluated in full text. 


\section{PICO Format}

Population patients with no history of root resorption

Intervention comprehensive orthodontics

Comparison people who have not had orthodontics / teeth that were not moved orthodontically

Outcome

external apical root resorption

Null Hypothesis

1) There is no difference in the incidence and severity of root resorption between patients, with no history of RR, undergoing comprehensive orthodontic treatment and a non-orthodontic treated group/teeth

2) There is no difference in the incidence and severity of root resorption between patients, with no history of $\mathrm{RR}$, undergoing comprehensive orthodontic treatment who receive tooth movement with different techniques

Table 3.1 PICO Format and Null Hypothesis 


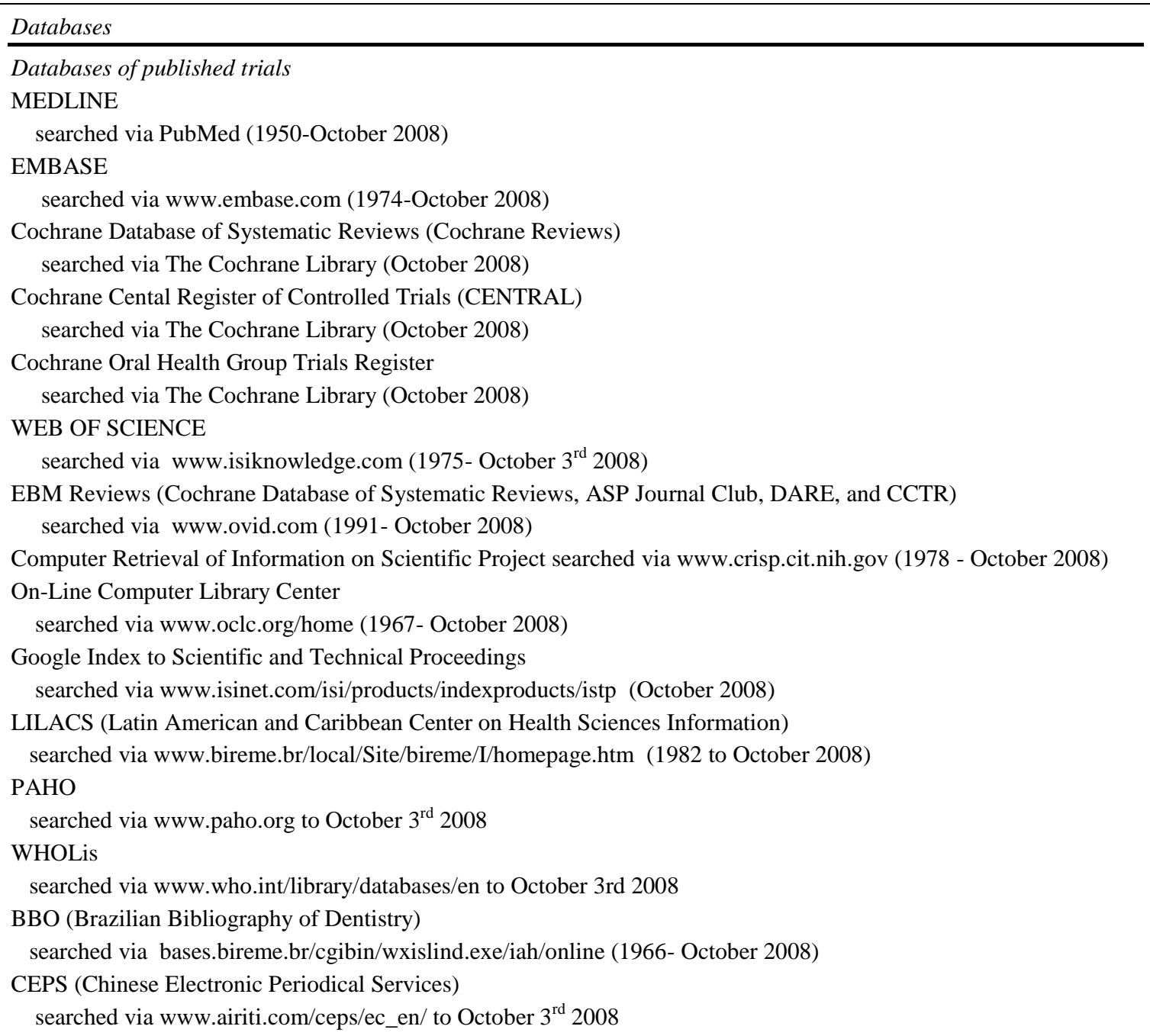

Databases of dissertations and conference proceedings

Conference Materials searched via www.bl.uk/services/bsds/dsc/conference.html October $3^{\text {rd }} 2008$

Cochrane Cental Register of Controlled Trials (CENTRAL) searched via The Cochrane Library (October 2008)

ProQuest Dissertation Abstracts and Thesis database searched via www.lib.umi.com/dissertations (1986 - October 2008)

Databases of research registers

TrialCentral searched via www.trialscentral.org on October $3^{\text {rd }} 2008$

National Research Register (UK) searched via www.controlled-trials.com on (1998-October 2008) www.Clinicaltrials.gov October $3^{\text {rd }} 2008$

Grey Literature

SIGLE (System for Information on Grey Literature in Europe) searched via http://opensigle.inist.fr/ 1980 to October 2005

Table 3.2 Databases included in the systematic review 


\begin{tabular}{|c|c|}
\hline Criteria Category & Definition \\
\hline Study Design & $\begin{array}{l}\text { Trials should be RCTs (published or unpublished) comparing root length before and } \\
\text { during/after treatment in Human subjects Split mouth trials were considered eligible if } \\
\text { randomization was used. }\end{array}$ \\
\hline Participant & $\begin{array}{l}\text { Trials included could involve individuals or teeth within the same individual, of any } \\
\text { age, gender, or ethnicity that underwent orthodontic treatment with fixed appliances }\end{array}$ \\
\hline Intervention & $\begin{array}{l}\text { Trials included could involve interventions of continuous versus non-continuous } \\
\text { forces, differing direction of tooth movement, light versus heavy forces, differing } \\
\text { durations of treatment, differing distances of tooth movement, Different types of } \\
\text { orthodontic appliances. }\end{array}$ \\
\hline Control & $\begin{array}{l}\text { Trials included could involve individuals or teeth within the same individual } \\
\text { (including the split mouth technique) not subjected to the orthodontic force either } \\
\text { through a placebo, bracket placement but no activation, or absence of the intervention. }\end{array}$ \\
\hline Outcome & $\begin{array}{l}\text { The trials included should record the presence/absence of External Apical Root } \\
\text { Resorption (EARR), by treatment group at the end of the treatment period. } \\
\text { Secondary outcomes include the severity and extent of root resorption between } \\
\text { experimental and control groups assessed either directly via histology or indirectly } \\
\text { using a radiograph technique, and patient based outcomes such as perception of root } \\
\text { resorption; further complications (mobility, tooth loss) and quality of life data. }\end{array}$ \\
\hline
\end{tabular}

Table 3.3 Criteria for selecting studies to be included in the meta-analysis 


\begin{tabular}{|c|c|c|}
\hline Component & Classification & Definition \\
\hline $\begin{array}{l}\text { Four main quality criteria: } \\
\text { 1) Method of randomization (Altman et } \\
\text { al) }\end{array}$ & $\begin{array}{l}\text { Adequate } \\
\text { Inadequate } \\
\text { Unclear }\end{array}$ & $\begin{array}{l}\text { Any random sequence generation satisfying the } \\
\text { CONSORT criteria. } \\
\text { Alternate assignment, case record number, dates of birth. } \\
\text { Just the term randomized or randomly allocated without } \\
\text { further elaboration of the exact methodology in the text } \\
\text { and unable to clarify with the author }\end{array}$ \\
\hline 2) Allocation concealment (Pildal et al) & $\begin{array}{l}\text { Adequate } \\
\text { Inadequate } \\
\text { Unclear }\end{array}$ & $\begin{array}{l}\text { Central randomization; Opaque sealed sequentially } \\
\text { numbered envelopes; Numbered, coded vehicles } \\
\text { implicitly or explicitly described containing treatment in } \\
\text { random order. } \\
\text { Allocation by alternate assignment, case record number, } \\
\text { dates of birth, or open tables of random numbers } \\
\text { No reported negation of disclosing participants' } \\
\text { prognostic data to central office staff before clinician } \\
\text { obtains treatment assignment; No reported information on } \\
\text { whether allocation sequence is concealed to central staff } \\
\text { before a participant is irreversible registered and no } \\
\text { assurance that the sequence is strictly sequentially } \\
\text { administered. Unclear in the text and unable to clarify } \\
\text { with the author } \\
\text { No method of allocation concealment used }\end{array}$ \\
\hline $\begin{array}{l}\text { 3) Blinding of outcome assessors } \\
\text { (Altman et al) }\end{array}$ & $\begin{array}{l}\text { Yes } \\
\text { No } \\
\text { Unclear }\end{array}$ & $\begin{array}{l}\text { Outcome assessors did not know which group to which } \\
\text { the participants were randomized. } \\
\text { The outcome assessor could assume to which group the } \\
\text { participant had been randomized } \\
\text { Unclear in the text and unable to clarify with the author }\end{array}$ \\
\hline $\begin{array}{l}\text { 4) Completeness to follow up (Altman et } \\
\text { al; Khan et al) }\end{array}$ & $\begin{array}{l}\text { Yes } \\
\text { No } \\
\text { Unclear }\end{array}$ & $\begin{array}{l}\text { Numbers in the methods and results were the same, and/or } \\
\text { not the same but with all dropouts explained } \\
\text { Numbers in the methods and the results were not the same } \\
\text { and dropouts were not explained } \\
\text { Unclear in the text and unable to clarify with the author }\end{array}$ \\
\hline Minor criteria: & & \\
\hline & Unclear & $\begin{array}{l}\text { Groups were not similar at baseline, no comparison } \\
\text { between groups at baseline was made. } \\
\text { Unclear in the text and unable to clarify with the author }\end{array}$ \\
\hline 2) Reporting of eligibility criteria & $\begin{array}{l}\text { Yes } \\
\text { No } \\
\text { Unclear }\end{array}$ & $\begin{array}{l}\text { No clear eligibility criteria } \\
\text { Unclear in the text and unable to clarify with the author }\end{array}$ \\
\hline $\begin{array}{l}\text { 3) Measure of variability of primary } \\
\text { outcome }\end{array}$ & $\begin{array}{l}\text { Yes } \\
\text { No } \\
\text { Unclear }\end{array}$ & Unclear in the text and unable to clarify with the author \\
\hline 4) Sample size calculation. & $\begin{array}{l}\text { Yes } \\
\text { No } \\
\text { Unclear }\end{array}$ & $\begin{array}{l}\text { Sample size calculation not done } \\
\text { Unclear in the text and unable to clarify with the author }\end{array}$ \\
\hline
\end{tabular}

Table 3.4 Criteria for assessing quality components in the trials included in the meta-analysis 


\begin{tabular}{ll} 
Study & Acar $\mathbf{1 9 9 9}$ \\
\hline Methods & RCT; Split Mouth Design \\
\hline Participants & $\begin{array}{l}\text { 22 first premolars from } 8 \text { patients aged 15-23 years, } 6 \text { control teeth patients } \\
\text { aged 14-20 }\end{array}$ \\
\hline Interventions & Continuous and Discontinuous 100g force application \\
\hline & $\begin{array}{l}\text { Extracted premolars - Composite electron micrographs were digitized and } \\
\text { Amount of root resorbed area calculated, visual assessment of apical }\end{array}$ \\
Outcomes & morphology - EARR severity. \\
\hline Notes & 9 week treatment period, No withdrawals, No assessor blinding \\
\hline Allocation Concealment & Unclear \\
\hline \hline
\end{tabular}

\begin{tabular}{ll} 
Study & Barbagallo 2008 \\
\hline Methods & RCT; Split Mouth Design \\
\hline Participants & $\begin{array}{l}\text { 54 Maxillary first premolars from 27 patients, } 15 \text { female, } 12 \text { male aged 12.5-20 } \\
\text { years: mean 15.3 }\end{array}$ \\
\hline Interventions & TA vs. Control, TA vs. 225g continuous force, TA vs. 25g continuous force \\
\hline Outcomes & $\begin{array}{l}\text { Extracted premolars - X-ray microtomography measuring the amount of RR in } \\
\text { cubed root volume. }\end{array}$ \\
\hline Notes & 8 week treatment period, No Withdrawals, No assessor blinding \\
\hline Allocation Concealment & No \\
\hline \hline Study & Brin 2003 \\
\hline Methods & RCT; retrospective collection of original data \\
\hline Participants & 138 children with Class II div 1 malocclusions (OJ > 7mm) \\
\hline Interventions & $\begin{array}{l}\text { One phase treatment versus phase 1 with HG or Bionator followed by Phase 2 } \\
\text { treatment of comprehensive orthodontics }\end{array}$ \\
\hline Outcomes & $\begin{array}{l}\text { Length of treatment, Trauma, Root development/timing of treatment, EARR, } \\
\text { Root morphology }\end{array}$ \\
\hline Notes & Withdrawals accounted for, Adequate assessor blinding \\
\hline Allocation Concealment & \begin{tabular}{l} 
Computer randomization, e-mailed to research associate \\
\hline \hline
\end{tabular} \\
\hline
\end{tabular}

\begin{tabular}{ll} 
Study & Chan 2004 \\
\hline Methods & RCT; Split Mouth Design \\
\hline Participants & 20 Maxillary first premolars from 10 patients, intraindividual controls \\
\hline Interventions & Light $(25 \mathrm{~g})$ or Heavy $(225 \mathrm{~g})$ continuous force vs. control \\
\hline & Extracted premolars - Volumetric measurement of RR craters via scanning \\
Outcomes & electron microscope, measured in mean volume x $10^{5} \mu^{3}$. \\
\hline Notes & 4 week treatment period, No Withdrawals, No Assessor Blinding \\
\hline Allocation Concealment & No
\end{tabular}

Table 3.5. Characteristics of Included Studies

Continued 
Table 3.5. Continued

Study

Chan 2005/2006;Darendeliler 2004

\begin{tabular}{ll}
\hline Methods & RCT; Split Mouth Design \\
\hline Participants & $\begin{array}{l}\text { 36 premolars in 16 patients, } 10 \text { boys, } 6 \text { girls aged 11.7-16.1: mean 13.9, } \\
\text { intraindividual controls }\end{array}$ \\
\hline Interventions & Light (25g) or Heavy (225g) continuous force vs. control \\
\hline & $\begin{array}{l}\text { Extracted premolars - Volumetric measurement of RR craters via scanning } \\
\text { electron microscope, measured in mean volume } \mathrm{x} 10^{6} \mu \mathrm{m}^{3} \text {, and to quantify by } \\
\text { volumetric measurements the extent of RR in the areas under compression and } \\
\text { tension }\end{array}$ \\
\hline Outcomes & 4 week treatment period, No Withdrawals, No Assessor Blinding \\
\hline Notes & No \\
\hline Allocation Concealment
\end{tabular}

Study

Han 2005

Methods RCT; Split Mouth Design

18 maxillary first premolars from 9 patients, 5 females, 4 males aged 12.7-20 years: mean 15.311 control teeth were obtained from 6 randomly selected

Participants patients aged 12-20.

Interventions Intrusion versus extrusion via $100 \mathrm{~g}$ continuous force

Extracted premolars - resorbed root area was calculated as a \% of total root area

Outcomes via SEM, and assessed qualitatively via visual assessment.

8 week treatment period, Control teeth extracted before orthodontic treatment,

Notes No Withdrawals, Observers were blinded.

Allocation Concealment Yes - randomization computer program, results mailed to operator

Study

Harris 2006

Methods

RCT; Split Mouth Design

54 Maxillary first premolars from 27 patients, 12 boys, 15 girls aged 11.9-19.3:

Participants mean 15.6

Heavy (225g) continuous force vs. control; light (25g) continuous force vs.

Interventions control; Light (25g) vs. heavy (225g) continuous force.

Extracted premolars - Volumetric assessment of root resorption crater magnitude

Outcomes and location

Notes

4 week treatment period, No Withdrawals, No assessor Blinding

Allocation Concealment No

\begin{tabular}{ll} 
Study & Levander 1994 \\
\hline Methods & RCT \\
\hline Participants & $\begin{array}{l}\text { 40 patients, 62 upper incisors, with initial RR during orthodontics, 15 boys, 25 } \\
\text { girls aged 12-18: mean 15. }\end{array}$ \\
\hline Interventions & $\begin{array}{l}\text { Planned treatment versus 2-3 month discontinuation of orthodontic treatment and } \\
\text { then planned treatment }\end{array}$ \\
\hline Outcomes & Periapical radiographic assessment of Maxillary Incisor root length \\
\hline Notes & $\begin{array}{l}\text { Patients randomized 6 months into treatment after identification of root } \\
\text { resorption, No Withdrawals }\end{array}$ \\
\hline \hline
\end{tabular}

Continued 
Table 3.5. Continued

Allocation Concealment Unclear

\begin{tabular}{|c|c|}
\hline Study & Mandall 2006 \\
\hline Methods & RCT - throwing an unweighted die, block randomization \\
\hline Participants & $\begin{array}{l}15410-17 \text { year old patients randomized } 6 \text { months into treatment after } \\
\text { identification of root resorption, No Withdrawals }\end{array}$ \\
\hline Interventions & 3 different archwire sequences \\
\hline Outcomes & $\begin{array}{l}\text { Patient discomfort at each wire change and in total, root resorption (root length) } \\
\text { of an upper left central incisor assessed by periapical radiography, time to reach } \\
\text { upper and lower working archwire }(0.019 \times 0.025 \text {-inch SS) in months, number of } \\
\text { patient visits. }\end{array}$ \\
\hline Notes & All withdrawals accounted for, Blinded assessors for RR \\
\hline Allocation Concealment & Adequate - Opaque Envelopes \\
\hline Study & Reukers 1998 \\
\hline Methods & RCT - balanced treatment allocation via computer \\
\hline Participants & $\begin{array}{l}149 \text { Class II patients, } 64 \text { male } 85 \text { female, mean age } 12 \text { years } 4 \text { months (1year } \\
2 \text { months SD), Range } 10 \mathrm{yr} 7 \mathrm{mo}-15 \mathrm{yr} 8 \mathrm{mo} \text {. }\end{array}$ \\
\hline Interventions & $\begin{array}{l}\text { Fully programmed edgewise (straight wire) versus partly programmed } \\
\text { (conventional) edgewise }\end{array}$ \\
\hline Outcomes & $\begin{array}{l}\text { Prevalence and degree of Root resorption seen via periapical radiography via a } \\
\text { bisecting angle technique. }\end{array}$ \\
\hline Notes & All withdrawals accounted for, Blinded assessors for RR \\
\hline Allocation Concealment & Adequate - Orthodontist informed by central trial registration \\
\hline Study & Scott 2008 \\
\hline Methods & RCT - balanced treatment allocation via restricted number table \\
\hline Participants & $\begin{array}{l}62 \text { patients, } 32 \text { male } 30 \text { female, mean age } 16.27 \text { years, with mandibular } \\
\text { irregularities of 5-12mm, requiring first premolar extraction in the lower arch. }\end{array}$ \\
\hline Interventions & $\begin{array}{l}\text { Damon3 self-ligating brackets versus Synthesis (Roth prescription) } \\
\text { conventionally ligated brackets. }\end{array}$ \\
\hline Outcomes & $\begin{array}{l}\text { Rapidity of tooth alignment; changes in root length; changes in arch dimension, } \\
\text { measured via lateral cephalograms and long cone periapical radiographs. }\end{array}$ \\
\hline Notes & All withdrawals accounted for, Blinded assessor for RR, 95\% power \\
\hline Allocation Concealment & Unclear \\
\hline
\end{tabular}




\begin{tabular}{|c|c|c|c|c|c|}
\hline Study & Randomization & $\begin{array}{l}\text { Allocation } \\
\text { concealed }\end{array}$ & $\begin{array}{l}\text { Assessor } \\
\text { blinding }\end{array}$ & $\begin{array}{l}\text { Drop outs } \\
\text { described }\end{array}$ & Risk of Bias \\
\hline Acar 1999 & No & Unclear & Unclear & Yes & High \\
\hline Barbagallo 2008 & Yes & No & No & Yes & Moderate \\
\hline Brin 2003 & Yes & Yes & Yes & Yes & Low - retrospective \\
\hline Chan 2004 & Yes & No & No & Yes & Moderate \\
\hline Chan 2006 & Yes & No & No & Yes & Moderate \\
\hline Han 2005 & Yes & Yes & Yes & Yes & Low \\
\hline Harris 2006 & Yes & No & No & Yes & Moderate \\
\hline Levander 1994 & Yes & Unclear & Unclear & Yes & Moderate \\
\hline Mandall 2006 & Yes & Yes & Yes & Yes & Low \\
\hline Reukers 1998 & Yes & Yes & Yes & Yes & Low \\
\hline Scott 2008 & Yes & Unclear & Yes & Yes & Low \\
\hline
\end{tabular}

Table 3.6 Quality Assessment - Major Criteria 


$\begin{array}{lllll}\text { Study } & \text { Sample Justified (size) } & \text { Baseline comparison } & \text { I/E criteria } & \text { Method Error } \\ \text { Acar 1999 } & \text { No } & \text { No } & \text { Unclear } & \text { Yes } \\ \text { Barbagallo 2008 } & \text { Yes } & \text { Yes } & \text { Yes } & \text { Yes } \\ \text { Brin 2003 } & \text { No } & \text { Yes } & \text { Yes } & \text { Yes } \\ \text { Chan 2004 } & \text { Yes } & \text { Yes } & \text { Yes } & \text { Yes } \\ \text { Chan 2006 } & \text { Yes } & \text { Yes } & \text { Yes } & \text { Yes } \\ \text { Han 2005 } & \text { No } & \text { Yes } & \text { Yes } & \text { Yes } \\ \text { Harris 2006 } & \text { Yes } & \text { Yes } & \text { Yes } & \text { Yes } \\ \text { Levander 1994 } & \text { No } & \text { Yes } & \text { Yes } & \text { Yes } \\ \text { Mandall 2006 } & \text { Yes } & \text { Yes } & \text { Yes } & \text { Yes } \\ \text { Reukers 1998 } & \text { Unclear } & \text { Yes } & \text { Yes } & \text { Yes } \\ \text { Scott 2008 } & \text { Yes } & \text { Yes } & \text { Yes } & \text { Yes }\end{array}$

Table 3.7. Quality Assessment - Minor Criteria 


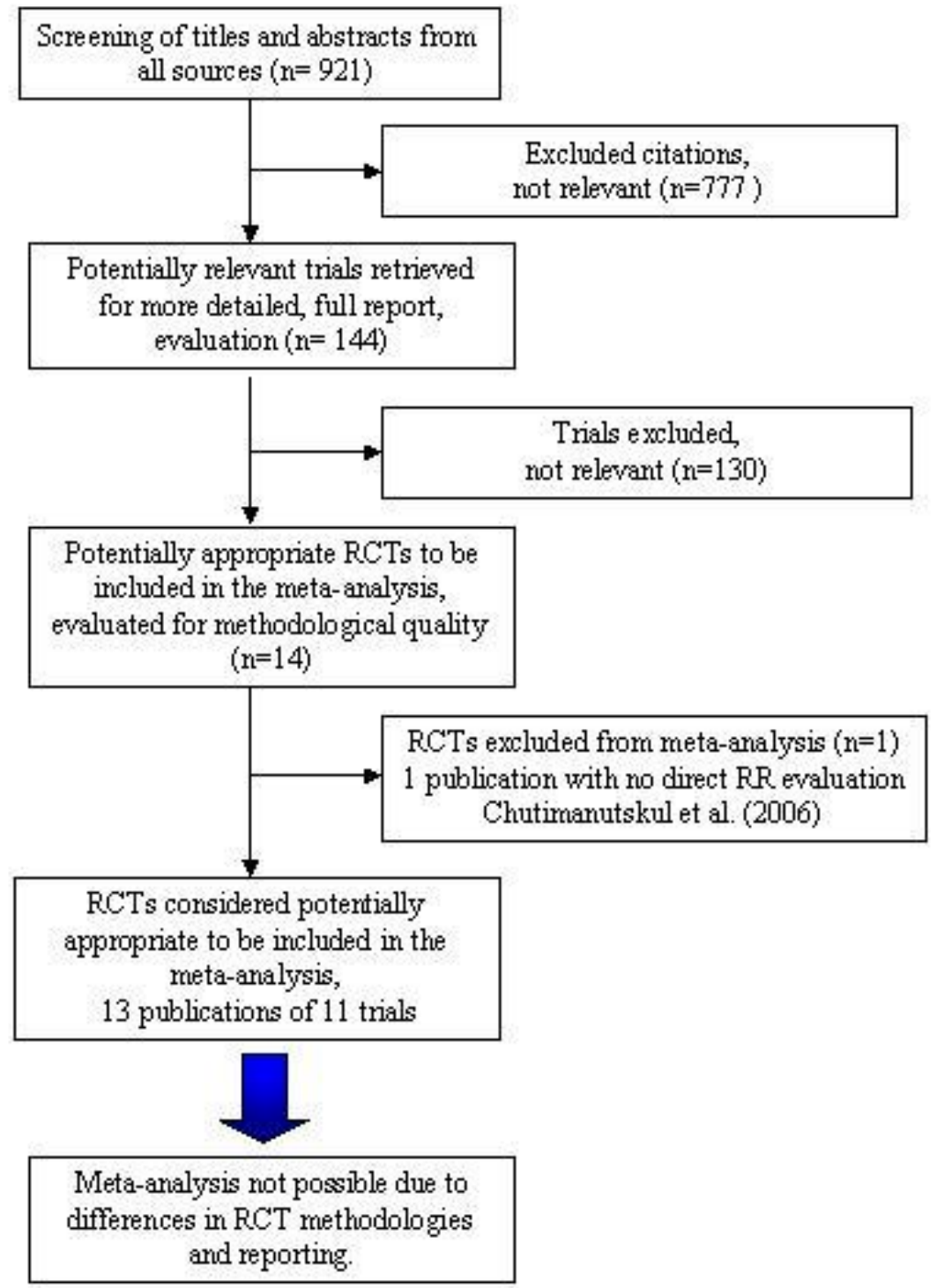

Figure 3.1. The QUOROM statement flow diagram of the citations retrieved by reviewing titles and abstracts, and trials that were evaluated in full text. 


\section{ACKNOWLEDGEMENTS}

The authors would like to recognize the financial support for this research

provided by the Dental Master's Thesis Award Program sponsored by Delta Dental

Foundation, which is the philanthropic affiliate of Delta Dental of Michigan, Ohio, and

Indiana.

We would also like to thank the Cochrane Oral Health Group and Professor Bill

Shaw for their guidance and wisdom.

\section{REFERENCES}

1. Harris EF, Robinson QC, Woods MA. An analysis of causes of apical root resorption in patients not treated orthodontically. Quintessence international (Berlin, Germany: 1985). 1993;24(6):41728.

2. Killiany DM. Root resorption caused by orthodontic treatment: an evidence-based review of literature. Semin Orthod. 1999 Jun;5(2):128-33. Review

3. Al-Qawasmi RA, Hartsfield JK Jr, Everett ET, et al. Genetic predisposition to external apical root resorption. Am J Orthod Dentofacial Orthop 2003a;123:242-52.

4. Harris EF, Kineret SE, Tolley EA. A heritable component for external apical root resorption in patients treated orthodontically. Am J Orthod Dentofacial Orthop. 1997 Mar;111(3):301-9.

5. Newman WG. Possible etiologic factors in external root resorption. Am J Orthod 1975;67:522-39.

6. Lee KS, Straja SR, Tuncay OC. Perceived long-term prognosis of teeth with orthodontically resorbed roots. Orthod Craniofac Res. 2003 Aug;6(3):177-91.

7. Stevnik A, Mjor IA. Pulp and dentine reactions to experimental tooth intrusion. A histological study of the initial changes. Am J Orthod 1970; 57: 370-85.

8. Harry MR, Sims MR. Root resorption in bicuspid intrusion. A Scanning electron microscope study. Angle Orthod 1982;52:235-58.

9. Mc Laughlin KD. Quantitative determination of root resorption during orthodontic treatment. Am J Orthod 1964;50:143.

10. Lupi JE, Handelman CS, Sadowsky C. Prevalence and severity of apical root resorption and alveolar bone loss in orthodontically treated adults. Am J Orthod Dentofacial Orthop. 1996 Jan;109(1):28-37. 
11. Linge BO, Linge L. Apical root resorption in upper anterior teeth. Eur J Orthod. 1983 Aug;5(3):173-83.

12. Linge $\mathrm{L}$, Linge BO. Patient characteristics and treatment variables associated with apical root resorption during orthodontic treatment. Am J Orthod Dentofacial Orthop 1991;99:35-43.

13. Mirabella AD, Artun J. Risk factors for apical root resorption of maxillary anterior teeth in adult orthodontic patients. Am J Orthod Dentofacial Orthop. 1995 Jul;108(1):48-55.

14. Mavragnani M, Boe OE, Wisth PJ, Selvig KA. Changes in root length during orthodontic treatment: advantages for immature teeth. Eur J Orthod 2002;24:91-7.

15. Sameshima GT, Sinclair PM. Predicting and preventing root resorption: Part I. Diagnostic factors. Am J Orthod Dentofacial Orthop. 2001a May;119(5):505-10.

16. Blake M, Woodside DG, Pharoah MJ. A radiographic comparison of apical root resorption after orthodontic treatment with the edgewise and Speed appliances. Am J Orthod Dentofacial Orthop. $1995 \mathrm{Jul} ; 108(1): 76-84$.

17. Levander E, Malmgren O. Evaluation of the risk of root resorption during orthodontic treatment: a study of upper incisors. Eur J Orthod 1988;10:30-8.

18. Janson GR, De Luca Canto G, Martins DR, Henriques JF, De Freitas MR. A radiographic comparison of apical root resorption after orthodontic treatment with 3 different fixed appliance techniques. Am J Orthod Dentofacial Orthop. 1999 Sep;118(3):262-73.

19. McNab S, Battistutta D, Taverne A, Symons AL. External apical root resorption of posterior teeth in asthmatics after orthodontic treatment. Am J Orthod Dentofacial Orthop 1999;116:545-51

20. Brin I, Tulloch JFC, Koroluk L, Philips C. External apical root resorption in Class II malocclusion: a retrospective review of 1- versus 2-phase treatment. Am J Orthod Dentofacial Orthop. 2003;124(2):151-6.

21. Levander E, Malmgren O, Stenback K. Apical root resorption during orthodontic treatment of patients with multiple aplasia: a study of maxillary incisors. Eur J Orthod 1998;20:427-34.

22. Taithongchai R, Sookkorn K, Killiany Dm. Facial and dentoalveolar structure ad the prediction of apical root shortening. Am J Orthod Dentofacial Orthop 1996;110:311-20.

23. Killany DM. Root resorption caused by orthodontic treatment: review of literature from 1998 to 2001 for evidence. Prog Orthod 2002;3:2-5.

24. Malmgren O, Goldson L, Hill C, Orwin A, et al. Root resorption after orthodontic treatment of traumatized teeth. Am J Orthod 1982;82:487-91.

25. Goldson L, Henrikson CO. Root resorption during Begg treatment; a longitudinal roentgenologic study. Am J Orthod. 1975 Jul;68(1):55-66.

26. Kennedy D, Joondeph D, Osterberg S, Little R. The effect of extraction and orthodontic treatment 
on dentoalveolar support. Am J Orthod 1983;84:183-90.

27. Kaley J, Phillips C. Factors related to root resorption in edgewise practice. Angle Orthod. 1991;61(2):125-32.

28. Kook Y-A, Park S, Sameshima GT. Peg-shaped and small lateral incisors not at higher risk for root resorption. Am J Orthod Dentofac Orthop 2003;123:253-8.

29. Otis L, Hong J, Tuncay O. Bone structure effect on root resorption. Orthodontics \& Craniofacial Research. 2004 08/21;7(3):165-77.

30. Segal G, Schiffman P, Tuncay O. Meta analysis of the treatment-related factors of external apical root resorption. Orthodontics \& Craniofacial Research. 2004 05/12;7(2):71-8.

31. DeShields RW. A study of root resorption in treated Class II, Division I malocclusions. Angle Orthod. 1969;39(4):231-45.

32. Baumrind S, Korn EL, Boyd RL. Apical root resorption in orthodontically treated adults. Am J Orthod Dentofacial Orthop. 1996 Sep;110(3):311-20.

33. Casa MA, Faltin RM, Faltin K, Sander FG, Arana-Chavez VE. Root resorptions in upper first premolars after application of continuous torque moment. Intra-individual study. J Orofac Orthop. 2001 Jul;62(4):285-95.

34. Jimenez-Pellegrin C, Arana-Chavez VE. Root resorption in human mandibular first premolars after rotation as detected by scanning electron microscopy. Am J Orthod Dentofacial Orthop. 2004 Aug;126(2):178,84; discussion 184-5.

35. Fox N. Longer orthodontic treatment may result in greater external apical root resorption. Evid Based Dent 2005;6:21.

36. McFadden WM, Engstrom C, Engstrom H, Anholm JM. A study of the relationship between incisor intrusion and root shortening. Am J Orthod Dentofacial Orthop. 1989 Nov;96(5):390-6.

37. Sameshima GT, Sinclair PM. Characteristics of patients with severe root resorption. Orthod Craniofac Res. 2004 May;7(2):108-14.

38. Beck BW, Harris EF. Apical root resorption in orthodontically treated subjects: analysis of edgewise and light wire mechanics. Am J Orthod Dentofacial Orthop. 1994 Apr;105(4):350-61.

39. Dermaut LR, De Munck A. Apical root resorption of upper incisors caused by intrusive tooth movement: a radiographic study. Am J Orthod Dentofacial Orthop. 1986 Oct;90(4):321-6.

40. Harris DA, Jones AS, Darendeliler MA. Physical properties of root cementum: part 8. Volumetric analysis of root resorption craters after application of controlled intrusive light and heavy orthodontic forces: a microcomputed tomography scan study. Am J Orthod Dentofacial Orthop. 2006;130(5):639-47. 
41. Barbagallo LJ, Jones AS, Petocz P, Darendeliler MA. Physical properties of root cementum: Part 10. Comparison of the effects of invisible removable thermoplastic appliances with light and heavy orthodontic forces on premolar cementum. A microcomputed-tomography study. Am J Orthod Dentofac Ortop 2008;133:218-27.

42. Faltin RM, Faltin K, Sander FG, Arana-Chavez VE. Ultrastructure of cementum and periodontal ligament after continuous intrusion in humans: a transmission electron microscopy study. Eur $\mathbf{J}$ Orthod. $2001 \mathrm{Feb} ; 23(1): 35-49$.

43. Chan EKM, Darendeliler MA. Exploring the third dimension in root resorption. Orthod Craniofacial Res 2004;7:64-70.

44. Chan E, Darendeliler MA. Physical properties of root cementum: Part 5. Volumetric analysis of root resorption craters after application of light and heavy orthodontic forces. Am J Orthod Dentofacial Orthop. 2005;127(2):186-95.

45. Chan E, Darendeliler MA. Physical properties of root cementum: part 7. Extent of root resorption under areas of compression and tension. Am J Orthod Dentofacial Orthop. 2006;129(4):504-10.

46. Parker RJ, Harris EF. Directions of orthodontic tooth movements associated with external apical root resorption of the maxillary central incisor. Am J Orthod Dentofacial Orthop. 1998 Dec;114(6):672-83.

47. Han G, Huang S, Von den Hoff, Johannes W, Zeng X, Kuijpers-Jagtman AM. Root resorption after orthodontic intrusion and extrusion: an intraindividual study. Angle Orthod. 2005;75(6):9128.

48. Costopoulos G, Nanda R. An evaluation of root resorption incident to orthodontic intrusion. Am J Orthod Dentofacial Orthop. 1996;109(5):543-8.

49. Thilander B, Ryghh P, Reitan K. Tissue reactions in Orthodontics. In: Graber TM, Vanarsdall RL, Vig KW,. Orthodontics current principles and techniques, fourth edition. St Louis: CV Mosby, 2005.

50. Acar A, Canyurek U, Kocaaga M, Erverdi N. Continuous vs. discontinuous force application and root resorption. Angle Orthod. 1999 Apr;69(2):159,63; discussion 163-4.

51. Konoo T, Kim YJ, Gu GM, et al. Intermittent force in orthodontic tooth movement. J Dent Res 2001;80:457-60.

52. Weiland F. Constant versus dissipating forces in orthodontics: the effect on initial tooth movement and root resorption. Eur J Orthod. 2003;25(4):335-42.

53. Owman-Moll P, Kurol J, Lundgren D. Continuous versus interrupted continuous orthodontic force related to early tooth movement and root resorption. Angle Orthod. 1995c;65(6):395-401; discussion 401-2.

54. Brezniak N, Wasserstein A. Orthodontically induced inflammatory root resorption. Part II: The clinical aspects. Angle Orthod 2002b;72:180-4. 
55. Brezniak N, Wasserstein A. Root resorption after orthodontic treatment: Part 1. Literature review. Am J Orthod Dentofac Orthop 1993;103:62-6.

56. Ketcham AH. A preliminary report of an investigation of apical root resorption of vital permanent teeth. Int J Orthod 1927;13:97-127.

57. Pandis N, Nasika M, Polychronopoulou A, Eliades T. External apical root resorption in patients treated with conventional and self-ligating brackets. Am J Orthod Dentofacial Orthop. 2008 Nov;134(5):646-51.

58. TenHoeve A, Mulie Rm. The effects of antero-postero incisor repositioning on the palatal cortex as studied with laminagraphy. J Clin Orthod 1976;10:804-22.

59. McNab S, Battistutta D, Taverne A, Symons AL. External apical root resorption following orthodontic treatment. Angle Orthod. 2000 Jun;70(3):227-32.

60. Lew K. Intrusion and apical resorption of mandibular incisors in Begg treatment: anchorage bend or curve? Aust Orthod J. 1990;11(3):164-8.

61. Alexander SA. Levels of root resorption associated with continuous arch and sectional arch mechanics. Am J Orthod Dentofacial Orthop. 1996 Sep;110(3):321-4.

62. Scott P, DiBiase AT, Sherriff M, Cobourne MT. Alignment efficiency of Damon3 self-ligating and conventional orthodontic bracket systems: A randomized clinical trial. Am J Orthod Dentofacial Orthop 2008;134:470.e1-e8.

63. Pizzo G, Licata ME, Guiglia R, Giuliana G. Root resorption and orthodontic treatment. Review of the literature. Minerva Stomatol. 2007 Jan-Feb;56(1-2):31-44.

64. Hartsfield JK Jr, Everett ET, Al-Qawasmi RA. Genetic factors in external apical root resorption and orthodontic treatment. Crit Rev Oral bio Med 2004;15:115-22.

65. Hamilton RS, Gutmann JL. Endodontic-orthodontic relationships: a review of integrated treatment planning challenges. Int Endod J. 1999 Sep;32(5):343-60. Review.

66. Drysdale C, Gibbs SL, Ford TR. Orthodontic management of root-filled teeth. Br J Orthod. 1996 Aug;23(3):255-60. Review.

67. Kjaer I. Morphological characteristics of dentitions developing excessive root resorption during orthodontic treatment. Eur J Orthod 1995;17:25-34.

68. Smale I, Artun J, Behbehani F, Doppel D, van't Hof M, Kuijpers-Jagtman AM. Apical root resorption 6 months after initiation of fixed orthodontic appliance therapy. Am J Orthod Dentofacial Orthop. 2005;128(1):57-67.

69. Thongudomporn U, Freer TJ. Anomalous dental morphology and root resorption during orthodontic treatment: a pilot study. Aust Orthod J. 1998 Oct;15(3):162-7.

70. Lee RY, Artun J, Alonzo TA. Are dental anomalies risk factors for apical root resorption in orthodontic patients? Am J Orthod Dentofacial Orthop. 1999 Aug;116(2):187-95. 
71. English H. External apical root resorption as a consequence of orthodontic treatment. J N Z Soc Periodontol. 2001(86):17-23.

72. Ngan DCS, Kharbanda OP, Byloff FK, Darendeliler MA. The genetic contribution to orthodontic root resorption: a retrospective twin study. Aust Orthod J. 2004;20(1):1-9.

73. Al-Qawasmi RA, Hartsfield JK,Jr, Everett ET, Flury L, Liu L, Foroud TM, et al. Genetic predisposition to external apical root resorption in orthodontic patients: linkage of chromosome-18 marker. J Dent Res. 2003b May;82(5):356-60.

74. Bollen A-M. Large overjet and longer teeth are associated with more root resorption when treated orthodontically. J Evid Base Dent Pract 2002;2:44-5.

75. Igarashi K, Adachi H, Mitani H, Shinoda H. Inhibitory effect of topical administration of a bisphosphonate (risedronate) on root resorption incident to orthodontic tooth movement in rats. J Dent res 1996;75:1644-9.

76. Adachi H, Igarashi K, Mitani H, Shinoda H. Effects of topical administration of a bisphosphonate (risedronate) on orthodontic tooth movement in rats. J Dent Res 1994;73:1478-86.

77. Attati I, Hammarstrom L. Root surface defects in rat molar induced by 1-hydroxyethylidene-1, 1bisphosphonate. Acta Odontol Scand 1996a;54:59-65.

78. Attati I, Hellsing E, Hammarstrom L. Orthodontically induced root resorption in rat molars after 1-hydroxyethylidene-1, 1-bisphosphonate injection. Acta Odontol Scand 1996b;54:102-8.

79. Villa PA, Oberti G, Moncada CA, Vasseur O, Jaramillo A, Tobon D, et al. Pulp-dentine complex changes and root resorption during intrusive orthodontic tooth movement in patients prescribed nabumetone. J Endod. 2005 Jan;31(1):61-6.

80. Poumpros E, Loberg E, Engstrom C. Thyroid function and root resorption. Angle Orthod 1994;64:389-93.

81. Shirazi M, Dehpour AR, Jefari F. The effect of thyroid hormone on orthodontic tooth movement in rats. J Clin Pediatr Dent 1999; 23:259-64.

82. Loberg EL, Engstrom C. Thyroid administration to reduce root resorption. Angle Orthod 1994;64:395-9.

83. Christiansen RL. Commentary: Thyroxine administration and its effects on root resorption. Angle Orthod 1994;64:399-400.

84. McNab S, Battistutta D, Taverne A, Symons AL. External apical root resorption of posterior teeth in asthmatics after orthodontic treatment. Am J Orthod Dentofacial Orthop. 1999 Nov;116(5):54551 .

85. Horiuchi A, Hotokezaka H, Kobayashi K. Correlation between cortical plate proximity and apical root resorption. Am J Orthod Dentofacial Orthop. 1998;114(3):311-8.

86. Rygh P, Reitan K. Ultrastructural changes in the periodontal ligament incident to orthodontic 
tooth movement. Trans Eur Orthod Soc 1972;393-405.

87. Goldie RS, King GJ. Root resorption and tooth movement in orthodontically treated, calciumdeficient, and lactating rats. Am J Orthod 1984;85:424-30.

88. Midgett RJ, Shaye R, Fruge JF Jr. The effect of altered bone metabolism on orthodontic tooth movement. Am J Orthod 1981;80:256-62.

89. Davidovitch Z, Godwin SL, Park YG, Taverne A, Dobeck JM, et al. The etiology of root resorption. In: McNamara JA, Trotman CA, editors. Orthodontic Treatment: The management of unfavorable sequelae. Ann Arbor, MI: University of Michigan Press; 1996. pp. 93-117.

90. Andreasen JO. External root resorption: its implication in dental traumatology, paedodontics, periodontics, orthodontics and endodontics. Int Endod J 1985; 18:109-18.

91. Mandall N, Lowe C, Worthington H, Sandler J, Derwent S, Abdi-Oskouei M, et al. Which orthodontic archwire sequence? A randomized clinical trial. Eur J Orthod. 2006;28(6):561-6.

92. Brezniak N, Wasserstein A. Orthodontically induced inflammatory root resorption. Part 1: The basic science aspects. Angle Orthod 2002a;72:175-9.

93. Wickwire NA, Mc Neil MH, Norton LA, Duell RC. The effects of tooth movement upon endodontically treated teeth. Angle Orthod. 1974 Jul;44(3):235-42.

94. Remington DN, Joondeph DR, Artun J, Riedel RA, Chapko MK. Long-term evaluation of root resorption occurring during orthodontic treatment. Am J Orthod Dentofacial Orthop. 1989 Jul;96(1):43-6.

95. Sameshima GT, Sinclair PM. Predicting and preventing root resorption: Part II. Treatment factors. Am J Orthod Dentofacial Orthop. 2001b May;119(5):511-5.

96. Taner T, Ciger S, Sencift Y. Evauation of apical root resorption following extraction therapy in subjects with class I amd class II maloclussions. Eur J Orthod 1999; 21: 491-6.

97. Reitan K. Initial tissue behaviour during apical root resorption. Angle Orthod 1974;44:68-82.

98. Harris EF, Baker WC. Loss of root length and crestal bone height before and during treatment in adolescent and adult orthodontic patients. Am J Orthod Dentofacial Orthop. 1990 Nov;98(5):4639.

99. Bishara SE, Vonwald L, Jakobsen JR. Changes in root length from early to mid-adulthood: resorption or apposition? Am J Orthod Dentofacial Orthop. 1999;115(5):563-8.

100.Spurrier SW, Hall SH, Joondeph DR, Shapiro PA, Riedel RA. A comparison of apical root resorption during orthodontic treatment in endodontically treated and vital teeth. Am J Orthod Dentofacial Orthop. 1990;97(2):130-4.

101.Higgins JPT, Green S, editors. Cochrane Handbook for Systematic Reviews of interventions 5.0.1 [Updated September 2008]. The Cochrane Collaboration, 2008. Available from www.cochrane- 
handbook.org

102.Levander E, Malmgren O, Eliasson S. Evaluation of root resorption in relation to two orthodontic treatment regimes. A clinical experimental study. Eur J Orthod. 1994;16(3):223-8.

103.Reukers E, Sanderink g, Kuijpers-Jagtman AM, van't Hof M. Assessment of apical root resorption using digital reconstruction. Dento-Maxillo-Fac Radiolog 1998;27:25-9.

104.Bader JD, Shugars DA, onito AJ. A systematic review of selected caries prevention and management methods. Community Dent Oral Epidemiol 2001; 29:399-411.

105.Hayashi M, Wilson NH, Yeung CA, Worthington HV. Systematic review of ceramic inlays. Clin Oral Invest 2003;7:8-19.

106.Chadwick BL, Roy J, Knox J, Treasure ET. The effect of topical fluorides on decalcification in patients with fixed orthodontic appliances: A systematic review. Am J Orthod Dentofacial Orthop 2005;128:601-6.

107.Chan EKM, Darendeliler MA. Exploring the third dimension in root resorption. Orthod Craniofacial Res 2004b;7:64-70.

108. Sameshima GT, Sinclair PM. Predicting and preventing root resorption: Part I. Diagnostic factors. Am J Orthod Dentofacial Orthop. 2001a May;119(5):505-10.

109. Katona TR. Flaws in root resorption assessment algorithms: role of tooth shape. Am J Orthod Dentofacial Orthop. 2006 Dec;130(6):698.e19-27.

110.Darendeliler MA, Kharbanda OP, Chan EK, Srivicharnkul P, Rex T, Swain MV, et al. Root resorption and its association with alterations in physical properties, mineral contents and resorption craters in human premolars following application of light and heavy controlled orthodontic forces. Orthod Craniofac Res. 2004 May;7(2):79-97.

111.Kvam E. Tissue changes on the marginal pressure side following experimental tooth movement. A histologic, autoradiographic, and scanning electron microscopic study. Nor Tannlaegeforen Tid. 1972 Nov;82(9):522-8.

112. Owman-Moll P, Kurol J, Lundgren D. Effects of a doubled orthodontic force magnitude on tooth movement and root resorptions. An inter-individual study in adolescents. Eur J Orthod. 1996a Apr;18(2):141-50.

113. Owman-Moll P, Kurol J, Lundgren D. The effects of a four-fold increased orthodontic force magnitude on tooth movement and root resorptions. An intra-individual study in adolescents. Eur J Orthod. 1996b Jun;18(3):287-94.

114.Brezniak N, Wasserstein A. Root resorption following treatment with aligners. Angle Orthod. 2008 Nov;78(6):1119-24.

115. Wheeler: In Press

116. Boyd RL. Complex orthodontic treatment using a new protocol for the Invisalign appliance. J Clin 
Orthod. 2007;41(9): 525-47.

117. Andreasen JO. External root resorption: its implication in dental traumatology, paedodontics, periodontics, orthodontics and endodontics. Int Endod J 1985; 18:109-18.

118. Kalkwarf KL, Krejci RF, Pao YC. Effect of apical root resorption on periodontal support. J Prosthet Dent 1986;56:317-9.

119. Remington DN, Joondeph DR, Artun J, Riedel RA, Chapko MK. Long-term evaluation of root resorption occurring during orthodontic treatment. Am J Orthod Dentofacial Orthop. 1989 Jul;96(1):43-6.

120.Levander E, Malmgren O. Long-term follow-up of maxillary incisors with severe apical root resorption. Eur J Orthod. 2000 Feb;22(1):85-92. 


\section{CHAPTER 4}

\section{GENERAL CONCLUSIONS}

\section{Implications for clinical practice}

There is evidence that comprehensive orthodontic treatment causes an increase in the incidence and severity of root resorption, and that heavy forces are particularly harmful. Until more high quality trials are conducted, we would recommend that best practice is using light, intermittent forces, if possible, especially when engaging in intrusive movements.

However, there is no evidence that archwire sequencing, bracket prescription, or self-ligation affects OIIRR. There is also little evidence that previous trauma (with no evidence of EARR) and unusual tooth morphology play a role in increased OIIRR.

During orthodontic treatment, progress radiographs should be obtained after 6-12 months in order to detect the occurrence of OIIRR early. In patients where OIIRR has been identified, there is some evidence that a 2-3 month treatment pause, with passive archwire), will lead to a decrease in total root resorption by the end of treatment.

If severe resorption is identified the treatment plan should be re-assessed with the patient. Alternative options might include prosthetic solutions to close spaces, releasing 
teeth from active archwires if possible, stripping instead of extracting, and early fixation of resorbed teeth (Brezniak 2002b).

After treatment, if severe OIIRR is present on the final radiographs, follow-up radiographic examinations are recommended until the resorption has stabilized. Termination of active OIIRR usually occurs after appliance removal. If it does not occur, sequential root canal therapy with calcium hydroxide may be considered (Pizzo, 2007). Caution should be exercised when retaining the teeth with fixed appliances since occlusal trauma of the fixed teeth or segments might lead to extreme EARR (Brezniak 2002b).

\section{Implications for research}

More evidence is required to determine risk factors identifying those susceptible to external apical root resorption and effective way to decrease the severity and prevalence of OIIRR in the orthodontic population. There is a need for parallel group studies, with appropriate randomization, allocation concealment and masking of outcome assessment. They must be based on a satisfactory sample size calculation to ensure adequate power, and be conducted over the full length of orthodontic treatment.

The use of standardized techniques to measure root length/volume before and after treatment should be encouraged to provide a permanent record, allowing before and after comparisons of incidence and severity of root resorption with proper assessment blinding, error analysis and consensus measures. Studies should also assess patient centered outcomes, including the effect of severe root resorption on quality of life post treatment, and occurrence of further complications such as mobility, and tooth loss, if budget allows. Other factors, such as genetic predisposition, and systemic factors should 
be assessed, so that we may better understand how individual susceptibility affects the incidence and severity of OIIRR.

\section{Conclusions}

1. Increased incidence and severity of OIIRR is found in patients undergoing comprehensive orthodontic therapy.

2. Heavy force application produced significantly more OIIRR than light force application or control.

3. Other trends from split mouth studies could not be substantiated because of small subject numbers and short treatment times.

4. Standard reporting methods of future clinical trials are recommended so data can be pooled and stronger clinical recommendations made. 


\section{LIST OF REFERENCES}

Acar A, Canyurek U, Kocaaga M, Erverdi N. Continuous vs. discontinuous force application and root resorption. Angle Orthod. 1999 Apr;69(2):159,63; discussion 163-4.

Adachi H, Igarashi K, Mitani H, Shinoda H. Effects of topical administration of a bisphosphonate (risedronate) on orthodontic tooth movement in rats. J Dent Res 1994;73:1478-86.

Adam M. [New aspects on the effect of orthodontic appliances]. Cesk Stomatol. 1968;68(1):54-61.

Aghili, H, Modaresi, J; Todehzaime, MH. Risk factors of root resorption in orthodontic patients treated with fixed appliances. J Kerman Univ Med Sci 2000; 13(4):223-9.

Ahlgren J. A ten-year evaluation of the quality of orthodontic treatment. Swed Dent J. 1993;17(5):201 9.

Alexander SA. Levels of root resorption associated with continuous arch and sectional arch mechanics. Am J Orthod Dentofacial Orthop. 1996 Sep;110(3):321-4.

Al-Qawasmi RA, Hartsfield JK Jr, Everett ET, et al. Genetic predisposition to external apical root resorption. Am J Orthod Dentofacial Orthop 2003a;123:242-52.

Al-Qawasmi RA, Hartsfield JK,Jr, Everett ET, Flury L, Liu L, Foroud TM, et al. Genetic predisposition to external apical root resorption in orthodontic patients: linkage of chromosome-18 marker. J Dent Res. 2003b May;82(5):356-60.

Al-Nazhan S. External root resorption after bleaching: A case report. Oral Surg Oral Med Oral Pathol 1991;72:607-9.

Alwali S, Marklund M, Persson M. Apical root resorption of upper first molars as related to anchorage system. Swed Dent J. 2000;24(4):145-53.

Amlani MS, Inocencio F, Hatibovic-Kofman S. Lateral incisor root resorption and active orthodontic treatment in the early mixed dentition. Eur J Paediatr Dent. 2007 Dec;8(4):188-92

Andreasen JO. External root resorption: its implication in dental traumatology, paedodontics, periodontics, orthodontics and endodontics. Int Endod J 1985; 18:109-18.

Ari-Demirkaya A, Masry MA, Erverdi N. Apical root resorption of maxillary first molars after intrusion with zygomatic skeletal anchorage. Angle Orthod. 2005 Sep;75(5):761-7.

Armstrong D, Kharbanda OP, Petocz P, Darendeliler MA. Root resorption after orthodontic treatment. Aust Orthod J. 2006 Nov;22(2):153-60.

Artun J, Smale I, Behbehani F, Doppel D, Van't Hof M, Kuijpers-Jagtman AM. Apical root resorption six and 12 months after initiation of fixed orthodontic appliance therapy. Angle Orthod. 2005 
Nov;75(6):919-26.

Attati I, Hammarstrom L. Root surface defects in rat molar induced by 1-hydroxyethylidene-1, 1bisphosphonate. Acta Odontol Scand 1996a;54:59-65.

Attati I, Hellsing E, Hammarstrom L. Orthodontically induced root resorption in rat molars after 1hydroxyethylidene-1, 1-bisphosphonate injection. Acta Odontol Scand 1996b;54:102-8.

Bader JD, Shugars DA, onito AJ. A systematic review of selected caries prevention and management methods. Community Dent Oral Epidemiol 2001; 29:399-411.

Barbagallo LJ, Jones AS, Petocz P, Darendeliler MA. Physical properties of root cementum: Part 10. Comparison of the effects of invisible removable thermoplastic appliances with light and heavy orthodontic forces on premolar cementum. A microcomputed-tomography study. Am J Orthod Dentofac Ortop 2008;133:218-27.

Barber AF, Sims MR. Rapid maxillary expansion and external root resorption in man: a scanning electron microscope study. Am J Orthod. 1981 Jun;79(6):630-52.

Bassigny F. Root resorptions of orthodontic origin. Rev Odontostomatol (Paris). 1982 Sep;11(4):30511.

Bau DJ. Root resorption during orthodontic treatment. Aust Orthod J. 2003;19(2):3A.

Baumann WR, Tavares D. Dental resorption caused by orthodontic treatment. RGO. 1988 MarApr;36(2):91,4, 96.

Baumrind S, Korn EL, Boyd RL. Apical root resorption in orthodontically treated adults. Am J Orthod Dentofacial Orthop. 1996 Sep;110(3):311-20.

Beck BW, Harris EF. Apical root resorption in orthodontically treated subjects: analysis of edgewise and light wire mechanics. Am J Orthod Dentofacial Orthop. 1994 Apr;105(4):350-61.

Biological mechanisms of tooth eruption and root resorption : proceedings of the international conference held at the Great Southern Hotel, Columbus, Ohio, April 28-30, 1988. Anonymous Columbus, Ohio: Ohio State University, College of Dentistry; 1988.

Bishara SE, Vonwald L, Jakobsen JR. Changes in root length from early to mid-adulthood: resorption or apposition? Am J Orthod Dentofacial Orthop. 1999;115(5):563-8.

Blake M, Woodside DG, Pharoah MJ. A radiographic comparison of apical root resorption after orthodontic treatment with the edgewise and Speed appliances. Am J Orthod Dentofacial Orthop. $1995 \mathrm{Jul} ; 108(1): 76-84$.

Bollen A-M. Large overjet and longer teeth are associated with more root resorption when treated orthodontically. J Evid Base Dent Pract 2002;2:44-5.

Boyd RL. Complex orthodontic treatment using a new protocol for the Invisalign appliance. J Clin Orthod. 2007;41(9): 525-47.

Brezniak N, Wasserstein A. Root resorption following treatment with aligners. Angle Orthod. 2008 
Nov;78(6):1119-24.

Brezniak N, Wasserstein A. Orthodontically induced inflammatory root resorption. Part 1: The basic science aspects. Angle Orthod 2002a;72:175-9.

Brezniak N, Wasserstein A. Orthodontically induced inflammatory root resorption. Part II: The clinical aspects. Angle Orthod 2002b;72:180-4.

Brezniak N, Wasserstein A. Root resorption after orthodontic treatment: Part 1. Literature review. Am J Orthod Dentofac Orthop 1993;103:62-6.

Brezniak N. Lower first molar mesiobuccal root resorption. Journal of clinical orthodontics : JCO. 1990;24(1):25-8.

Brice GL, Sampson WJ, Sims MR. An ultrastructural evaluation of the relationship between epithelial rests of Malassez and orthodontic root resorption and repair in man. Aust Orthod J. 1991 Oct;12(2):90-4.

Brin I, Tulloch JFC, Koroluk L, Philips C. External apical root resorption in Class II malocclusion: a retrospective review of 1- versus 2-phase treatment. Am J Orthod Dentofacial Orthop. 2003;124(2):151-6.

Brudvik P, Rygh P. Multi-nucleated cells remove the main hyalinized tissue and start resorption of adjacent root surfaces. Eur J Orthod 1994;16:265-73.

Buck DL, Church NH. A histologic study of human tooth movement. Am J Orthod. 1972 Nov;62(5):507-16.

Casa MA, Faltin RM, Faltin K, Arana-Chavez VE. Root resorption on torqued human premolars shown by tartrate-resistant acid phosphatase histochemistry and transmission electron microscopy. Angle Orthod. 2006 Nov;76(6):1015-21.

Casa MA, Faltin RM, Faltin K, Sander FG, Arana-Chavez VE. Root resorptions in upper first premolars after application of continuous torque moment. Intra-individual study. J Orofac Orthop. 2001 Jul;62(4):285-95.

Chadwick BL, Roy J, Knox J, Treasure ET. The effect of topical fluorides on decalcification in patients with fixed orthodontic appliances: A systematic review. Am J Orthod Dentofacial Orthop 2005;128:601-6.

Chan EKM, Darendeliler MA. Physical properties of root cementum: Part 5. Volumetric analysis of root resorption craters after application of light and heavy orthodontic forces. Am J Orthod Dentofacial Orthop. 2005;127(2):186-95.

Chan EKM, Darendeliler MA. Physical properties of root cementum: part 7. Extent of root resorption under areas of compression and tension. Am J Orthod Dentofacial Orthop. 2006;129(4):50410 .

Chan EKM, Darendeliler MA, Petocz P, Jones AS. A new method for volumetric measurement of orthodontically induced root resorption craters. Eur J Oral Sci. 2004a;112(2):134-9.

Chan EKM, Darendeliler MA. Exploring the third dimension in root resorption. Orthod Craniofacial 
Res 2004b;7:64-70.

Chen Xin, He Hong. Effect of flat bite plate on the root resorption during orthodontic treatment. Journal of oral science research 2007; 23(4) 454-5.

Chiqueto K, Martins DR, Janson G. Effects of accentuated and reversed curve of spee on apical root resorption. Am J Orthod Dentofacial Orthop 2008; 133: 261-8.

Choy K, Pae EK, Park Y, Kim KH, Burstone CJ. Effect of root and bone morphology on the stress distribution in the periodontal ligament. Am J Orthod Dentofacial Orthop. 2000 Jan;117(1):98105.

Christiansen RL. Commentary: Thyroxine administration and its effects on root resorption. Angle Orthod 1994;64:399-400.

Chutimanutskul W, Ali Darendeliler M, Shen G, Petocz P, Swain MV. Changes in the physical properties of human premolar cementum after application of 4 weeks of controlled orthodontic forces. Eur J Orthod. 2006 Aug;28(4):313-8.

Copeland S, Green LJ. Root resorption in maxillary central incisors following active orthodontic treatment. Am J Orthod. 1986 Jan;89(1):51-5.

Costopoulos G, Nanda R. An evaluation of root resorption incident to orthodontic intrusion. Am J Orthod Dentofacial Orthop. 1996;109(5):543-8.

Counts Al, Widlak RA. Generalized idiopathic external root resorption. J clin orthod 1993;27:511-3.

Darendeliler MA, Kharbanda OP, Chan EK, Srivicharnkul P, Rex T, Swain MV, et al. Root resorption and its association with alterations in physical properties, mineral contents and resorption craters in human premolars following application of light and heavy controlled orthodontic forces. Orthod Craniofac Res. 2004 May;7(2):79-97.

Davidovitch Z, Godwin SL, Park YG, Taverne A, Dobeck JM, et al. The etiology of root resorption. In: McNamara JA, Trotman CA, editors. Orthodontic Treatment: The management of unfavorable sequelae. Ann Arbor, MI: University of Michigan Press; 1996. pp. 93-117.

de Freitas MR, Beltrao RT, Janson G, Henriques JF, Chiqueto K. Evaluation of root resorption after open bite treatment with and without extractions. Am J Orthod Dentofacial Orthop. 2007 Aug;132(2):143.e15,143.e22.

Deguchi T, Murakami T, Kuroda S, et al. Comparion of the intrusion effects on the maxillary incisors between implant anchorage and J-hook headgear. Am J Orthod Dentofacial Orthop 2008; 133:654-60.

Dermaut LR, De Munck A. Apical root resorption of upper incisors caused by intrusive tooth movement: a radiographic study. Am J Orthod Dentofacial Orthop. 1986 Oct;90(4):321-6.

DeShields RW. A study of root resorption in treated Class II, Division I malocclusions. Angle Orthod. 1969;39(4):231-45.

Diedrich P. [Biomechanical principles of orthodontic movement of teeth with periodontal involvement]. 
Dtsch Zahnarztl Z. 1990;45(2):78-81.

Douki, N; Zokkar, N; Zouiten S; Boughzala, A; Mokn, M; Baccouche, C. Root resorption in orthodontics. Maghreb Med 2006; 26(279):142-4.

Drysdale C, Gibbs SL, Ford TR. Orthodontic management of root-filled teeth. Br J Orthod. 1996 Aug;23(3):255-60. Review.

Eisel A, Katsaros C, Berg R. [The course and results of the orthodontic treatment of 44 consecutively treated Class-II cases]. Fortschr Kieferorthop. 1994;55(1):1-8.

El-Bialy T, El-Shamy I, Graber TM. Repair of orthodontically induced root resorption by ultrasound in humans. Am J Orthod Dentofacial Orthop. 2004 Aug;126(2):186-93.

English H. External apical root resorption as a consequence of orthodontic treatment. J N Z Soc Periodontol. 2001(86):17-23.

Erverdi N, Okar I, Kucukkeles N, Arbak S. A comparison of two different rapid palatal expansion techniques from the point of root resorption. Am J Orthod Dentofacial Orthop. $1994 ; 106(1): 47-51$.

Esteves T, Ramos AL, Pereira CM, Hidalgo MM. Orthodontic root resorption of endodontically treated teeth. J Endod. 2007 Feb;33(2):119-22.

Faltin RM, Arana-Chavez VE, Faltin K, Sander FG, Wichelhaus A. Root resorptions in upper first premolars after application of continuous intrusive forces. Intra-individual study. Journal of orofacial orthopedics $=$ Fortschritte der Kieferorthopadie $:$ Organ/official journal Deutsche Gesellschaft fur Kieferorthopadie. 1998;59(4):208-19.

Faltin RM, Faltin K, Sander FG, Arana-Chavez VE. Ultrastructure of cementum and periodontal ligament after continuous intrusion in humans: a transmission electron microscopy study. Eur $\mathbf{J}$ Orthod. 2001 Feb;23(1):35-49.

Feiglin B. Root resorption. Aust Dent J. 1986 Feb;31(1):12-22.

Flannelly Blake M. A radiographic comparison of apical root resorption following orthodontic treatment with the Edgewise and Speed appliances. Anonymous Toronto: Faculty of Dentistry, University of Toronto; 1992.

Fox N. Longer orthodontic treatment may result in greater external apical root resorption. Evid Based Dent 2005;6:21.

Fritz U, Diedrich P, Wiechmann D. Apical root resorption after lingual orthodontic therapy. Journal of orofacial orthopedics $=$ Fortschritte der Kieferorthopadie : Organ/official journal Deutsche Gesellschaft fur Kieferorthopadie. 2003;64(6):434-42.

Fuss Z, Tsesis I, Lin S. Root resorption - diagnosis, classification and treatment choices based on stimulation factors. Dent Traumatology 2003;19:175-82.

Goerigk B, Diedrich P, Wehrbein H. [Intrusion of the anterior teeth with the segmented-arch technic of Burstone--a clinical study]. Fortschr Kieferorthop. 1992;53(1):16-25. 
Goldberg M. The biomechanics of tooth movement with Begg. Int J Orthod. 1972;10(4):115-24.

Goldie RS, King GJ. Root resorption and tooth movement in orthodontically treated, calcium-deficient, and lactating rats. Am J Orthod 1984;85:424-30.

Goldin B. Labial root torque: effect on the maxilla and incisor root apex. Am J Orthod Dentofacial Orthop. 1989;95(3):208-19.

Goldman HM, Gianelly AA. Histology of tooth movement. Dent Clin North Am. 1972 Jul;16(3):43948.

Goldson L, Henrikson CO. Root resorption during Begg treatment; a longitudinal roentgenologic study. Am J Orthod. 1975 Jul;68(1):55-66.

Goz G, Rakosi T. Apical root resorption during orthodontic treatment. Fortschr Kieferorthop. 1989 Jun;50(3):196-206.

Hamilton RS, Gutmann JL. Endodontic-orthodontic relationships: a review of integrated treatment planning challenges. Int Endod J. 1999 Sep;32(5):343-60. Review.

Han G, Huang S, Von den Hoff, Johannes W, Zeng X, Kuijpers-Jagtman AM. Root resorption after orthodontic intrusion and extrusion: an intraindividual study. Angle Orthod. 2005;75(6):912-8.

Harris DA, Jones AS, Darendeliler MA. Physical properties of root cementum: part 8. Volumetric analysis of root resorption craters after application of controlled intrusive light and heavy orthodontic forces: a microcomputed tomography scan study. Am J Orthod Dentofacial Orthop. 2006;130(5):639-47.

Harris EF, Baker WC. Loss of root length and crestal bone height before and during treatment in adolescent and adult orthodontic patients. Am J Orthod Dentofacial Orthop. 1990 Nov;98(5):463-9.

Harris EF, Boggan BW, Wheeler DA. Apical root resorption in patients treated with comprehensive orthodontics. J Tenn Dent Assoc. 2001 Winter;81(1):30-3.

Harris EF, Hassankiadeh S, Harris JT. Maxillary incisor crown-root relationships in different angle malocclusions. Am J Orthod Dentofacial Orthop. 1993b Jan;103(1):48-53.

Harris EF, Kineret SE, Tolley EA. A heritable component for external apical root resorption in patients treated orthodontically. Am J Orthod Dentofacial Orthop. 1997 Mar;111(3):301-9.

Harris EF, Robinson QC, Woods MA. An analysis of causes of apical root resorption in patients not treated orthodontically. Quintessence international (Berlin, Germany: 1985). 1993a;24(6):41728.

Harry MR, Sims MR. Root resorption in bicuspid intrusion. A Scanning electron microscope study. Angle Orthod 1982;52:235-58.

Hartsfield JK Jr, Everett ET, Al-Qawasmi RA. Genetic factors in external apical root resorption and orthodontic treatment. Crit Rev Oral bio Med 2004;15:115-22. 
Hayashi M, Wilson NH, Yeung CA, Worthington HV. Systematic review of ceramic inlays. Clin Oral Invest 2003;7:8-19.

Hendrix I, Carels C, Kuijpers-Jagtman AM, Van 'T Hof M. A radiographic study of posterior apical root resorption in orthodontic patients. Am J Orthod Dentofacial Orthop. 1994 Apr;105(4):345-9.

Higgins, J. P. T., Thompson, S. G., Deeks, J. J., \& Altman, D. G. Measuring inconsistency in meta analyses. British Medical Journal. 2003; 327:557-560.

Higgins JPT, Green S, editors. Cochrane Handbook for Systematic Reviews of interventions 5.0.1 [Updated September 2008]. The Cochrane Collaboration, 2008. Available from www.cochrane-handbook.org

Hogberg M, Rosenqvist L. Root resorption following activator treatment. Odontol Foren Tidskr. 1974 Oct;38(3):185-92.

Holtta P, Nystrom M, Evalahti M, Alaluusua S. Root-crown ratios of permanent teeth in a healthy Finnish population assessed from panoramic radiographs. Eur J Orthod. 2004;26(5):491-7.

Horiuchi A, Hotokezaka H, Kobayashi K. Correlation between cortical plate proximity and apical root resorption. Am J Orthod Dentofacial Orthop. 1998;114(3):311-8.

Igarashi K, Adachi H, Mitani H, Shinoda H. Inhibitory effect of topical administration of a bisphosphonate (risedronate) on root resorption incident to orthodontic tooth movement in rats. J Dent res 1996;75:1644-9.

Janson G, Nakamura A, de Freitas, Marcos Roberto, Henriques JFC, Pinzan A. Apical root resorption comparison between Frankel and eruption guidance appliances. Am J Orthod Dentofacial Orthop. 2007;131(6):729-35.

Janson GR, De Luca Canto G, Martins DR, Henriques JF, De Freitas MR. A radiographic comparison of apical root resorption after orthodontic treatment with 3 different fixed appliance techniques. Am J Orthod Dentofacial Orthop. 1999 Sep;118(3):262-73.

Jiang RP, Zhang D, Fu MK. A factors study of root resorption after orthodontic treatment. Zhonghua Kou Qiang Yi Xue Za Zhi. 2003 Nov;38(6):455-7.

Jimenez-Pellegrin C, Arana-Chavez VE. Root resorption in human mandibular first premolars after rotation as detected by scanning electron microscopy. Am J Orthod Dentofacial Orthop. 2004 Aug;126(2):178,84; discussion 184-5.

Jimenez-Pellegrin C, Arana-Chavez VE. Root resorption repair in mandibular first premolars after rotation. A transmission electron microscopy analysis combined with immunolabeling of osteopontin. Am J Orthod Dentofacial Orthop. 2007 Aug;132(2):230-6.

Kaley J, Phillips C. Factors related to root resorption in edgewise practice. Angle Orthod. 1991;61(2):125-32.

Kalkwarf KL, Krejci RF, Pao YC. Effect of apical root resorption on periodontal support. J Prosthet Dent 1986;56:317-9. 
Katona TR. Flaws in root resorption assessment algorithms: Role of tooth shape. Am J Orthod Dentofacial Orthop 2006; 130:698.e19-e27.

Katsaros C, Berg R. Anterior open bite malocclusion: a follow-up study of orthodontic treatment effects. Eur J Orthod. 1993;15(4):273-80.

Kennedy D, Joondeph D, Osterberg S, Little R. The effect of extraction and orthodontic treatment on dentoalveolar support. Am J Orthod 1983;84:183-90.

Ketcham AH. A preliminary report of an investigation of apical root resorption of vital permanent teeth. Int J Orthod 1927;13:97-127.

Killany DM. Root resorption caused by orthodontic treatment: review of literature from 1998 to 2001 for evidence. Prog Orthod 2002;3:2-5.

Killiany DM. Root resorption caused by orthodontic treatment: an evidence-based review of literature. Semin Orthod. 1999 Jun;5(2):128-33. Review

Kjaer I. Morphological characteristics of dentitions developing excessive root resorption during orthodontic treatment. Eur J Orthod 1995;17:25-34.

Konoo T, Kim YJ, Gu GM, et al. Intermittent force in orthodontic tooth movement. J Dent Res 2001;80:457-60.

Kook Y, Park S, Sameshima GT. Peg-shaped and small lateral incisors not at higher risk for root resorption. Am J Orthod Dentofacial Orthop. 2003;123(3):253-8.

Krishnan V, Davidovitch Z. The effect of drugs on orthodontic tooth movement. Orthodontics \& Craniofacial Research. 2006 11/30;9(4):163-71.

Kurol J, Owman-Moll P, Lundgren D. Time-related root resorption after application of a controlled continuous orthodontic force. Am J Orthod Dentofacial Orthop. 1996 Sep;110(3):303-10.

Kvam E. Scanning electron microscopy of tissue changes on the pressure surface of human premolars following tooth Movement. Scand J Dent Res. 1972;80:357-68.

Lee KS, Straja SR, Tuncay OC. Perceived long-term prognosis of teeth with orthodontically resorbed roots. Orthod Craniofac Res. 2003 Aug;6(3):177-91.

Lee RY, Artun J, Alonzo TA. Are dental anomalies risk factors for apical root resorption in orthodontic patients? Am J Orthod Dentofacial Orthop. 1999 Aug;116(2):187-95.

Levander E, Malmgren O, Eliasson S. Evaluation of root resorption in relation to two orthodontic treatment regimes. A clinical experimental study. Eur J Orthod. 1994;16(3):223-8.

Levander E, Malmgren O, Stenback K. Apical root resorption during orthodontic treatment of patients with multiple aplasia: a study of maxillary incisors. Eur J Orthod 1998;20:427-34.

Levander E, Malmgren O. Evaluation of the risk of root resorption during orthodontic treatment: a study of upper incisors. Eur J Orthod 1988;10:30-8. 
Levander E, Malmgren O. Long-term follow-up of maxillary incisors with severe root resorption. Eur J Orthod 2000;22:85-92.

Lew K. Intrusion and apical resorption of mandibular incisors in Begg treatment: anchorage bend or curve? Aust Orthod J. 1990;11(3):164-8.

Limpanichkul W, Godfrey K, Srisuk N, Rattanayatikul C. Effects of low-level laser therapy on the rate of orthodontic tooth movement. Orthodontics \& Craniofacial Research. 2006 02/32;9(1):3843.

Lin Y, Zhong PP, Zhang DQ. Investigation of the possible factors related to root resorption during orthodontic treatment in Adolescents. Shanghai oral medicine 2007;16(1): 24-7.

Linge BO, Linge L. Apical root resorption in upper anterior teeth. Eur J Orthod. 1983 Aug;5(3):173-83

Linge L, Linge BO. Patient characteristics and treatment variables associated with apical root resorption during orthodontic treatment. Am J Orthod Dentofacial Orthop 1991;99:35-43.

Loberg EL, Engstrom C. Thyroid administration to reduce root resorption. Angle Orthod 1994;64:3959.

Lundgren D, Owman-Moll P, Kurol J. Early tooth movement pattern after application of a controlled continuous orthodontic force. A human experimental model. Am J Orthod Dentofacial Orthop. 1996 Sep;110(3):287-94.

Lupi JE, Handelman CS, Sadowsky C. Prevalence and severity of apical root resorption and alveolar bone loss in orthodontically treated adults. Am J Orthod Dentofacial Orthop. 1996 Jan;109(1):28-37.

Luther F, Dominguez-Gonzalez S, Fayle SA. Teamwork in orthodontics: limiting the risk of root resorption. Brit Dent J 2005; 198: 407-11.

Mah J, Prasad N. Dentine phosphoproteins in gingival crevicular fluid during root resorption. Eur J Orthod. 2004;26(1):25-30.

Makedonas D, Hansen K. Diagnosis, screening, and treatment of root resorption in orthodontic practices in Greece and Sweden. Angle Orthodontist: Vol. 78, 248-253. Angle Orthod. 2008 Mar;78(2):248-53.

Malagnino VA, Gambarini G, De Luca M. External inflammatory root resorption. Attual Dent. 1990 Feb 4;6(4):21,2, 27-31.

Malmgren O, Goldson L, Hill C, Orwin A, et al. Root resorption after orthodontic treatment of traumatized teeth. Am J Orthod 1982;82:487-91.

Mandall N, Lowe C, Worthington H, Sandler J, Derwent S, Abdi-Oskouei M, et al. Which orthodontic archwire sequence? A randomized clinical trial. Eur J Orthod. 2006;28(6):561-6.

Martins DR, Henriques JF, De Freitas MR. A radiographic comparison of apical root resorption after orthodontic treatment with 3 different fixed appliance techniques. Am J Orthod Dentofacial Orthop. 1999 Sep;118(3):262-73. 
Mavragani M, Apisariyakul J, Brudvik P, Selvig KA. Is mild dental invagination a risk factor for apical root resorption in orthodontic patients? Eur J Orthod. 2006;28(4):307-12.

Mavragani M, Boe OE, Wisth PJ, Selvig KA. Changes in root length during orthodontic treatment: advantages for immature teeth. Eur J Orthod. 2002;24(1):91-7.

Mavragani M, Vergari A, Selliseth NJ, Boe OE, Wisth PL. A radiographic comparison of apical root resorption after orthodontic treatment with a standard edgewise and a straight-wire edgewise technique. Eur J Orthod. 2000 Dec;22(6):665-74.

Mc Laughlin KD. Quantitative determination of root resorption during orthodontic treatment. Am J Orthod 1964;50:143.

McFadden WM, Engstrom C, Engstrom H, Anholm JM. A study of the relationship between incisor intrusion and root shortening. Am J Orthod Dentofacial Orthop. 1989 Nov;96(5):390-6.

McNab S, Battistutta D, Taverne A, Symons AL. External apical root resorption following orthodontic treatment. Angle Orthod. 2000 Jun;70(3):227-32.

McNab S, Battistutta D, Taverne A, Symons AL. External apical root resorption of posterior teeth in asthmatics after orthodontic treatment. Am J Orthod Dentofacial Orthop 1999;116:545-51

Midgett RJ, Shaye R, Fruge JF Jr. The effect of altered bone metabolism on orthodontic tooth movement. Am J Orthod 1981;80:256-62.

Mirabella AD, Artun J. Prevalence and severity of apical root resorption of maxillary anterior teeth in adult orthodontic patients. Eur J Orthod. 1995a Apr;17(2):93-9.

Mirabella AD, Artun J. Risk factors for apical root resorption of maxillary anterior teeth in adult orthodontic patients. Am J Orthod Dentofacial Orthop. 1995 Jul;108(1):48-55.

Mohandesan H, Ravanmehr H, Valaei N. A radiographic analysis of external apical root resorption of maxillary incisors during active orthodontic treatment. Eur J Orthod. 2007;29(2):134-9.

Nasiopoulos AT, Athanasiou AE, Papadopoulos MA, Kolokithas G, Ioannidou I. Premolar root changes following treatment with the banded herbst appliance. Journal of orofacial orthopedics $=$ Fortschritte der Kieferorthopadie : Organ/official journal Deutsche Gesellschaft fur Kieferorthopadie. 2006;67(4):261-71.

Newman WG. Possible etiologic factors in external root resorption. Am J Orthod 1975;67:522-39.

Ngan DCS, Kharbanda OP, Byloff FK, Darendeliler MA. The genetic contribution to orthodontic root resorption: a retrospective twin study. Aust Orthod J. 2004;20(1):1-9.

Ng'ang'a PM, Ng'ang'a RN. Maxillary incisor root forms in orthodontic patients in Nairobi, Kenya. East Afr Med J. 2003;80(2):101-4.

Nigul K, Jagomagi T. Factors related to apical root resorption of maxillary incisors in orthodontic patients. Stomatologija. 2006;8(3):76-9.

Nishioka M, Ioi H, Nakata S, Nakasima A, Counts A. Root resorption and immune system factors in the 
Japanese. Angle Orthod. 2006;76(1):103-8.

Odenrick L, Karlander EL, Pierce A, Kretschmar U. Surface resorption following two forms of rapid maxillary expansion. Eur J Orthod. 1991 Aug;13(4):264-70.

Otis L, Hong J, Tuncay O. Bone structure effect on root resorption. Orthodontics \& Craniofacial Research. 2004 08/21;7(3):165-77.

Owman-Moll P. Orthodontic tooth movement and root resorption with special reference to force magnitude and duration. A clinical and histological investigation in adolescents. Swed Dent J Suppl. 1995a;105:1-45.

Owman-Moll P, Kurol J, Lundgren D. Repair of orthodontically induced root resorption in adolescents. Angle Orthod. 1995b;65(6):403,8; discussion 409-10.

Owman-Moll P, Kurol J, Lundgren D. Continuous versus interrupted continuous orthodontic force related to early tooth movement and root resorption. Angle Orthod. 1995c;65(6):395-401; discussion 401-2.

Owman-Moll P, Kurol J, Lundgren D. Effects of a doubled orthodontic force magnitude on tooth movement and root resorptions. An inter-individual study in adolescents. Eur J Orthod. 1996a Apr;18(2):141-50.

Owman-Moll P, Kurol J, Lundgren D. The effects of a four-fold increased orthodontic force magnitude on tooth movement and root resorptions. An intra-individual study in adolescents. Eur J Orthod. 1996b Jun;18(3):287-94.

Owman-Moll P, Kurol J. Root resorption after orthodontic treatment in high- and low-risk patients: analysis of allergy as a possible predisposing factor. Eur J Orthod. 2000 Dec;22(6):657-63.

Oyama K, Motoyoshi M, Hirabayashi M, Hosoi K, Shimizu N. Effects of root morphology on stress distribution at the root apex. Eur J Orthod. 2007;29(2):113-7.

Parker RJ, Harris EF. Directions of orthodontic tooth movements associated with external apical root resorption of the maxillary central incisor. Am J Orthod Dentofacial Orthop. 1998 Dec;114(6):672-83.

Pandis N, Nasika M, Polychronopoulou A, Eliades T. External apical root resorption in patients treated with conventional and self-ligating brackets. Am J Orthod Dentofacial Orthop. 2008 Nov;134(5):646-51

Perona G, Wenzel A. Radiographic evaluation of the effect of orthodontic retraction on the root of the maxillary canine. Dentomaxillofac Radiol. 1996;25(4):179-85.

Pizzo G, Licata ME, Guiglia R, Giuliana G. Root resorption and orthodontic treatment. Review of the literature. Minerva Stomatol. 2007 Jan-Feb;56(1-2):31-44.

Poumpros E, Loberg E, Engstrom C. Thyroid function and root resorption. Angle Orthod 1994;64:38993.

Proffit WR, Fields HW, Sarver,DM. Contemporary Orthodontics: Fourth Edition. Missouri: CV 
Mosby, 2006.

Rateitschak KH, Herzog-specht FA. [REACTION AND REGENERATION OF THE PERIODONTIUM FOLLOWING ORTHODONTIC TREATMENT WITH FIXED APPLIANCES.]. Schweizerische Monatsschrift fur Zahnheilkunde $=$ Revue mensuelle suisse dodonto-stomatologie / SSO. 1965;75:741-55.

Ravn JJ. Intrusion of permanent incisors. Tandlaegebladet. 1975 Sep;79(16):643-6.

Re Stephania, Cardaropoli D, Corrente, G Abundo R. Apical root resorption of Maxillary entral Incisors by orthodontic Intrusion in Adult Periodontal Patients. World J Orthod 2003;4(4):321-5

Reitan K. Initial tissue behaviour during apical root resorption. Angle Orthod 1974;44:68-82.

Reitan K. Biomechanical principles and reactions. In: Graber TM, Vanarsdall R, Vig K: Orthodontics Current Principles and Techniques, St Louis: CV Mosby, 2005.

Remington DN, Joondeph DR, Artun J, Riedel RA, Chapko MK. Long-term evaluation of root resorption occurring during orthodontic treatment. Am J Orthod Dentofacial Orthop. 1989 Jul;96(1):43-6.

Reukers E, Sanderink g, Kuijpers-Jagtman AM, van't Hof M. Assessment of apical root resorption using digital reconstruction. Dento-Maxillo-Fac Radiolog 1998;27:25-9.

Reukers EA, Sanderink GC, Kuijpers-Jagtman AM, van't Hof MA. Radiographic evaluation of apical root resorption with 2 different types of edgewise appliances. Results of a randomized clinical trial. J Orofac Orthop. 1998;59(2):100-9.

Rivera EM, Walton RE. Extensive idiopathic apical root resorption. A case report. Oral Surg Oral Med Oral Pathol Oral Radiol Endod 1994;78:673-7.

Ronnerman A, Larsson E. Overjet, overbite, intercanine distance and root resorption in orthodontically treated patients. A ten year follow-up study. Swed Dent J. 1981;5(1):21-7.

Rossi M, Whitcomb S, Lindemann R. Interleukin-1 beta and tumor necrosis factor-alpha production by human monocytes cultured with L-thyroxine and thyrocalcitonin: relation to severe root shortening. Am J Orthod Dentofacial Orthop. 1996;110(4):399-404.

Rygh P, Reitan K. Ultrastructural changes in the periodontal ligament incident to orthodontic tooth movement. Trans Eur Orthod Soc 1972;393-405.

Rygh P. Orthodontic root resorption studied by electron microscopy. Angle Orthod. 1977 Jan;47(1):116.

Sameshima GT, Asgarifar KO. Assessment of root resorption and root shape: periapical vs panoramic films. Angle Orthod. 2001c Jun;71(3):185-9.

Sameshima GT, Sinclair PM. Characteristics of patients with severe root resorption. Orthod Craniofac Res. 2004 May;7(2):108-14.

Sameshima GT, Sinclair PM. Predicting and preventing root resorption: Part I. Diagnostic factors. Am J 
Orthod Dentofacial Orthop. 2001a May;119(5):505-10.

Sameshima GT, Sinclair PM. Predicting and preventing root resorption: Part II. Treatment factors. Am J Orthod Dentofacial Orthop. 2001b May;119(5):511-5.

Schmidt HJ, Stensgaard S, Thestrup L, Gjessing PE, Wenzel A. [Root resorption in maxillary incisors following orthodontic treatment]. Tandlaegebladet. 1988;92(3):87-91.

Schwartz AM. Tissue changes incidental to tooth movement. Int J Orthod 1932;96:331-52.

Scott P, DiBiase AT, Sherriff M, Cobourne MT. Alignment efficiency of Damon3 self-ligating and conventional orthodontic bracket systems: A randomized clinical trial. Am J Orthod Dentofacial Orthop 2008;134:470.e1-e8.

Segal G, Schiffman P, Tuncay O. Meta analysis of the treatment-related factors of external apical root resorption. Orthodontics \& Craniofacial Research. 2004 05/12;7(2):71-8.

Shirazi M, Dehpour AR, Jefari F. The effect of thyroid hormone on orthodontic tooth movement in rats. J Clin Pediatr Dent 1999; 23:259-64.

Smale I, Artun J, Behbehani F, Doppel D, van't Hof M, Kuijpers-Jagtman AM. Apical root resorption 6 months after initiation of fixed orthodontic appliance therapy. Am J Orthod Dentofacial Orthop. 2005;128(1):57-67.

Snelgrove RA. Generalized idiopathic apical root resorption as an incidental finding in an adolescent: A case history. Dent Update 1995;22:276-8.

Spurrier SW, Hall SH, Joondeph DR, Shapiro PA, Riedel RA. A comparison of apical root resorption during orthodontic treatment in endodontically treated and vital teeth. Am J Orthod Dentofacial Orthop. 1990;97(2):130-4.

Stevnik A, Mjor IA. Pulp and dentine reactions to experimental tooth intrusion. A histological study of the initial changes. Am J Orthod 1970; 57: 370-85.

Taithongchai R, Sookkorn K, Killiany Dm. Facial and dentoalveolar structure ad the prediction of apical root shortening. Am J Orthod Dentofacial Orthop 1996;110:311-20.

Taner T, Ciger S, Sencift Y. Evauation of apical root resorption following extraction therapy in subjects with class I amd class II maloclussions. Eur J Orthod 1999; 21: 491-6.

TenHoeve A, Mulie Rm. The effects of antero-postero incisor repositioning on the palatal cortex as studied with laminagraphy. J lin Orthod 1976;10:804-22.

Thilander B, Ryghh P, Reitan K. Tissue reactions in Orthodontics. In: Graber TM, Vanarsdall RL, Vig $\mathrm{KW}$, . Orthodontics current principles and techniques, fourth edition. St Louis: CV Mosby, 2005.

Thongudomporn U, Freer TJ. Anomalous dental morphology and root resorption during orthodontic treatment: a pilot study. Aust Orthod J. 1998 Oct;15(3):162-7.

Togari A. Apical root resorption of maxillary central incisors following orthodontic treatment. Nippon 
Kyosei Shika Gakkai Zasshi. 1989 Oct;48(5):535-45.

Trope M. Root resorption of dental traumatic origin: classification based on etiology. Pract Periodont Aesthet Dent 1998; 10:515-22.

Van Loenen M, Dermaut LR, Degrieck and GA De Pauw. Apical root resorption of upper incisors during the torquing stage of the tip-edge technique. Eur J Orthod 2007; 29: 583-8.

Verwoerd WS, Fourie OL, van der Merwe EJ, Steyn CL. Tipping of teeth--the relation between force and intraperiodontal pressure. J Dent Assoc S Afr. 1979 Jul;34(7):381-4.

Villa PA, Oberti G, Moncada CA, Vasseur O, Jaramillo A, Tobon D, et al. Pulp-dentine complex changes and root resorption during intrusive orthodontic tooth movement in patients prescribed nabumetone. J Endod. 2005 Jan;31(1):61-6.

Weiland F. Constant versus dissipating forces in orthodontics: the effect on initial tooth movement and root resorption. Eur J Orthod. 2003;25(4):335-42.

Weissman J. Orthodontic extrusion of endodontically treated anterior teeth. CDA J. 1983 Nov;11(11):21-4.

Wickwire NA, Mc Neil MH, Norton LA, Duell RC. The effects of tooth movement upon endodontically treated teeth. Angle Orthod. 1974 Jul;44(3):235-42.

Woods, Marjorie A. Age-progressive changes in Pulp widths and root lengths during adulthood: A study of American Blacks and whites. Gerodontology 1990; 9(1-3): 41-50.

Yuan XP, Yang SW, Huang SH. Clinic study of root resorption caused by edgewise appliance combined with flat bite plate treatment. Hua Xi Kou Qiang Yi Xue Za Zhi, 2006 Aug; 24(4): 332-4. 


\section{APPENDIX A}

\section{ADDITIONAL TABLES AND FIGURES}


Study

Adam 1968

Aghili 2000

Ahlgren 1993

Alexander 1996

Al-Qawasmi 2003

Alwali 2000

Amlani 2007

Ari-Demirkaya 2005

Armstrong 2006

Artun 2005

Barber 1981

Bassigny 1982

Bau 2003

Baumann 1988

Baumrind 1996

Beck 1994

Bishara 1999

Blake 1992

Flannelly Blake 1995

Brezniak 1990

Brice 1991

Buck 1972

Casa 2001

Casa 2006

Chan 2005

Chen 2007

Chiqueto 2008

Choy 2000

Chutimanutskul 2006

Copeland 1986

Costopoulos 1996

Darendeliler 2004

de Freitas 2007

Deguchi 2008

Dermaut 1986
Reason for Exclusion

Translated from Czech. Review Article

English abstract, Case-Control Study

Retrospective study

Non-randomized, non-controlled prospective clinical trial

Retrospective identification of patients with EARR

Non-randomized, controlled, prospective clinical trial

Retrospective Data Collection

Case-Control study

Retrospective chart audit

Cohort study

Non-randomized, quasi controlled, prospective clinical trial

[Control (md premolars) versus experimental (Mx premolars)]

Translated from French. Retrospective study

Comment / Review

Could not locate - in Portuguese

Retrospective study

Retrospective chart audit - Begg vs. Tweed

Growth study looking at root length with age, no comprehensive orthodontic treatment

Case-Control, thesis

Case-Control study

Case Report

Non-randomized, non-controlled, prospective clinical trial

Quasi randomized, non-controlled, prospective clinical trial no quantification of root loss

Non-randomized, controlled clinical trial

Non-randomized, controlled clinical trial

Duplicate publication

Translated from Chinese. Case-control study.

Retrospective study

Computer model Analysis, no live patients

RCT - no direct outcome measure of root resorption

Retrospective Study

Non-randomized, controlled, prospective clinical trial

Duplicate publication, no direct RR measurement

Retrospective chart audit

Non-random, non-controlled, prospective clinical trial

Non-random, quasi-controlled, prospective clinical trial

(control group -untreated dental students)

Table A.1: Characteristics of Excluded Studies

Continued 
Table A.1 Continued

DeShields 1969

Diedrich 1990

Douki 2006

Eisel 1994

El-Baily 2004

English 2001

Erverdi 1994

Esteves 2007

Faltin 1998

Faltin 2001

Feiglin 1986

Fritz 2003

Goerigk 1992

Goldberg 1972

Goldin 1989

Goldman 1972

Goldson 1975

Goz 1989

Harris 1990

Harris 1993a

Harris 1993b

Harris 1997

Harris 2001

Hendrix 1994

Hogberg 1974

Holtta 2004

Horiuchi 2004

Janson 2000

Janson 2007

Jiang 2003

Jimenez-Pellegrin 2004

Jimenez-Pellegrin 2007

Kaley 1991

Katsaros 1993

Kook 2003

Krishnan 2006

Kurol 1996

Lee 1999

Levander 1998
Literature review and Retrospective Study

Review

Could not locate - in Arabic

Translated from German. Retrospective chart audit.

Non-random, quasi-controlled, prospective clinical trial, [no no-treatment control]

Review Article

Non-randomized, non-controlled, prospective clinical trial

Case-Control Study

Non-randomized, quasi controlled, prospective clinical trial

Non-randomized, controlled clinical trial

Review Article

Retrospective chart audit

Translated from German. No control group, retrospective study

Retrospective chart audit

Retrospective chart audit

Review Article

Retrospective chart audit

Case-control (English summary)

Retrospective chart audit

Retrospective chart audit

Retrospective chart audit

Retrospective chart audit of sibling pairs

Retrospective chart audit

Retrospective chart audit

Translated from Swedish. Retrospective study

Cohort study (growth study, no orthodontics)

Retrospective chart audit

Final radiographs taken prospectively, but study selection was retrospective and non-randomized

Retrospective Study

Translated from Chinese. Retrospective study.

Non-randomized, controlled, prospective clinical trial

Non-randomized, controlled, prospective clinical trial

Case-series and retrospective study

Retrospective study

Case-control study

Review Article

Non-randomized, controlled, prospective clinical trial

Case-control study

Retrospective chart audit 
Table A.1 Continued

\begin{tabular}{|c|c|}
\hline Lew 1990 & Retrospective study \\
\hline Limpanichkul 2006 & Double blind RCT, but did not evaluate root resorption \\
\hline Lin/Yan 2007 & Translated from Chinese. Retrospective chart audit. \\
\hline Linge 1983 & Retrospective chart audit \\
\hline Lundgren 1996 & Non-randomized, controlled, prospective clinical trial \\
\hline Lupi 1996 & Retrospective chart audit \\
\hline Mah 2004 & Looking at markers to identify root resorption, but not at causative factors \\
\hline Makedonas 2008 & Descriptive study \\
\hline Malagnino 1990 & $\begin{array}{l}\text { Translated from Italian, not an RCT, not looking at comprehensive orthodontic } \\
\text { patients }\end{array}$ \\
\hline Mavragani 2000 & Retrospective study 2 exp groups \\
\hline Mavragani 2002 & Retrospective study 2 exp groups \\
\hline Mavragani 2006 & Retrospective study case-control \\
\hline McFadden 1989 & Retrospective chart audit \\
\hline $\mathrm{McNab} 2000$ & Retrospective chart audit \\
\hline Mirabella 1995a & Retrospective chart audit \\
\hline Mirabella 1995b & Retrospective chart audit \\
\hline Mohandesan 2007 & Non-randomized, non-controlled, prospective clinical trial \\
\hline Nasiopoulos 2006 & Non-randomized, quasi controlled, prospective clinical trial \\
\hline Ngan 2004 & Retrospective Twin Study \\
\hline Ng'ang'a 2003 & Retrospective chart audit \\
\hline Nigul 2006 & Retrospective chart audit \\
\hline Nishioka 2006 & Case control study \\
\hline Odenrick 1991 & $\begin{array}{l}\text { Non-randomized, quasi-controlled, prospective clinical trial } \\
\text { (Md premolars as controls, Mx premolars as experimental) }\end{array}$ \\
\hline Otis 2004 & Retrospective chart audit \\
\hline Owman-Moll 1995a & Non-randomized, controlled, prospective clinical trial \\
\hline Owman-Moll 1995b & $\begin{array}{l}\text { Non-randomized, quasi-controlled, prospective clinical trial (no no treatment } \\
\text { control) }\end{array}$ \\
\hline Owman-Moll 1995c & $\begin{array}{l}\text { Non-randomized, quasi-controlled, prospective clinical trial (no no treatment } \\
\text { control) }\end{array}$ \\
\hline Owman-Moll 1996a & Non-randomized controlled clinical trial \\
\hline Owman-Moll 1996b & $\begin{array}{l}\text { Non-randomized, quasi-controlled, prospective clinical trial (no no treatment } \\
\text { control) }\end{array}$ \\
\hline Owman-Moll 2000 & Analysis of previously collected data from controlled clinical trials \\
\hline Oyama 2007 & Computer model Analysis, no live patients \\
\hline Parker 1998 & Mixed longitudinal retrospective analysis \\
\hline Perona 1996 & $\begin{array}{l}\text { Non-randomized, quasi-controlled, prospective clinical trial } \\
\text { (Md premolars as controls, Mx premolars as experimental) }\end{array}$ \\
\hline Pizzo 2007 & Review Article \\
\hline Rateitschak 1965 & Retrospective chart audit \\
\hline Ravn 1975 & English summary - Case report, trauma \\
\hline $\operatorname{Re} 2003$ & Non-randomized, non-controlled, prospective clinical trial, adults with severe \\
\hline
\end{tabular}


Table A.1 Continued

periodontitis

\begin{tabular}{ll}
\hline Remington 1989 & $\begin{array}{l}\text { Descriptive study - recalled patients with previous root resorption } \\
\text { to evaluate long term changes }\end{array}$ \\
\hline Ronnerman 1981 & Retrospective study \\
\hline Rossi 1996 & Case control study, to identify metabolic factors associated with root resorption \\
\hline Rygh 1977 & Review, rat study and clinical trial (no control group or randomization) \\
\hline Sameshima 2001a & Retrospective chart audit \\
\hline Sameshima 2001b & Retrospective chart audit \\
\hline Sameshima 2001c & Retrospective chart audit \\
\hline Sameshima 2004 & Case-control study \\
\hline Schmidt 1988 & Translated from Swedish. Retrospective study \\
\hline Segal 2004 & Meta-analysis, used retrospective studies \\
\hline Smale 2005 & Non-randomized, non-controlled, prospective clinical trial \\
\hline Spurrier 1990 & Retrospective chart audit \\
\hline Taner 1999 & Retrospective chart audit \\
\hline Thongudomporn 1998 & Retrospective chart audit \\
\hline Togari 1989 & Translated from Japanese. Retrospective chart audit \\
\hline Van Loenen 2007 & $\begin{array}{l}\text { Non-randomized, quasi-controlled, prospective clinical trial (no no treatment } \\
\text { control) }\end{array}$ \\
\hline Verwoerd 1979 & Computer model Analysis, no live patients \\
\hline Villa 2005 & Non-randomized, controlled, prospective clinical trial \\
\hline Weiland 2003 & $\begin{array}{l}\text { Non-randomized, quasi-controlled, prospective clinical trial } \\
\text { (Control teeth were selected from patients with agenesis of the } \\
\text { contralateral tooth and they were extracted before the start of the experiment) }\end{array}$ \\
\hline \hline Weissman 1983 & Case-Report \\
\hline Woods 1990 & Cross-sectional study \\
\hline Translated from Chinese. Retrospective chart audit. \\
\hline
\end{tabular}




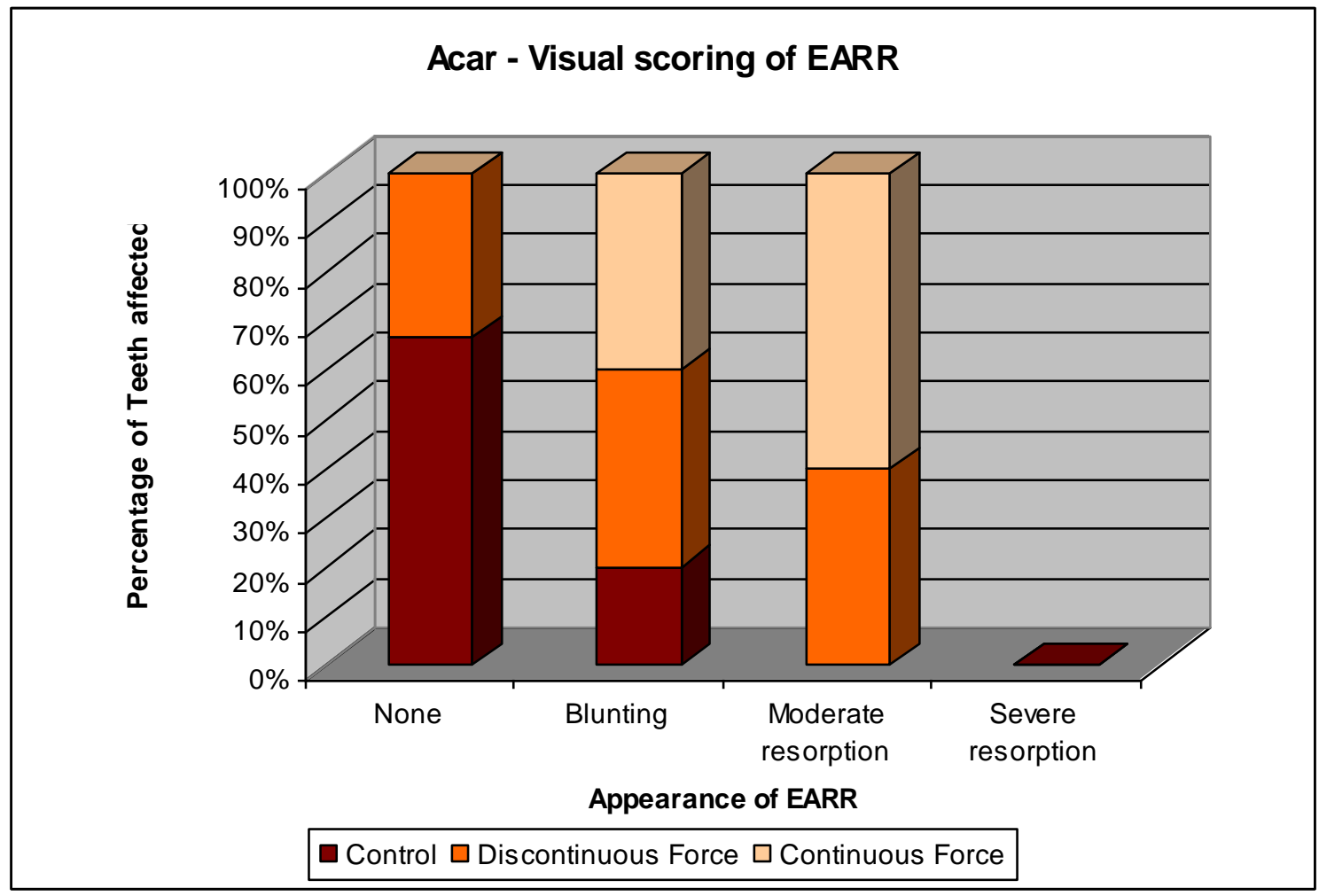

Figure A.1: Acar - Visual scoring of EARR

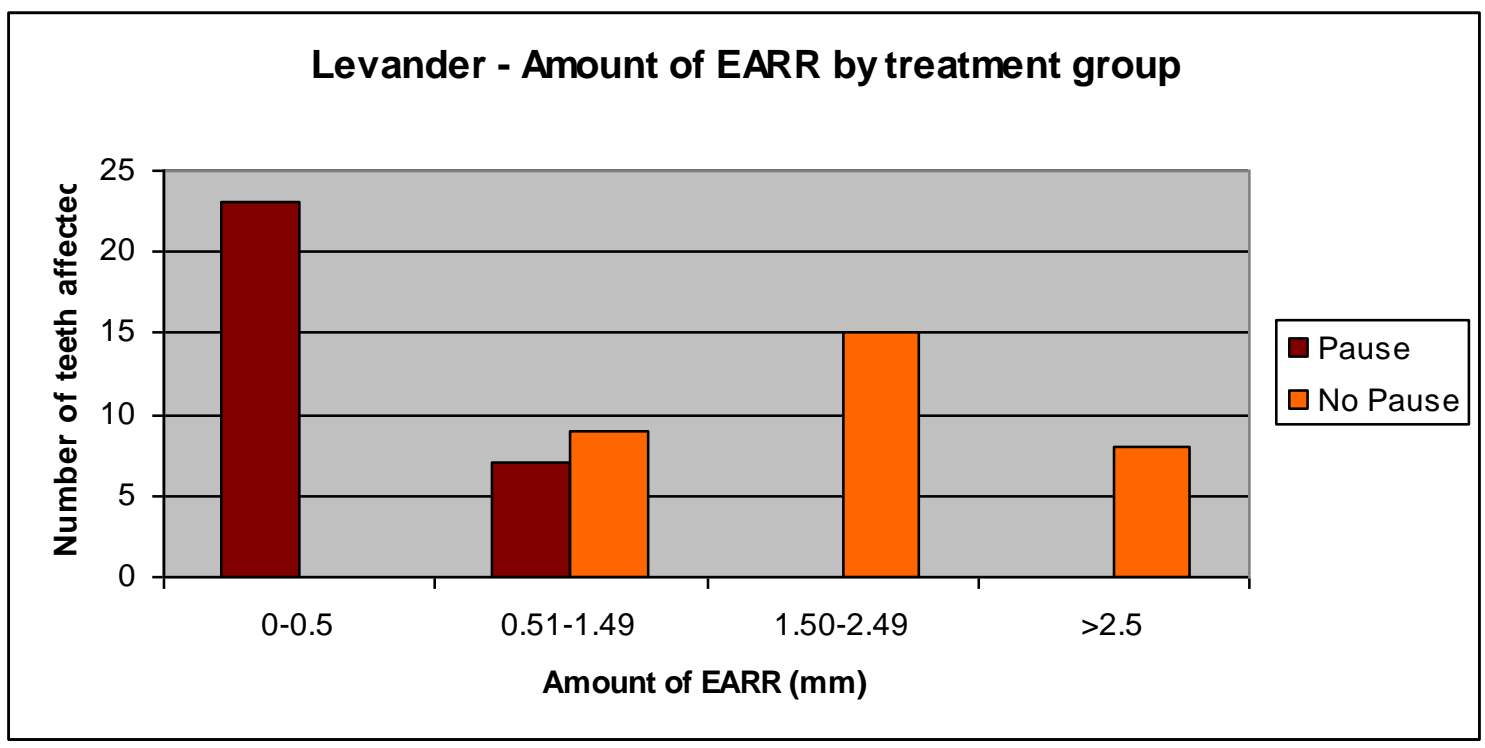

Figure A.2: Levander - Amount of EARR by treatment group 
FORREST PLOT DATA FROM REVMAN 5

1 Discontinuous Versus Continuous Force

1.1 Percentage of resorbed root area

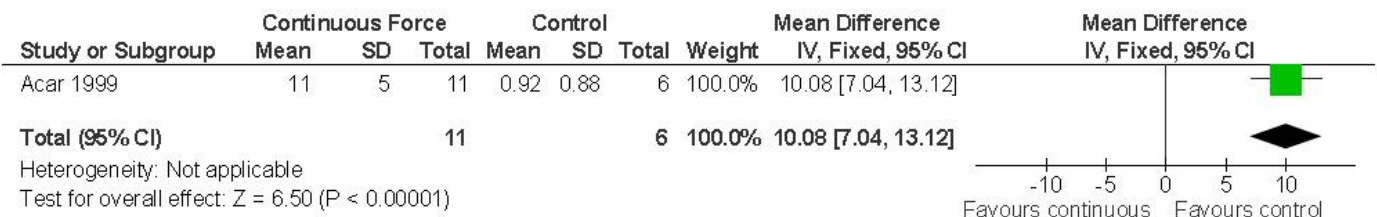

1.2 Percentage of resorbed root area

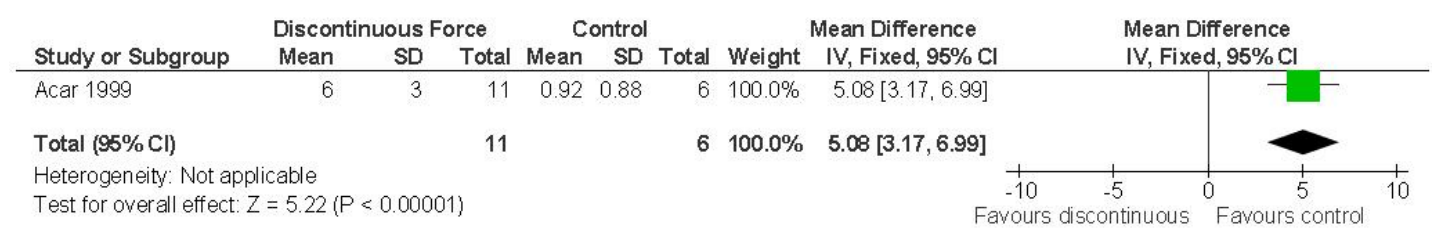

1.3 Percentage of resorbed root area

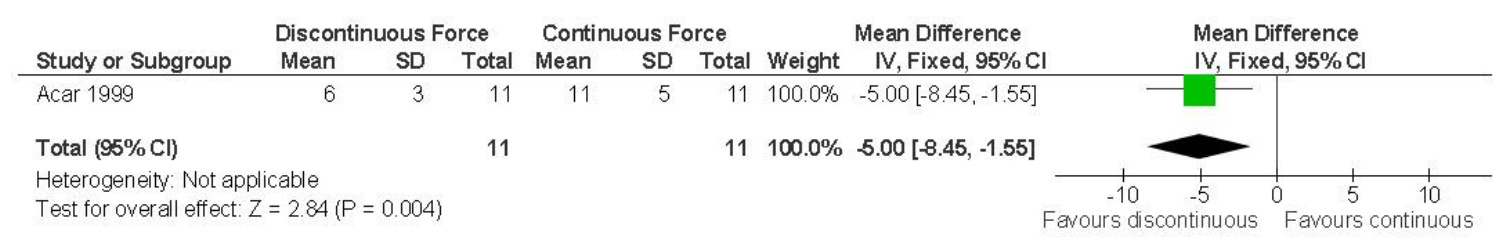

1.4 Severity of root resorption

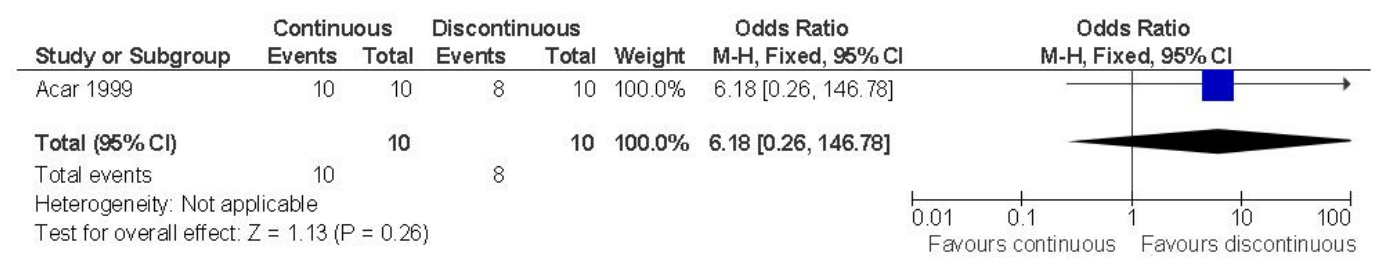

2 Removable thermoplastic appliance versus fixed appliance light and heavy forces

2.1 cube root volume of resorbed root area

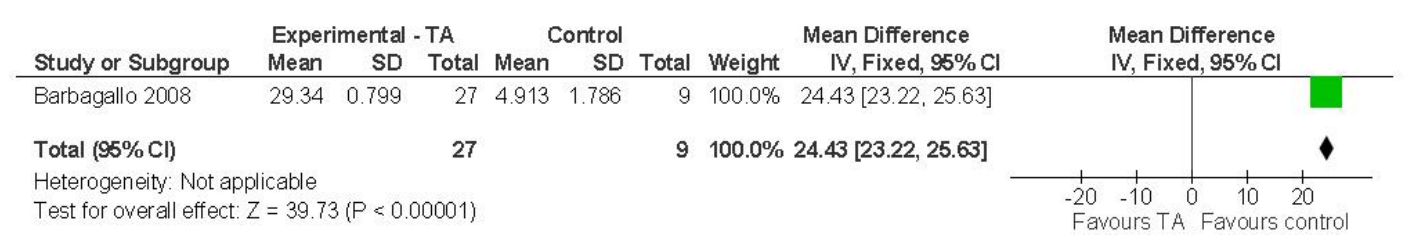


2.2 cube root volume of resorbed root area

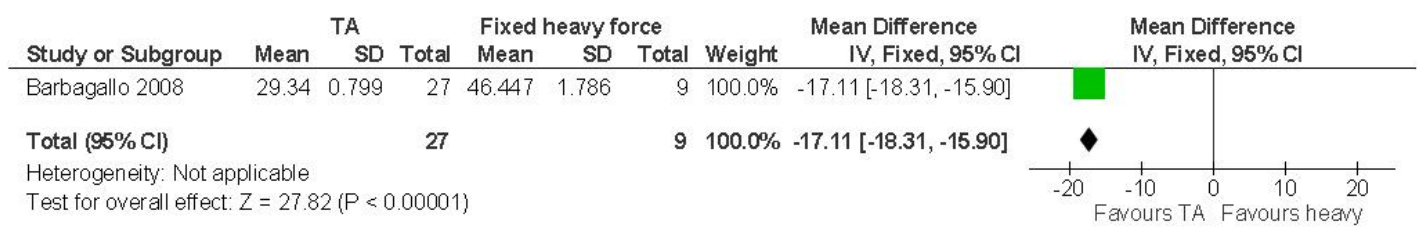

2.3 cube root volume of resorbed root area

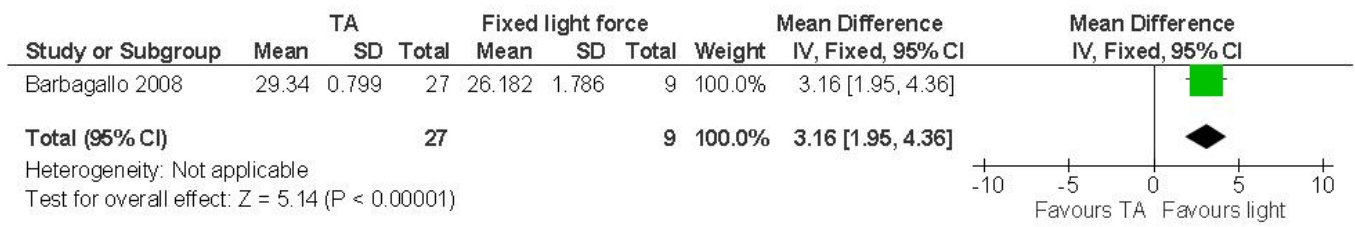

3 Light $(25 \mathrm{~g})$ Versus Heavy $(225 \mathrm{~g})$ Continuous Force

3.1 volume of resorbed root area $10^{5} \mathrm{um}$

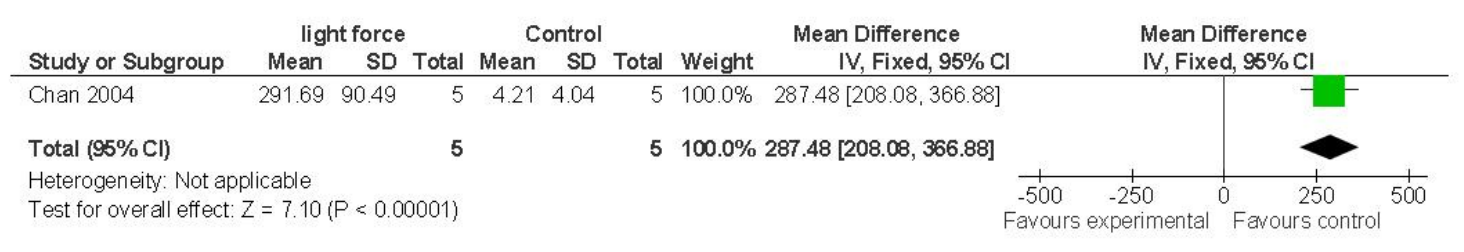

3.2 volume of resorbed root area $10^{5} \mathrm{um}$

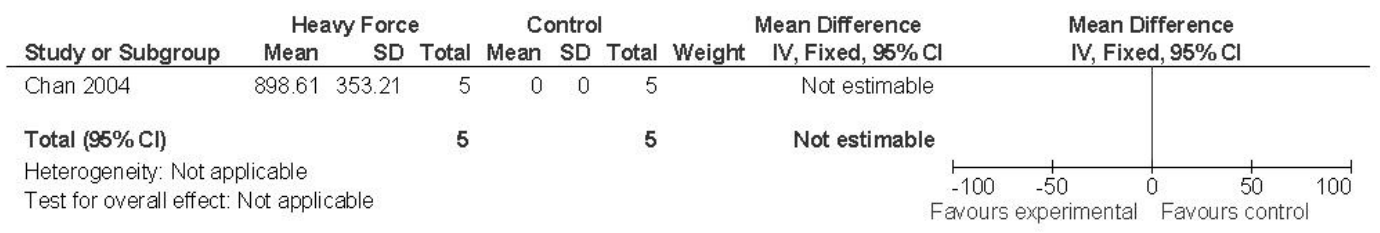

3.3 volume of resorbed root area $10^{5} \mathrm{um}$

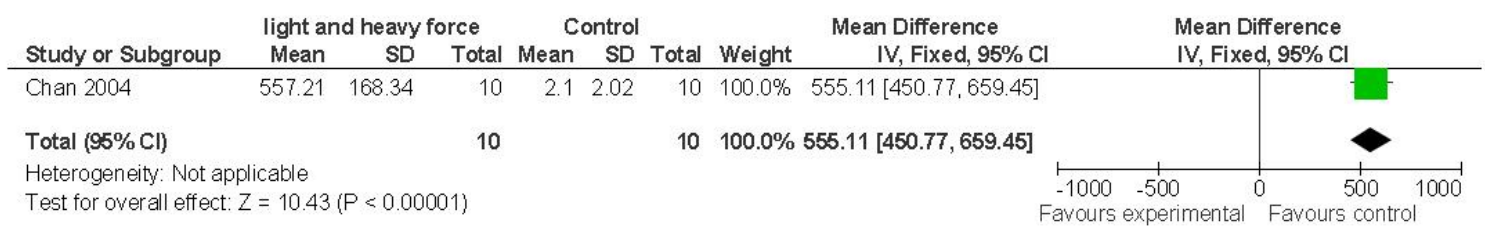


3.4 volume of resorbed root area $10^{5} \mathrm{um}$

\begin{tabular}{|c|c|c|c|c|c|c|c|c|c|c|}
\hline Study or Subgroup & \multicolumn{3}{|c|}{ light force } & \multicolumn{3}{|c|}{ heavy force } & \multicolumn{2}{|r|}{ Mean Difference } & \multicolumn{2}{|c|}{$\begin{array}{l}\text { Mean Difference } \\
\text { IV, Fixed, } 95 \% \mathrm{Cl}\end{array}$} \\
\hline Chan 2004 & 291.69 & 90.49 & 5 & 898.61 & 353.21 & 5 & $100.0 \%$ & $-606.92[-926.52,-287.32]$ & - & \\
\hline Total $(95 \% \mathrm{Cl})$ & & & 5 & & & 5 & $100.0 \%$ & $-606.92[-926.52,-287.32]$ & & \\
\hline $\begin{array}{l}\text { Heterogeneity: Not ap } \\
\text { Test for overall effect: }\end{array}$ & $\begin{array}{l}\text { licable } \\
z=3.72\end{array}$ & $P=0.00$ & & & & & & & $\begin{array}{l}-1000-500 \\
\text { Favours light force }\end{array}$ & $\begin{array}{lll}0 & 500 & 1000 \\
\text { Favours heavy force }\end{array}$ \\
\hline
\end{tabular}

3.5 volume of resorbed root area $10^{6} \mathrm{um}$

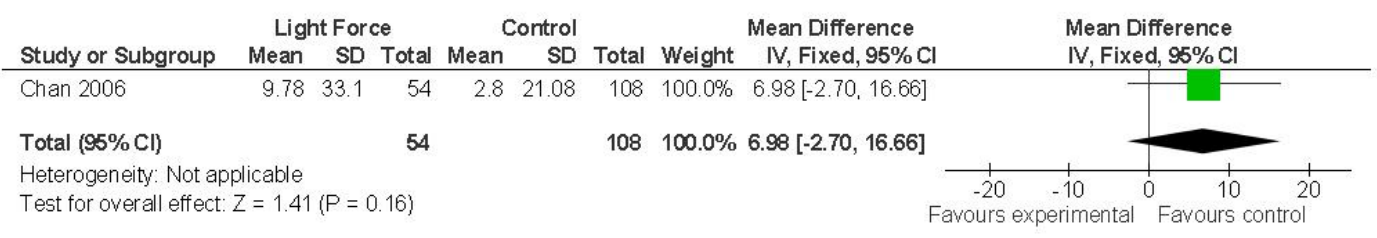

3.6 volume of resorbed root area $10^{6} \mathrm{um}$

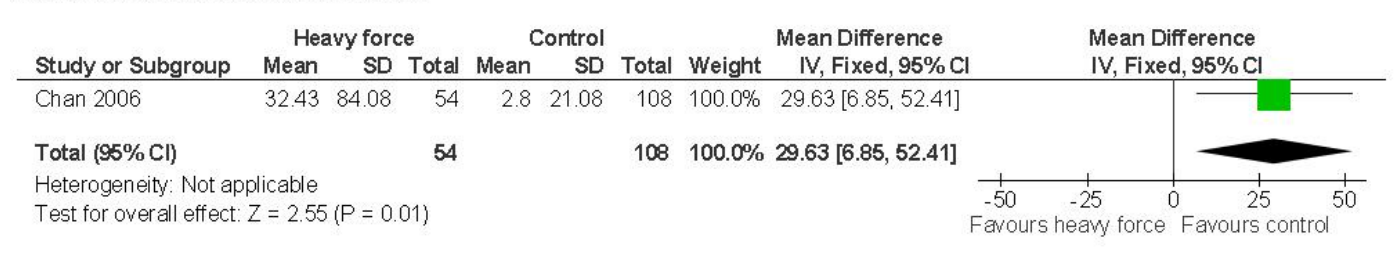

3.7 volume of resorbed root area $10^{6} \mathrm{um}$

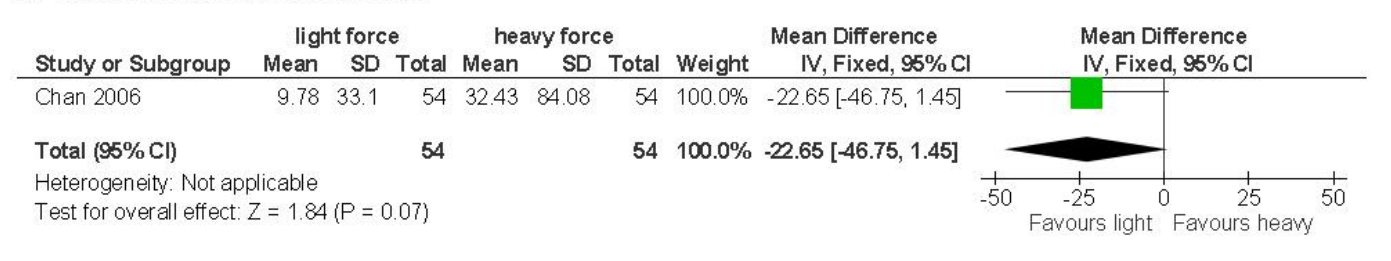

3.8 mean crater volume of resorbed root area $10^{6}$ um

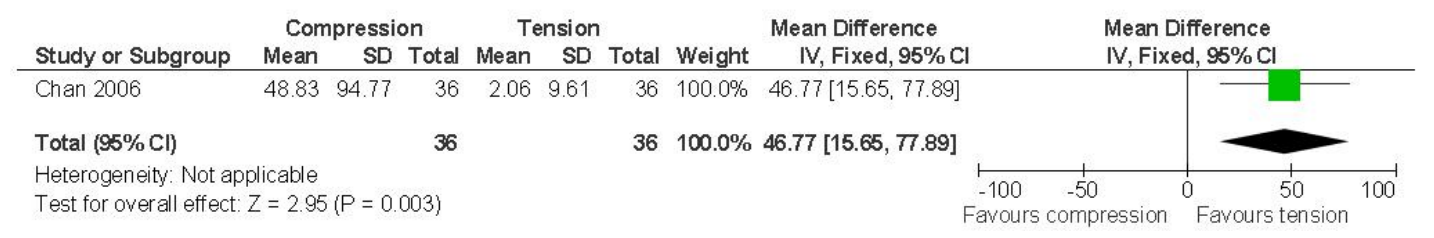


3.9 cube root volume of resorbed root area

\begin{tabular}{|c|c|c|c|c|c|c|c|c|c|}
\hline Study or Subgroup & \multicolumn{3}{|c|}{ light force } & \multicolumn{3}{|c|}{ Control } & \multicolumn{2}{|r|}{ Mean Difference } & $\begin{array}{l}\text { Mean Difference } \\
\text { IV, Fixed, } 95 \% \mathrm{Cl}\end{array}$ \\
\hline Barbagallo 2008 & 26.182 & 1.786 & 9 & 4.913 & 1.786 & 9 & $100.0 \%$ & $21.27[19.62,22.92]$ & \\
\hline Total $(95 \% \mathrm{Cl})$ & & & 9 & & & 9 & $100.0 \%$ & $21.27[19.62,22.92]$ & \\
\hline $\begin{array}{l}\text { Heterogeneity: Not ap } \\
\text { Test for overall effect: }\end{array}$ & $\begin{array}{l}\text { licable } \\
=25.26\end{array}$ & $(P<0.0$ & $00001)$ & & & & & & $\begin{array}{ccc}-10 & 0 & 1 \\
-10 & \\
\text { erimental } & \text { Favours }\end{array}$ \\
\hline
\end{tabular}

3.10 cube root volume of resorbed root area

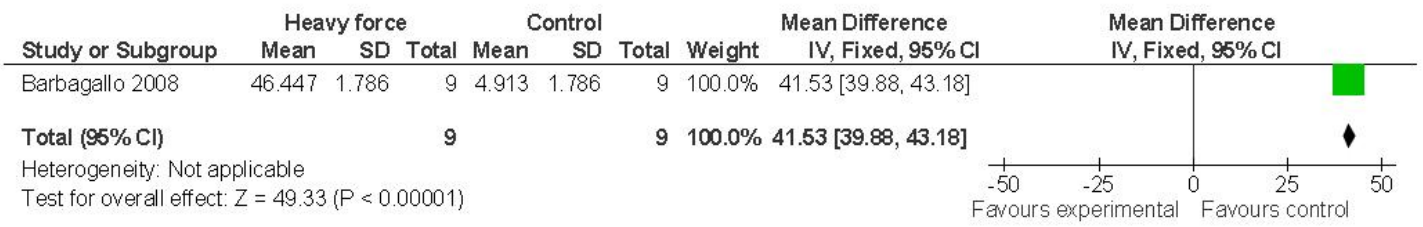

3.11 cube root volume of resorbed root area

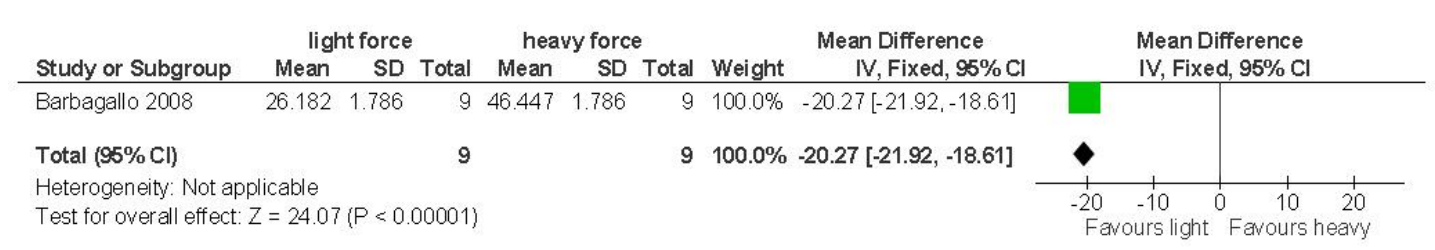

4 Intrusive Versus Extrusive Force

4.1 Percentage of resorbed root area

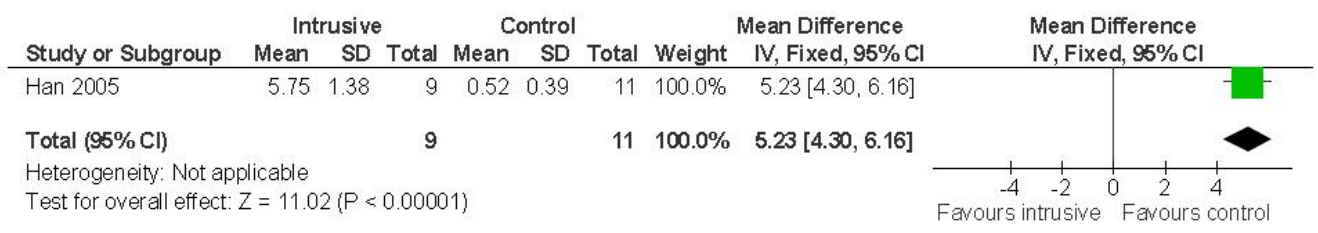

4.2 Percentage of resorbed root area

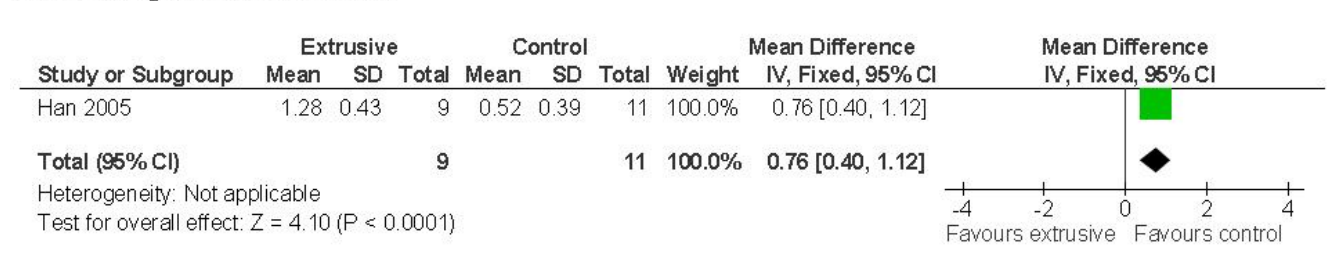


4.3 Percentage of resorbed root area

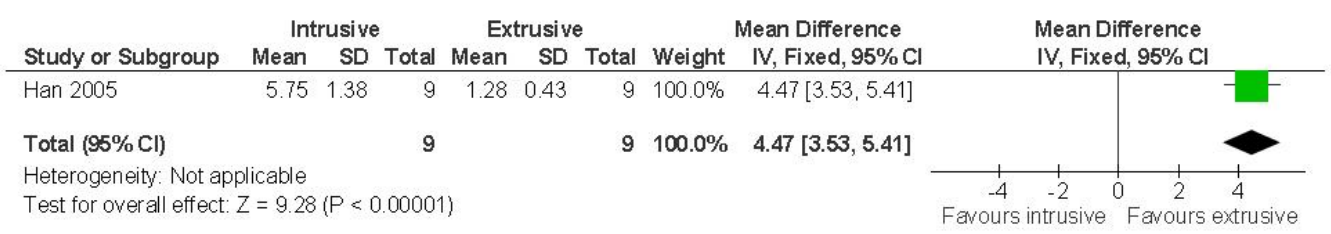

4.4 cube root volume

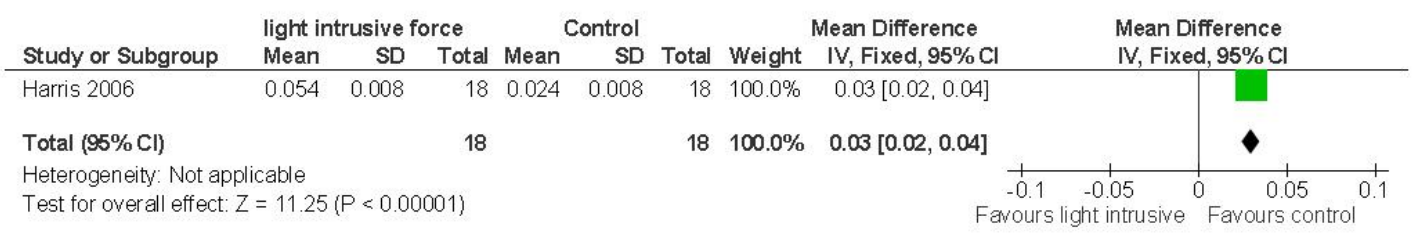

4.5 cube root volume

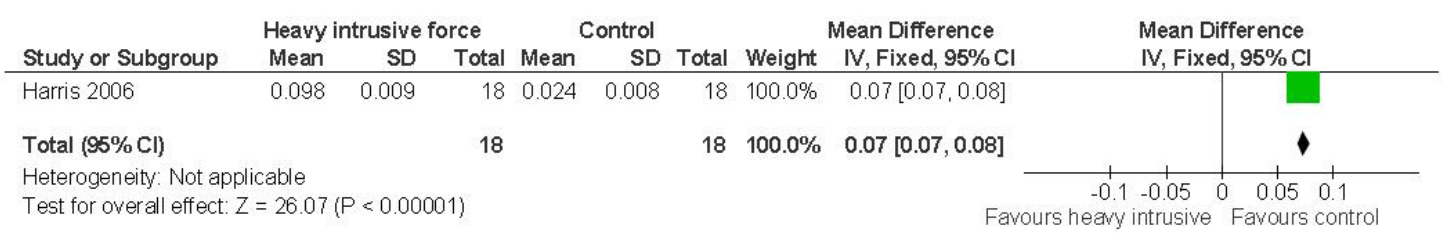

4.6 cube root volume

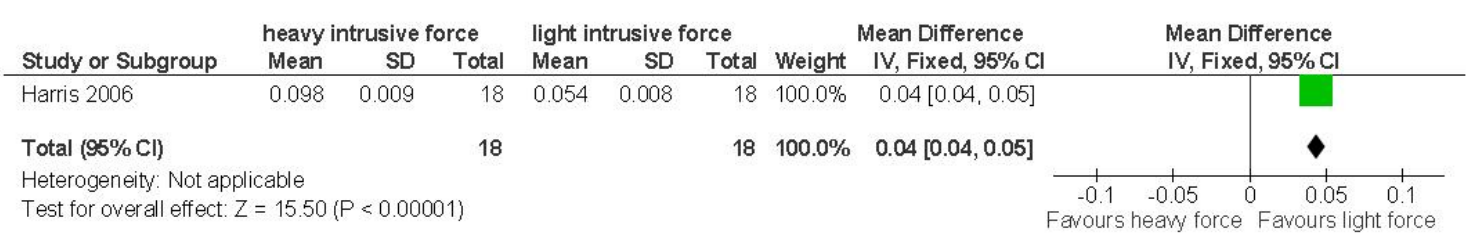

5 Archwire Sequence

5.1 mean Root Resorption in $\mathrm{mm}$

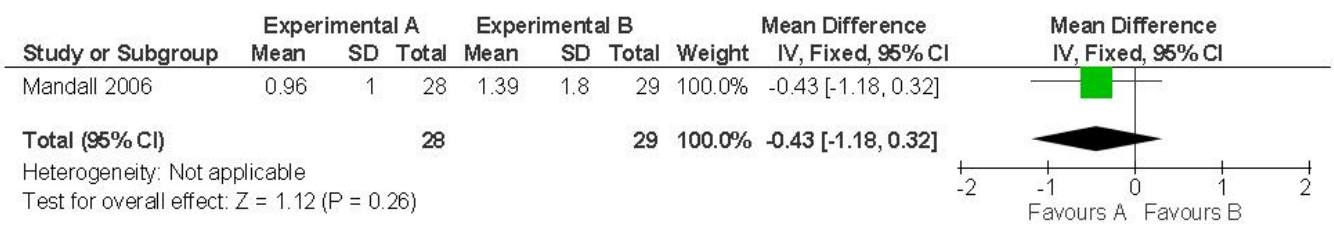


5.2 mean Root Resorption in $\mathrm{mm}$

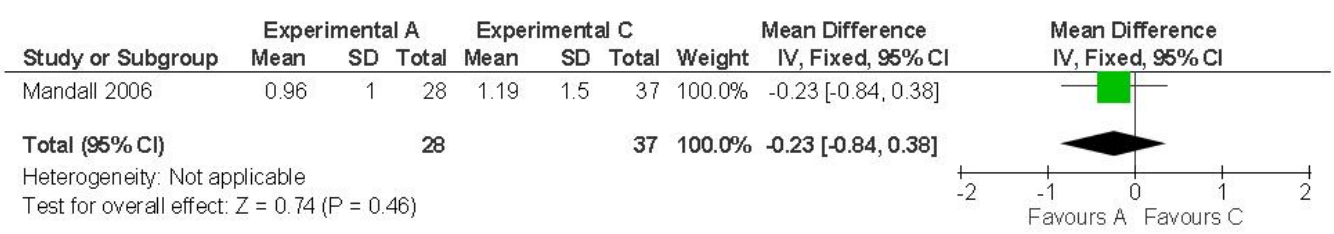

5.3 mean Root Resorption in $\mathrm{mm}$

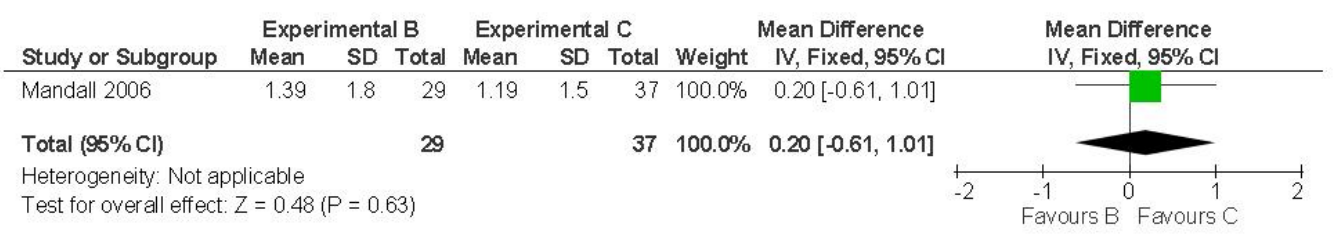

6 Effect of a treatment pause in patients experiencing orthodontically induced root resorption

6.1 Average $\mathrm{mm}$ change in tooth length

\begin{tabular}{|c|c|c|c|c|c|c|c|c|c|}
\hline \multirow[b]{2}{*}{ Study or Subgroup } & \multicolumn{3}{|c|}{ treatment with pause } & \multicolumn{3}{|c|}{ no pause } & \multicolumn{2}{|r|}{ Mean Difference } & \multirow{2}{*}{$\begin{array}{l}\text { Mean Difference } \\
\text { IV, Fixed, } 95 \% \mathrm{Cl}\end{array}$} \\
\hline & Mean & SD & Total & Mean & $\mathrm{SD}$ & Total & Weight & IV, Fixed, $95 \% \mathrm{Cl}$ & \\
\hline Levander 1994 & -1.5 & 0.8 & 32 & -0.4 & 0.7 & 30 & $100.0 \%$ & $-1.10[-1.47,-0.73]$ & \\
\hline Total $(95 \% \mathrm{Cl})$ & & & 32 & & & 30 & $100.0 \%$ & $-1.10[-1.47,-0.73]$ & \\
\hline $\begin{array}{l}\text { Heterogeneity: Not ap } \\
\text { Test for overall effect: }\end{array}$ & $\begin{array}{l}\text { cable } \\
=5.77(\mathrm{~F}\end{array}$ & 0.000 & & & & & & & $\begin{array}{ccccc}1 & 1 & 1 & 1 & 1 \\
-4 & -2 & 0 & 2 & 4 \\
\text { Favours pause } & \text { Favours no } p\end{array}$ \\
\hline
\end{tabular}

7 Straightwire versus Standard Edgewise

7.1 Prevalence of root resorption

\begin{tabular}{|c|c|c|c|c|c|c|c|}
\hline \multirow[b]{2}{*}{ Study or Subgroup } & \multicolumn{2}{|c|}{ Standard edgewise } & \multicolumn{2}{|c|}{ Straightwire } & \multirow[b]{2}{*}{ Weight } & \multirow{2}{*}{$\begin{array}{c}\text { Odds Ratio } \\
\text { M-H, Fixed, } 95 \% \mathrm{Cl}\end{array}$} & \multirow{2}{*}{$\begin{array}{c}\text { Odds Ratio } \\
\text { M-H, Fixed, } 95 \% \mathrm{Cl}\end{array}$} \\
\hline & Events & Total & Events & Total & & & \\
\hline Reukers 1998 & 16 & 29 & 24 & 32 & $100.0 \%$ & $0.41[0.14,1.21]$ & \\
\hline Total $(95 \% \mathrm{Cl})$ & & 29 & & 32 & $100.0 \%$ & $0.41[0.14,1.21]$ & \\
\hline Total events & 16 & & 24 & & & & \\
\hline $\begin{array}{l}\text { Heterogeneity: Not ap } \\
\text { Test for overall effect: }\end{array}$ & $\begin{array}{l}\text { icable } \\
=1.61(\mathrm{P}=\end{array}$ & & & & & & 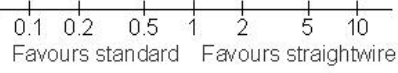 \\
\hline
\end{tabular}

7.2 Average change in tooth length (\%)

\begin{tabular}{|c|c|c|c|c|c|c|c|c|c|c|c|}
\hline Study or Subgroup & \multicolumn{3}{|c|}{ Standard edgewise } & \multicolumn{3}{|c|}{ Straightwire } & \multicolumn{2}{|r|}{ Mean Difference } & \multicolumn{2}{|c|}{$\begin{array}{l}\text { Mean Difference } \\
\text { IV, Fixed, } 95 \% \mathrm{Cl}\end{array}$} & \\
\hline Reukers 1998 & 7.5 & 7.6 & 29 & 8.2 & 6.4 & 32 & $100.0 \%$ & $-0.70[-4.25,2.85]$ & & & \\
\hline Total $(95 \% \mathrm{Cl})$ & & & 29 & & & 32 & $100.0 \%$ & $-0.70[-4.25,2.85]$ & & & \\
\hline \multicolumn{4}{|c|}{$\begin{array}{l}\text { Heterogeneity: Not applicable } \\
\text { Test for overall effect: } Z=0.39(P=0.70)\end{array}$} & & & & & & $\begin{array}{c}-2 \\
-2 \\
\text { dgewise }\end{array}$ & $0 \frac{1}{0}$ & $\begin{array}{l}4 \\
\text { straightwire }\end{array}$ \\
\hline
\end{tabular}

8 Trauma vs No Trauma

9 Teeth with unusual morphology 